Florida International University FIU Digital Commons

\title{
A Functional Trait Approach to Examine Plant Community Dynamics in South Florida Hardwood Hammock Forests
}

Suresh Chandra Subedi

ssubedi@fiu.edu

DOI: $10.25148 /$ etd.FIDC001963

Follow this and additional works at: https://digitalcommons.fiu.edu/etd

Part of the Other Earth Sciences Commons

\section{Recommended Citation}

Subedi, Suresh Chandra, "A Functional Trait Approach to Examine Plant Community Dynamics in South Florida Hardwood Hammock Forests" (2017). FIU Electronic Theses and Dissertations. 3373.

https://digitalcommons.fiu.edu/etd/3373 


\title{
FLORIDA INTERNATIONAL UNIVERSITY
}

Miami, Florida

\section{A FUNCTIONAL TRAIT APPROACH TO EXAMINE PLANT COMMUNITY \\ DYNAMICS IN SOUTH FLORIDA HARDWOOD HAMMOCK FORESTS}

\author{
A dissertation submitted in partial fulfillment of \\ the requirements for the degree of \\ DOCTOR OF PHILOSOPHY \\ in \\ EARTH SYSTEM SCIENCES
}

by

Suresh Chandra Subedi 
To: Dean Michael R. Heithaus

College of Arts, Sciences and Education

This dissertation, written by Suresh Chandra Subedi, and entitled A Functional Trait Approach to Examine Plant Community Dynamics in South Florida Hardwood Hammock Forests, having been approved in respect to style and intellectual content, is referred to you for judgment.

We have read this dissertation and recommend that it be approved.

Steven F. Oberbauer

$\begin{array}{r}\hline \text { Jay P. Sah } \\ \hline \text { Jed Redwine } \\ \hline \text { Leonard J. Scinto } \\ \hline \text { Michael Ross, Major Professor }\end{array}$

Date of Defense: July 29, 2017

The dissertation of Suresh Chandra Subedi is approved.

Dean Michael R. Heithaus College of Arts, Sciences and Education

Andrés G. Gil

Vice President for Research and Economic Development and Dean of the University Graduate School

Florida International University, 2017 


\section{ACKNOWLEDGMENTS}

I am deeply grateful to my mentor, Dr. Michael Ross for his continued guidance, support, and encouragement to complete this dissertation. I would also like to thank my committee members, Dr. Steve Oberbauer, Dr. Jay P Sah, Dr. Jed Redwine, and Dr. Leonard Scinto for their valuable guidance, support, and their reviews for this dissertation.

I would like to thank to Dr. Kenneth Feeley, Dr. Christopher Baraloto, Dr. Leo Sternberg, and Dr. Yuying Zhang for providing me with much constructive advice. I would like to thank many volunteers for their time to help me collect samples, and data in often very hot and buggy environment of the Florida Keys and Everglades. I would like to specially thank to Bina Thapa, Susanna Stoffella, Rosario Vilades, Leah Ramnath, and Josh Diamond for their tireless help. Thanks to Himadri Biswas for helping me to make maps. I would like to thank Dr. Leo Sternberg's, Dr. Scinto's and Dr. Anderson's labs for providing laboratory facilities. I also thank the Earth and Environment Department for a teaching assistantship and other support during this degree process.

I would like to thank to International center for Tropical Botany scholarship and FIU Doctoral Evidence Acquisition Fellowship for their support to accomplish this dissertation. Thanks to South Florida Terrestrial Ecosystem Lab (SOFTEL) for providing field and lab supplies. I am thankful to SOFTEL lab mates for their help in the field and lab. I am also thankful to the Florida State Parks, the US Fish and Wildlife Service, and Everglades National Park for allowing me to access sites and collect samples.

Finally, I would like to thank my wife (Kalpana) and my family, who have provided unconditional support during this journey. 


\title{
ABSTRACT OF THE DISSERTATION
}

A FUNCTIONAL TRAIT APPROACH TO EXAMINE PLANT COMMUNITY

DYNAMICS IN SOUTH FLORIDA HARDWOOD HAMMOCK FORESTS

\author{
by
}

Suresh Chandra Subedi

Florida International University, 2017

Miami, Florida

\section{Professor Michael Ross, Major Professor}

The tropical hardwood forests of south Florida persist as well-drained patches of broadleaf forest separated by brackish water swamp, marsh, or pineland. In this dissertation, a functional trait approach was used to understand the structure and dynamics of these communities and their responses to abiotic and biotic variation. Twenty-seven permanent plots $\left(20 \times 20 \mathrm{~m}^{2}\right)$ were established across the south Florida landscape, representing four sub-regions: Everglades marsh, Long Pine Key, Upper Keys, and Lower Keys. Community weighted mean trait values for four of six selected traits showed significant inter-sub-regional variation. Out of them, three traits (specific leaf area, tree height, and leaf phosphorus) increased significantly from dry and low productivity Florida Keys in the south to the moist and productive areas on the south Florida mainland, while wood density showed the opposite pattern. Trait variance ratios (T-statistic metrics) was used to explore internal filtering (processes that operate within a community) and external filtering (processes that operate at larger scale than that of the individual population or community) on community structure. Both external and internal filtering in the functional composition of south Florida hardwood hammock forest were 
important for local communities differing in freshwater accessibility, or that occupy different positions along strong edaphic or climatic gradients.

To understand the underlying mechanisms that drive species assembly during forest succession in Florida dry sub-tropical forest, 13 leaf, stem, reproductive, and architectural traits of resident tree species across the successional gradient were measured. Tests of null models showed that younger communities are shaped by environmentally driven processes, while mature communities are shaped by competitively driven processes. The overall trait similarities among species present in North Key Largo tropical dry forest suggest that tree species are specialists on the local environment, and their ability to survive and grow in a stressful environment may be more important than competition for resources at larger scale. Moreover, tree species in these forests may exhibit specialization or trait plasticity in coping with drought by changes in their stomatal morphology or activity, allowing for a balance between gas exchange and water loss in a periodically stressful environment. A significant negative correlation between stomatal density and size, and a positive correlation between leaf $\delta^{13} \mathrm{C}$ and stomatal density were observed across habitat gradient for one of the dominant hardwood hammock species (Bursera simaruba). Small and densely distributed stomates in tandem seems to represent a strategy that allows hammock species to conserve water under physiological drought. Furthermore, findings from this work also showed both intra- and inter-specific trait variation at regional and local scales influence community assembly patterns in hardwood hammock communities in South Florida. 


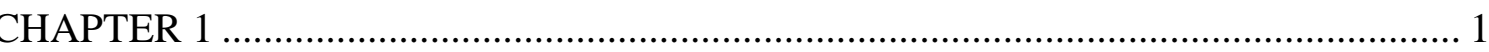

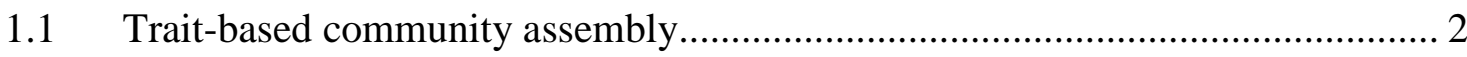

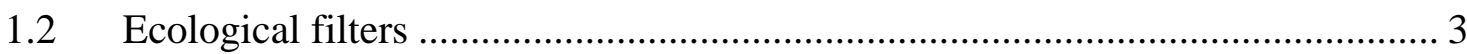

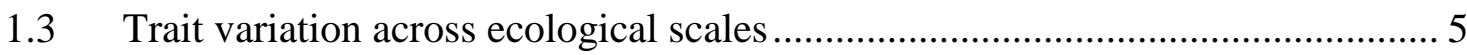

1.4 Distribution of hardwood hammock communities across the landscape in south

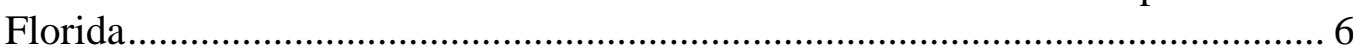

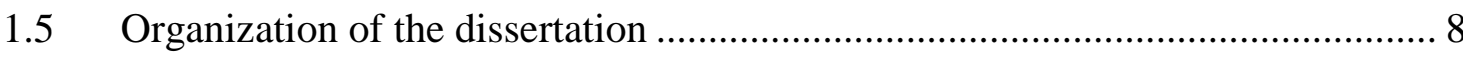

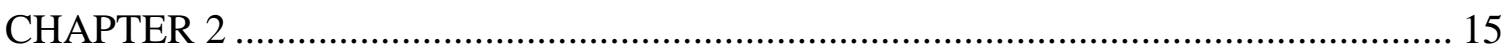

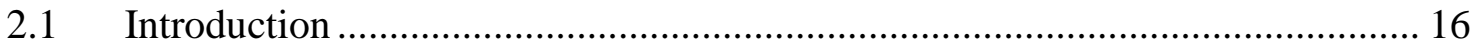

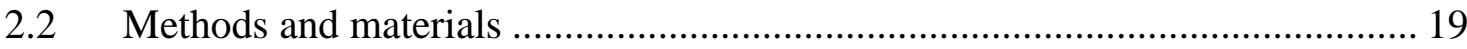

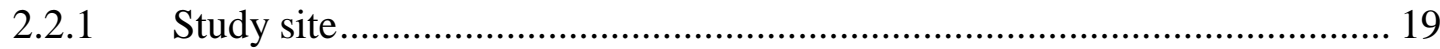

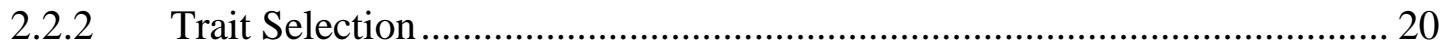

2.2.3 Study design and trait measurement .......................................................... 21

2.2.4 Environmental variables .................................................................. 22

2.2.5 Statistical analysis ........................................................................... 22

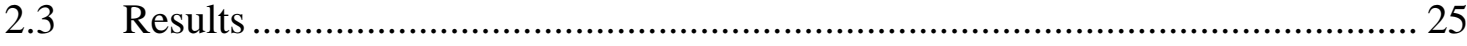

2.3.1 Species diversity across the four sub-regions .......................................... 25

2.3.2 Variation in community trait means along the gradient............................... 25

2.3.3 Comparison of community weighted traits across regions .......................... 26

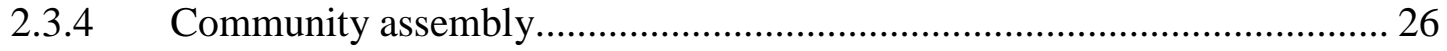

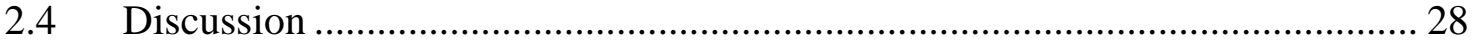

2.4.1 Variation in community-weighted traits across the region ......................... 28

2.4.2 Community assembly patterns across sub-regions ...................................... 29

2.5 Conclusions .............................................................................................. 34

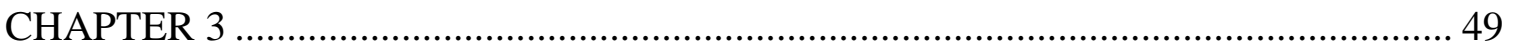

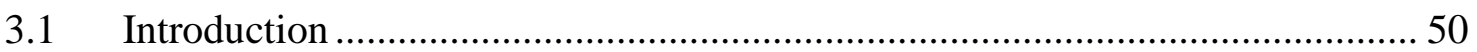

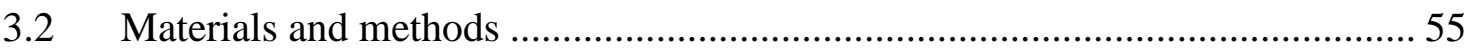

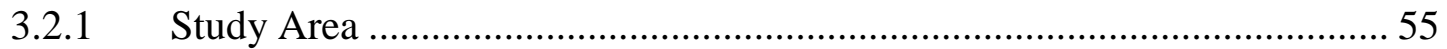

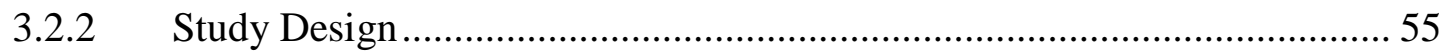

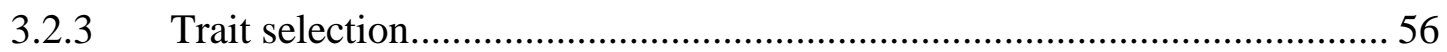




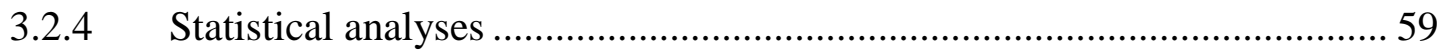

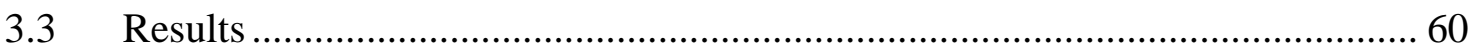

3.3.1 Variation in traits across the scales (intra-specific, inter-specific, and

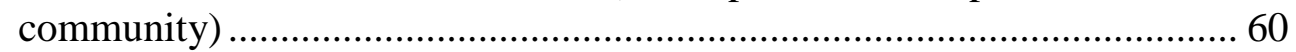

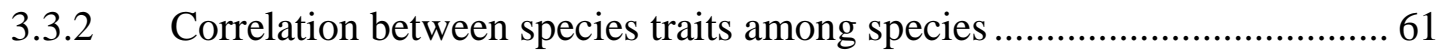

3.3.3 Pattern of trait variation across successional gradient ................................ 62

3.3.4 Niche overlap in important functional traits between species .................... 62

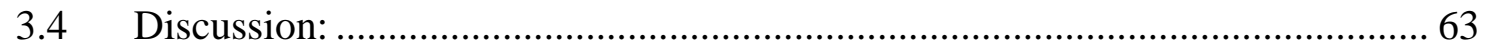

3.4.1 Intra-specific, inter-specific, and community sources of trait variation ..... 64

3.4.2 Major trait niche axes among species in north Key Largo DTF forest....... 66

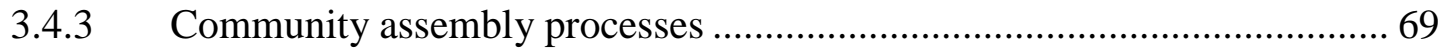

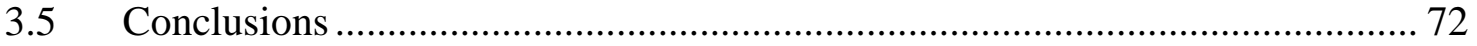

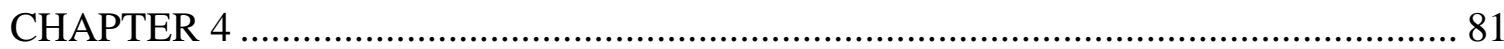

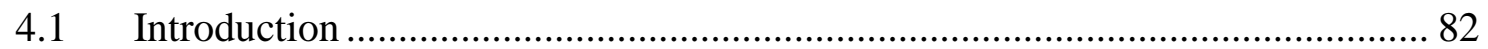

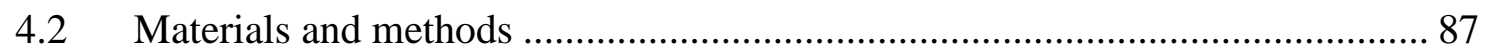

4.2.1 Field sites and experimental design ...................................................... 87

4.2.2 Stomatal density and size measurement ……………………………...... 88

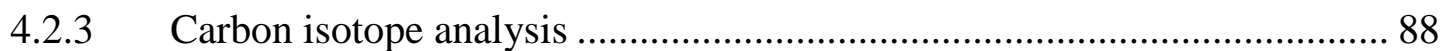

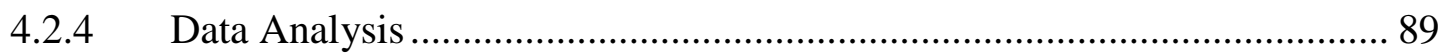

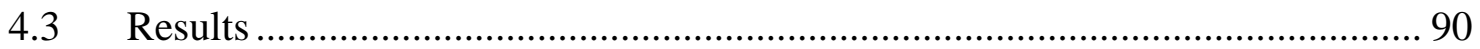

4.3.1 Variation in environmental variables across sites...................................... 90

4.3.2 Variance Partitioning in leaf traits .......................................................... 90

4.3.3 Relationships among leaf traits............................................................. 90

4.3.4 Stomatal traits and environmental variables .............................................. 91

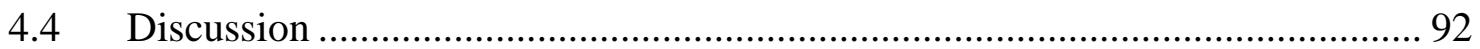

4.4.1 Stomatal trait partitioning across scales................................................. 92

4.4.2 Stomatal traits and plant stress............................................................. 95

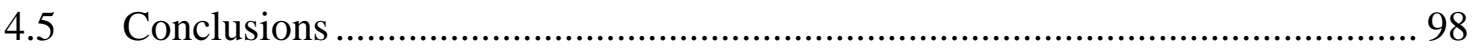

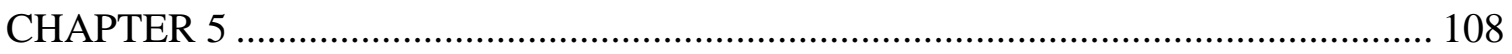

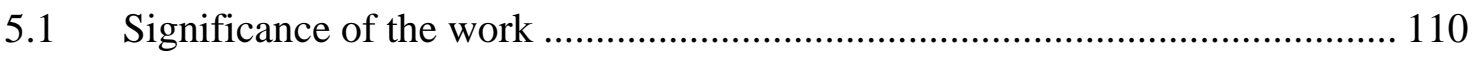

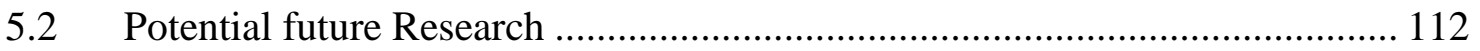




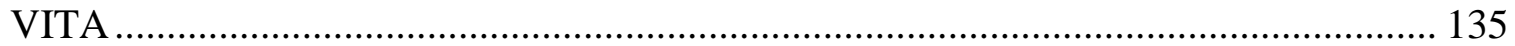




\section{LIST OF TABLES}

TABLES

PAGE

Table 1 Comparisons of potential environmental filters across sub-regions in south Florida. 11

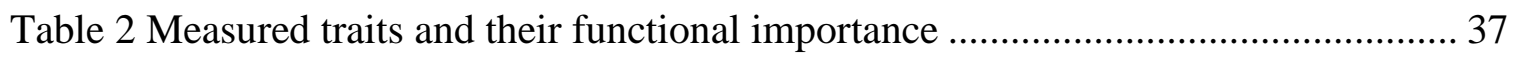

Table 3 Description of the null models used to calculate significance for T-statistics..... 38

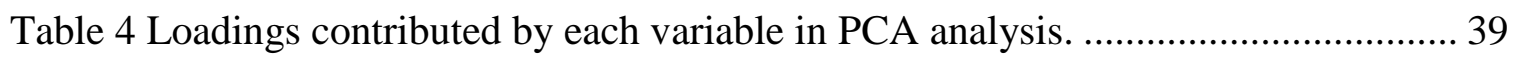

Table 5 Mean and standard deviation (in parenthesis) of each environmental variable across sub-regions.

Table 6 List of traits measured at different scales.

Table 7 Percentage of trait variation at three different scales (site, species, and individual), unweighted (presence-absence matrix).

Table 8 Trait contribution to first three components contributed by each factor. 75

Table 9 Community weighted trait contribution to first two components contributed by each factor.

Table 10 Mean niche overlap between species occurred across the successional gradient.

Table 11 Measures of the evenness vs. clustering of community assembly................... 77

Table 12 Environmental variation across sites.

Table 13 Decomposition of the total variation in stomatal density, stomatal length, and leaf $\delta^{13} \mathrm{C}$ traits across three hierarchical levels (site, tree, and leaf) ................... 101

Table 14 Multiple regression analyses results. 102 


\section{LIST OF FIGURES}

FIGURES

PAGE

Figure 1 Different processes that might produce assembly rules. ............................... 12

Figure 2 Processes affecting trait variation across various ecological scales .................. 13

Figure 3 Hardwood hammock community in south Florida and potential filters across

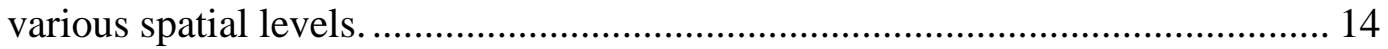

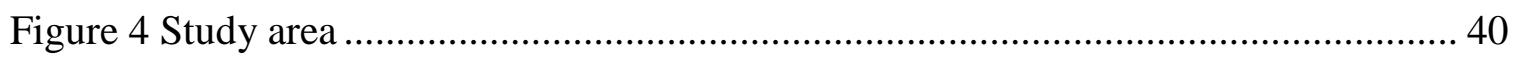

Figure 5 Tree species diversity across four sub-regions ........................................ 41

Figure 6 Bi-plot showing site variation across South Florida hammocks. ..................... 42

Figure 7 Relationship between CWM SLA and site characteristics........................... 43

Figure 8 Relationship between CWM WD values and site characteristics .................... 43

Figure 9 Relationship between CWM HT values and site characteristics ..................... 44

Figure 10 Relationship between CWM TN values and site characteristics.................... 44

Figure 11 Relationship between $\mathrm{CWM} \delta^{13} \mathrm{C}$ trait values and site characteristics ........... 45

Figure 12 Relationship between CWM TP values and site characteristics .................... 45

Figure 13 Box plots showing CWM trait variation across the sub-regions.................... 46

Figure 14 Standardized effect size (SES) of T-statistics of six traits ............................. 47

Figure 15 Standardized effect size (SES) of T-statistics by sub-region ........................ 48

Figure 16 Study area and location of plots and transects with stand age. ..................... 73

Figure 17 Species-trait bi-plot for PCA of Key Largo dry tropical forests ..................... 78

Figure 18 Community-weighted trait bi-plot for PCA of Key Largo dry tropical forests.79

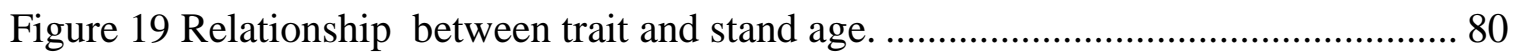

Figure 20 Plant stress in response to distance from the ground water table and salinity 103

Figure 21 Hypothesized two alternative models in response to plant stress................. 103

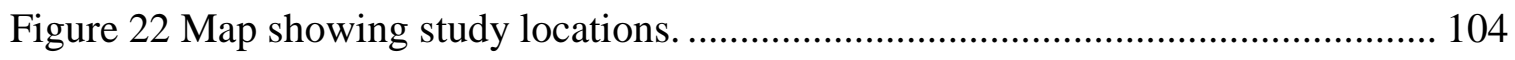


Figure 23 Relationship between stomatal density and stomatal length at site level...... 105

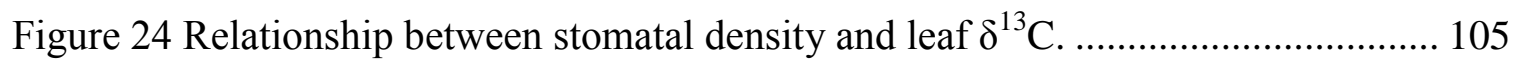

Figure 253 -D surface plot showing stomatal density co-variation with GWS and

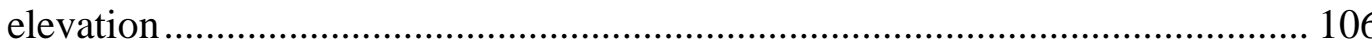

Figure 26 3-D surface plot showing stomatal length co-variation with GWS and elevation.. 


\section{CHAPTER 1}

\section{INTRODUCTION}

One of the fundamental questions in ecology is to understand community assembly by identifying its underlying mechanisms. Diamond (1975) first coined the term "assembly rules" to describe the effects of biotic interactions on community composition (Diamond 1975; Gotzenberger et al. 2012). Wilson and Gitay (1995) redefined assembly rules as ecological restrictions on the observed patterns of species presence or abundance that are derived from the presence of one or more other species or group of species. Basically, two distinct explanations for community assembly are currently discussed: neutral theory and niche-based theory. According to neutral theory, communities result from a stochastic balance between dispersal of individuals and local demography, and niche differences do not influence fitness differences among individuals (Hubbell 2001; Munoz \& Huneman 2016). In contrast, niche theory proposes that community assembly is determined by niche differences (Keddy 1992). In this view, the assembly process is assumed to represent the outcome of differing strengths of two opposing forces: abiotic constraints, or environmental filtering, whereby species are selected depending on their stress tolerances; and biotic filtering, caused primarily by competition among species for the same resources (Spasojevic et al. 2014). Niche theory views biodiversity patterns as deterministic, and seeks to identify differences among species regarding their environmental requirements and competitive rankings. Any species' distribution and abundance in each place and time is predictable from its ability 
to coexist under local abiotic conditions, in conjunction with biotic effects exerted by neighbors. In contrast to the deterministic view, neutral concepts question the relevance of niches. More generally, they assume net ecological equality among species and even individuals, viewing community composition as the result of a largely stochastic processes (Hubbell 2001). The functional trait concept that I explore in the dissertation serves as an alternative to taxonomic, species-based approaches in investigating whether deterministic or neutral processes are primarily responsible for community assembly (McGill et al. 2006). By focusing on functional variation rather than taxonomic identities, recurring patterns are sometimes revealed in situations where species-based approaches fail because of functional redundancy among species (Messier, McGill \& Lechowicz 2010).

\subsection{Trait-based community assembly}

A trait may be defined as any morphological, physiological or phenological characteristic, measurable at the individual level or averaged from a collection of individuals (Shipley 2010), which impacts fitness via its effect on growth, reproduction, and/or survival (Violle et al. 2007). Plant traits are used to functionally and causally describe plant responses to environmental factors. As such, plant traits are increasingly considered key variables needed to generalize regarding plant responses to environmental factors (e.g., resources or disturbance), plant effects on ecosystem functioning, and vegetation responses to environment under climate change (Lavorel \& Garnier 2002; Violle et al. 2007; Suding et al. 2008). 
On the basis of the observation that plants with similar ecological properties often share distinct traits, community ecologists have hypothesized that the response of a given species to abiotic and biotic environments (Weiher, Clarke \& Keddy 1998) may be predictable through a functional trait approach. As a result of its focus on functional variations rather than taxonomic identities, the functional trait approach can be used to predict the response of species across environmental gradients. It can help to overcome the problem exposed by the redundancy of functionally similar species. Therefore, the functional trait approach can facilitate identification of more marked responses to environmental factors than is possible when considering taxonomic units (Weiher \& Keddy 1999; Duckworth, Kent \& Ramsay 2000; Messier et al. 2010). It may also enable the formulation of principles more general than species-specific approaches, in that it can be applied to species and ecosystems different from those examined (Weiher and Keddy 1999).

\subsection{Ecological filters}

Species composition within a community is often viewed as a product of an assembly process by which species, via their traits, pass through dispersal (regional), abiotic (habitat), and biotic (competition) filters (Weiher \& Keddy 1995) (Figure 1). Dispersal is a key component of the community assembly process, as a plant must arrive at a location first before it can become a member of the community. Seed dispersal is accomplished by a wide variety of mechanisms, including movement by wind, water, and dispersal by animals. To a limited extent, seeds are dispersed randomly with respect to the distribution of environments or communities where a species is most likely to 
germinate and successfully establish. Abiotic/environmental filtering is the process that causes species composition to change along environmental gradients such as light, water availability, soil fertility, elevation, and latitude. These changes in species identity are often reflected in changes in the functional traits of species, such that average trait values across species in the community shift along the gradient. In contrast, biotic interactions such as competition operate between neighboring individuals, and therefore at small spatial scales within the community (Holdaway \& Sparrow 2006). Competition is expected to impact community assembly by the failure of species to establish or persist at a location in the face of competitive interactions for resources.

Recently, however, the traditional paradigm of filtering has been questioned because these filters are operationally difficult to disentangle (Violle et al. 2012). To simplify these processes, Violle et al. (2012) proposed a new spatially explicit framework that comprises two filters: the 'external' and 'internal' filters (Figure 1). External filter includes all assembly processes that operate outside the community, whereas the internal filter includes all that are internal to the community. The external filter conditions sort species from a regional pool, while the internal filter represents all local processes, including micro-environmental heterogeneity and density-dependent processes (Chesson 2000; Baraloto et al. 2010). External and internal filtering processes in assembly theory is able to disentangle the role of both filters in the establishment and persistence of traits and taxa in the community through the comparison of intra- and inter-specific trait variation at local and regional scales (Taudiere \& Violle 2016). 


\subsection{Plant trait variation across ecological scales}

Plant traits are influenced by their position along a hierarchy of environmental filters ranging from regional to local factors (Figure 2) (Gillison 2016). Identifying which scales cause the most variation in traits provides important information regarding the patterns and processes that are ecologically most critical at that scale (McGill 2008). The primary factors that drive trait similarities include climate, topography, disturbance, and edaphic factors (Keddy 1992; Grime 2006a; Mayfield \& Levine 2010; Paine et al. 2011). In contrast, factors that drive trait dissimilarities are mainly competition (Grime 2006a) and environmental heterogeneity (Cavender-Bares, Keen \& Miles 2006). Community trait similarity increases with increasing environmental variation at the regional scale (Willis et al. 2010) and with increasing size of the regional pool considered (Swenson et al. 2006). Trait differentiation mechanisms (e.g., competition) are believed to be particularly strong at small spatial scales. Maximum competition filtering is expected in places like tropical rainforests, when the densities of species with large capacities to capture light, water, or nutrients are high and trait variation among species is large relative to that within species (Cornelissen et al. 2003). While variation within a population focuses on differences among individuals in a species resulting from genetic variation and/or phenotypic plasticity.

Furthermore, different sets of traits may be important with variation in the major environmental stressor (Lavorel \& Garnier 2002). For instance, several studies showed that communities in regularly disturbed habitats were sorted according to their abilities to tolerate disturbance (De Bello, Lepš \& Sebastia 2005; Quétier et al. 2007). In waterlimited systems, species lacking traits associated with the ability to reduce or avoid water 
losses are filtered out (Fonseca et al. 2000; Cingolani et al. 2007), and along gradients of soil resource availability, height and leaf traits are most important (Cornwell \& Ackerly 2009).

\subsection{Distribution of hardwood hammock communities across the landscape in south Florida}

The research focus of this dissertation concerns the environmental filters and functional traits that comprise the community assembly process in the tropical dry forests of south Florida. These forests, colloquially known as hardwood hammocks, are widely distributed throughout the region, including the coastal barrier islands in Florida Keys as well as Everglades National Park and adjacent areas on the south Florida mainland. On the basis of physical, edaphic, climatic, and hydrological conditions, broadly, the whole region is divided into four main sub-regions: Everglades marsh hammocks, Pine Rockland, Upper Keys, and Lower Keys (Table 1). On the Florida mainland, numerous rockland hammocks and those in the Florida Keys (Lower and Upper Keys), are occupying shallow organic soils above well-drained limestone substrates. The exception are hammocks embedded in the Everglades peatland itself. Such hammocks are rarely flooded, but are rooted in deep mineral soils. For example, soil nutrient availability, particularly phosphorus in Everglades' marsh hammocks is exceptionally high (Ross et al. 2006; Wetzel et al. 2009) compared with hammock patches in the Florida Keys, while elevated ground water salinity is a stressor for coastal forests in the Keys that is absent in the interior Everglades. The Florida Keys are drier than the rest of South Florida, and the variable proximity of marine waters, warmed by passage of the Gulf Stream, adds further

climatic heterogeneity. Mean annual precipitation decreases from about $1400 \mathrm{~mm}$ per 
year in the north mainland to $1100 \mathrm{~mm}$ in the south Florida Keys (Moses et al. 2013). In much of the region, the hardwood hammocks are found on shallow soils above limestone bedrock, where the water-table is typically $0.5 \mathrm{~m}$ or more below the surface, and fires are infrequent.

The existence of geographically-patterned species composition between hardwood communities across the landscape gives an indication that physical and biotic conditions in a site filter species from a regional pool. A view of the filtering processes across this landscape is presented in Figure 3. Species' success in establishment in local community is primarily determined by series of filters. Plants are assembled into local communities from possible colonizers found in the surrounding region. As many empirical studies have shown that colonization of plants from the regional species pool is dispersal limited (Myers and Harms 2009). Dispersal is highly patchy and successful establishment is locally controlled by disturbance and related micro-climatic conditions. Hammock forests in South Florida, most tree species are fleshy-fruited, and likely to be dispersed by birds and small animals (Ross et al. 2016); the mobility of birds allows seeds to be relatively well-distributed across the landscape. Habitat filtering restricts species occurrence and is one of the most important factors in determining the local context of species occurrence at a sub-regional and community level (Reitalu et al. 2008). Species interactions (i.e., the biotic or competition filter) can strongly affect assembly rules control on the composition of communities (Fargione, Brown \& Tilman 2003). Together, dispersal limitation and habitat filtering can initially determine which species arrive at a particular site, while processes like competition, causing limiting similarity, will determine species persistence (Marteinsdóttir \& Eriksson 2014). The hypotheses 
tested in this dissertation are predicted on the expected that the subtropical forests of southern Florida are defined by these types of regional and patch-specific processes.

\subsection{Organization of the dissertation}

The dissertation is focused on patterns of community composition and spatial change in terms of functional traits, thereby providing insight into pertinent questions regarding the mechanisms underlying the current assemblages of hardwood hammock tree communities in south Florida. Broadly, the intent of the dissertation is to discern how the hardwood hammock communities are structured, and what drives changes in species composition during forest formation at local and regional scales. A second objective of this study is to investigate evidence for variation in trait-based community assembly patterns among the sub-regions of South Florida hardwood hammock forests.

Following this introduction, the dissertation is organized as three chapters (chapters 2-4), which are in manuscript format for submission to peer-reviewed scientific journals. References are placed after the concluding chapter (Chapter 5) and are in the format specified by the Functional Ecology journal. Author guidelines for reference format followed the "Functional Ecology" journal, which can be found in Appendix B. Chapter 5 summarizes the overall conclusions from chapters 2 through 4.

In Chapter 2 (to be submitted in journal of Vegetation Science), community assembly patterns of tropical hardwood hammock forest in four sub-regions of South Florida: the pine rocklands and interior marshes of Everglades National Park; the Florida Keys bordering on Florida Bay; and the hammocks of North Key Largo are analyzed. Considering the strong environmental variation among these sub-regions, trait variation 
across the sub-regions is examined. Patterns of trait-variation at various levels (individual, population, and community) are evaluated to test hypotheses related to the processes driving community assembly across sub-regions.

The focus of Chapter 3 (to be submitted to the Journal of Vegetation Science) is to understand the underlying mechanisms that drive species assembly during forest succession in Florida dry sub-tropical forest. Three primary research questions are addressed: a) How is variation distributed among inter and intra-specific levels during forest succession in Florida dry tropical forest? b) Is there any pattern in community weighted mean traits across the successional gradient? c) What is the underlying mechanism that drives species assembly during forest succession in Florida dry tropical forest? By decomposing the trait variation across ecological scales (community, species, individual), the dynamics of species response to environmental changes may be better understood. Moreover, comparisons of multiple trait patterns along an environmental gradient may advance understanding of the role of community assembly processes such as environmental filtering and competition (Spasojevic \& Suding 2012).

Chapter 4 (reviewed in Functional Plant Biology) examines variation in a rarely explored set of functional traits in a single species, Bursera simaruba, found commonly throughout the Florida Keys. It focuses on two questions: a) How is the variance in stomatal traits (size and density) of B. simaruba partitioned across a hierarchy of organizational levels? and b) At the site level, does variation in B. simaruba stomatal traits reflect physiological stress expressed across the habitat gradient of Florida Keys forests? Stomatal size and density in this widespread canopy occupant are examined. Differences in environmental conditions such as elevation, geology, and groundwater 
salinity are analyzed to determine the variation in stomatal structure and physiological stress, as reflected by carbon isotope ratios. Variance in stomatal traits across a hierarchy of scales - site, tree, and leaf levels - are employed to identify the cross-scale processes that are ecologically most important.

Chapter 5 summarizes three chapters 2-4. Here, overall findings of the dissertation are analyzed by revisiting the objectives and questions posed in each chapter. To conclude, future work is identified, which are most needed to complement the overall contribution of the dissertation in ecological theory and management of dry tropical forest. 
Table 1 Comparisons of potential environmental filters across sub-regions in south Florida.

\begin{tabular}{|l|l|l|l|l|}
\hline $\begin{array}{l}\text { Environmental } \\
\text { variables }\end{array}$ & $\begin{array}{l}\text { Marsh } \\
\text { hammocks in } \\
\text { Everglades }\end{array}$ & $\begin{array}{l}\text { Long } \\
\text { Pine Key }\end{array}$ & Upper Keys & $\begin{array}{l}\text { Lower } \\
\text { Keys }\end{array}$ \\
\hline Precipitation & High & High & Intermediate & Low \\
\hline $\begin{array}{l}\text { Soil } \\
\text { Phosphorus }\end{array}$ & High & Low & Low & Low \\
\hline $\begin{array}{l}\text { Moisture } \\
\text { retention }\end{array}$ & High & Low & Low & Low \\
\hline $\begin{array}{l}\text { Storm surge } \\
\text { frequency }\end{array}$ & Low & Low & Intermediate & High \\
\hline Soil depth & High & Low & Low & Low \\
\hline GW salinity & Low & Low & High & Intermediate \\
\hline
\end{tabular}




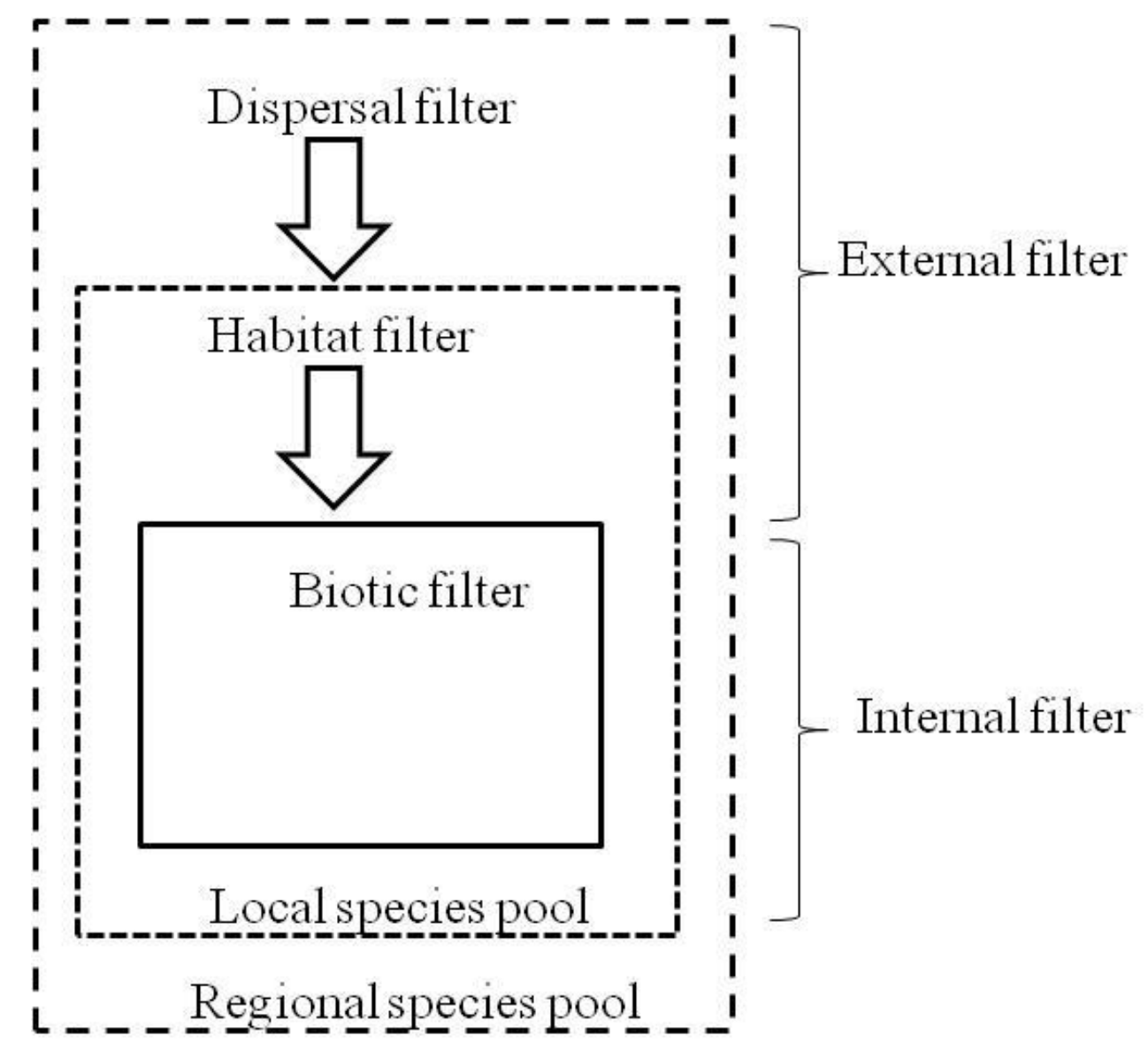

Figure 1 Different processes that might produce assembly rules.

Figure 1 shows the different processes that might produce assembly rules and the relative scales at which they are most influential (adapted from Weiher and Keddy 1995). At a given local site the species pool constitutes species from the regional species pool that can disperse there (dispersal assembly). At the local site, habitat filtering and biotic interactions define the actual assemblage of plant species (ecological assembly). External filter includes all assembly processes outside the community, whereas the internal filter includes all of the assembly processes internal to the community (Violle et al. 2012). 


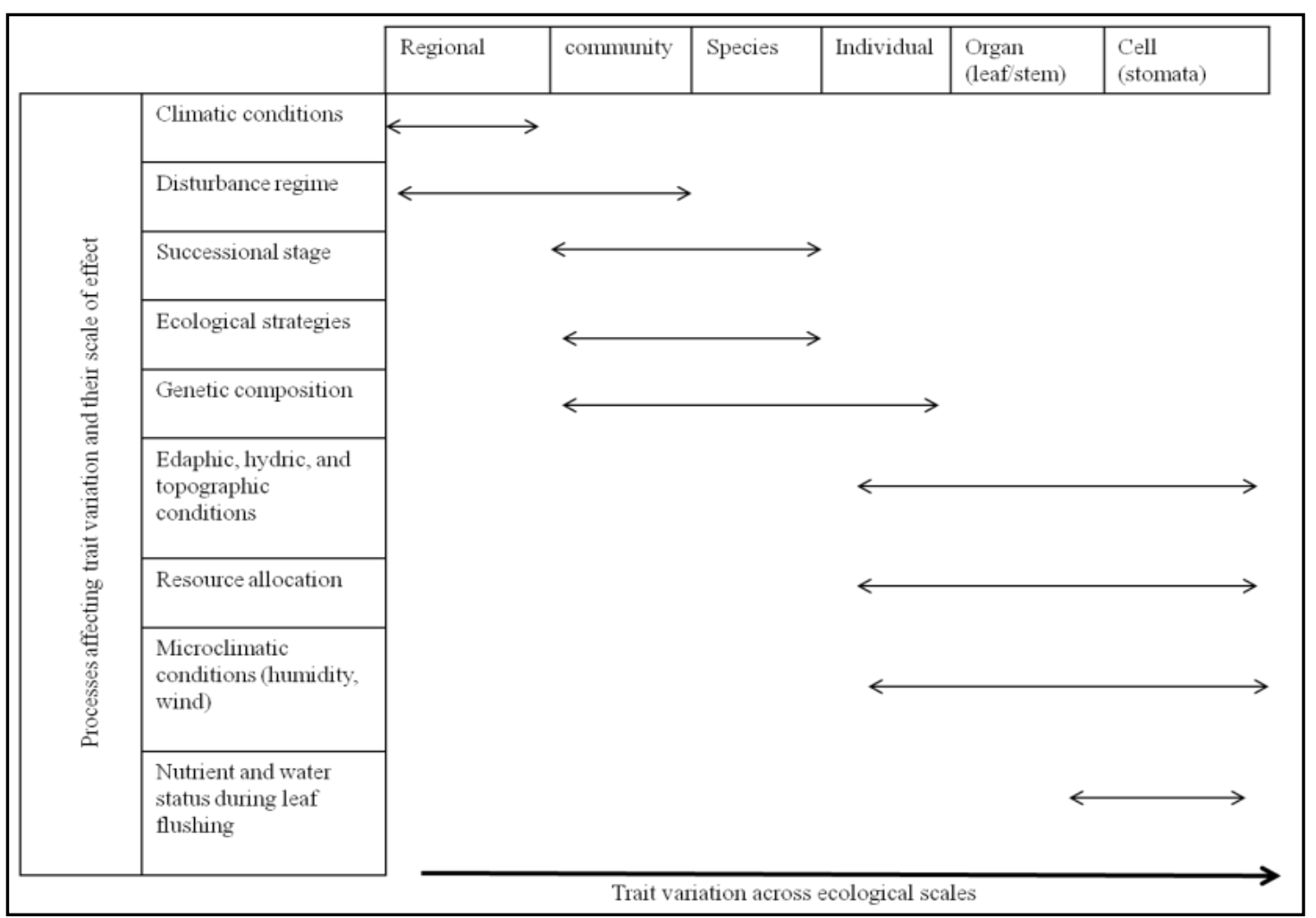

Figure 2 Processes affecting trait variation across various ecological scales

(adapted from Messier et al. 2010) 


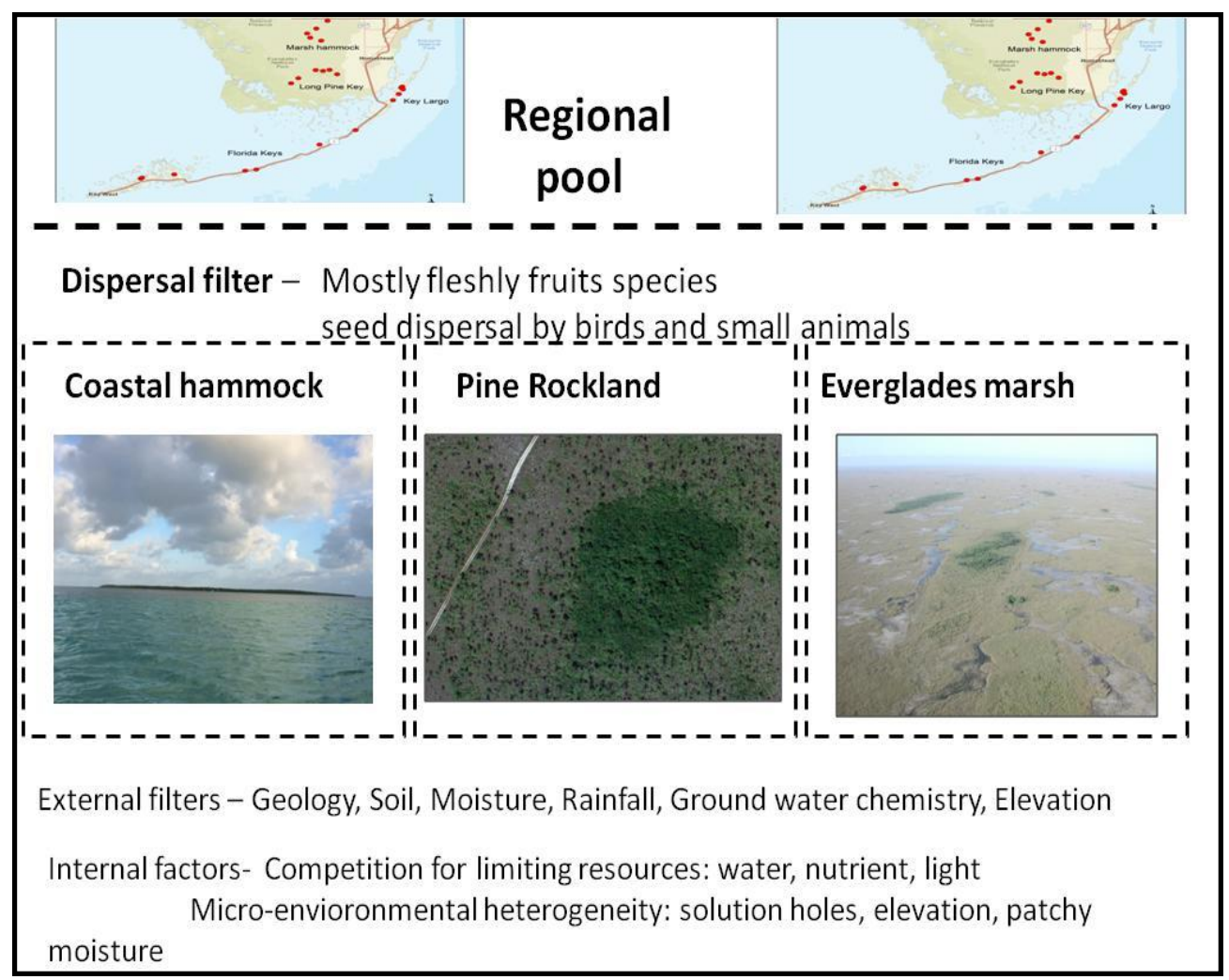

Figure 3 Hardwood hammock community in south Florida and potential filters across various spatial levels. 


\title{
CHAPTER 2
}

\section{Evidence for trait-based community assembly patterns in South Florida hardwood hammocks}

(To be submitted to the Journal of Vegetation Science)

\begin{abstract}
The tropical hardwood forests of south Florida persist as well-drained patches of broadleaf forest separated by brackish water swamp, marsh, or pineland. The functional trait approach is useful in understanding the structure and dynamics of these communities and their responses to abiotic and biotic variation. The present study is designed to examine community assembly patterns of tropical hardwood hammock forest in four subregions of South Florida: the pine rocklands and the interior marshes of Everglades National Park; the Florida Keys bordering on Florida Bay; and the hammocks of North Key Largo. Considering the strong environmental variation among these sub-regions, it is hypothesized that environmental filters play an important role in community assembly along a bioclimatic gradient from the relatively dry and unproductive Florida Keys in the south to the moist and productive areas on the south Florida mainland. Patterns of traitvariation at various levels (individual, population, and community) were explored to evaluate broad hypotheses related to the processes driving community assembly across sub-regions. Trait variance ratios (T-statistic metrics) were used to explore internal filtering (processes that operate at a local scale such as competition and microenvironmental heterogeneity) and external filtering (processes that operate at larger scale than that of the individual population or community, such as climate and regional geology) on community structure in each sub-region. Community weighted mean trait
\end{abstract}


values for four of six selected traits showed significant inter-sub-regional variation. Three traits (specific leaf area, tree height, and leaf phosphorus) increased significantly from dry and low productive Florida Keys in the south to the moist and productive areas on the south Florida mainland, while wood density showed the opposite pattern. A strong internal filtering that was observed within all sub-regions may be the result of variation in inter-specific competition for limiting resources within a community. Significant environmental filtering was also observed at the individual level, possibly a consequence of variation in water, light, and nutrient availability between sub-regions; within a species, only those individuals with traits matching the local conditions should successfully establish under a community's external filters. Therefore, both external and internal filtering in the functional composition of south Florida hardwood hammock forest are important for local communities differing in freshwater accessibility, or that occupy different positions along strong edaphic or climatic gradients.

Keywords: Community assembly, environmental filtering, internal filtering, hardwood hammock, T-statistics, south Florida

\subsection{Introduction}

Functional traits result from interactions of individuals with abiotic and biotic factors (Díaz \& Cabido 2001; Violle et al. 2007). Study of functional traits is useful in understanding the structure and dynamics of vegetation as well as plant community responses to changes in abiotic and biotic factors (Lavorel \& Garnier 2002; Kunstler et al. 2016). Ecologists are interested in understanding the link between the spatial distribution of trait values and community assembly patterns (Anderson et al. 2011). 
Functional traits and their associated metrics have been used to quantify plant community assembly processes across temporal (Enquist et al. 2015), climatic (Hulshof et al. 2013), elevational (Körner 2007; Bryant et al. 2008), latitudinal (Swenson et al. 2012; Lamanna et al. 2014; Lawson \& Weir 2014), and compositional gradients (Marques et al. 2000). Violle et al. (2012) introduced the concept of external (environmental) and internal filters (competition) to explore trait variation across hierarchical levels, i.e., individual, population, community, and region. External and internal filters are involved in processes operating at different spatial extents. External filters are processes that operate at a scale larger than that of the individual population or community (Violle et al. 2012), and tend to decrease local trait variation. For example, climatic conditions are generally an external filter that may select for a set of physiological traits for an entire population. Internal filters are processes that operate within populations or community and increase local trait variation (Violle et al. 2012). For example, competition for resources (water, nutrients, light) and micro-environmental heterogeneity are internal filters that may increase resource variation within a population or community. If external filters are the dominant process governing a given trait, species will have low trait variation within populations. In contrast, if internal filters predominantly determine trait values, species will have high within-population trait variation and functional diversity within communities will be high.

The dry tropical forests of south Florida (locally called hammocks) are considered a part of the Caribbean biodiversity hotspot (Tomlinson 1980), and persist today as patches separated by various ecosystems such as brackish water wetlands, fresh water marshes, and rockland pine forests. On the basis of presence/absence data from 
hammocks across a substantial portion of the region, tree composition in these hammocks exhibit a nested structure with clumped range boundaries, i.e., nestedness changes in successive jumps across sub-regions (Ross et al. 2016) that differ sharply in environment. For example, soil nutrient availability in Everglades' marsh hammocks is exceptionally high (Ross et al. 2006; Wetzel et al. 2009; Hanan \& Ross 2010; Ross \& Sah 2011) compared with hammock patches in the Florida Keys, while elevated ground water salinity is a stressor for coastal forests in the Keys that is absent in the interior Everglades. When environmental conditions change across sub-regions, most individuals in communities with low trait variation may respond similarly, and population size may change suddenly and dramatically. Alternatively, when a population with greater trait variation experiences the same change in environmental conditions, only some individuals may respond, and population fluctuations will be less pronounced (Bolnick et al. 2011). Despite the recognition that intra-specific variation is a key parameter in explaining a population's resilience to environmental changes and its ability to coexist and compete with its neighbors (Albert et al. 2010; Jung et al. 2010), few studies have proposed combining intra- and inter-specific variability to understand diversity patterns across local and regional spatial scales (Paine et al. 2011; Hulshof et al. 2013; Le Bagousse-Pinguet et al. 2014). Moreover, while studies have examined compositional variation among south Florida hardwood hammocks (e.g., Ross et al, 2016; Armentano et al. 2002), no studies have addressed trait variation in relation to external and internal drivers. To my knowledge, this study is the first to use trait variation to explore community assembly across multiple sites and regions with different environmental conditions within the sub-tropical dry forests of Southeast United States. 
To assess trait variance, six important traits (specific leaf area, wood density, height, leaf nitrogen, leaf phosphorus, and leaf $\delta^{13} \mathrm{C}$ ) of the sub-tropical dry forest were measured across a range of south Florida landscapes. Specifically, I chose forests within four sub-regions (1) marsh tree island hammocks in Everglades National Park (Everglades), (2) Pine Rockland hammocks in Long Pine Key (LPK), (3) hammocks in North Key Largo (NKL), and 4) hammocks in the lower and middle Florida Keys (Lower Keys). Patterns of trait-variation at various levels (individual, population, and community) were explored to evaluate broad hypotheses related to the processes driving community assembly across sub-regions. Considering the strong environmental variation across the study area, environmental (external) filters expected to play an important role in community assembly, extending from relatively unproductive coastal Florida Keys sites in the south to more productive marsh tree islands in the north. Since species richness is greater in coastal and pine-rockland hardwood hammocks than in Everglades hammocks (Ross et al. 2016), and thus more competitors are involved in the assembly process.

\subsection{Methods and materials}

\subsubsection{Study site}

The study took place in the Florida Keys and Everglades National Park in the southeastern portion of peninsular Florida. Hardwood hammocks are widely distributed throughout the region, including the coastal barrier islands as well as Everglades National Park and adjacent areas on the south Florida mainland. In general, these hammocks occupy shallow soil above well-drained limestone substrates and are rarely flooded. 
Numerous hammocks are embedded in various habitat matrices, such as pinelands, freshwater marshes, and coastal wetlands (Figure 4). Hardwood hammock patches, which are distinct features in the Everglades, occur as either individual forest fragments surrounded by marsh or as part of a larger forested tree patch, in combination with a range of swamp forest types (Ross et al. 2006). In the latter case, hardwood hammocks usually occupy less than $1000 \mathrm{~m}^{2}$ in the heads of the tree islands, while the entire tree island may sometimes encompass ten hectares or more. Hardwood hammocks are also a common feature in pine forests dominated by slash pine (Pinus elliotti var densa), which once occupied uplands throughout the Atlantic Coastal Ridge, but today are most common on Long Pine Key (LPK) in Everglades National Park. Hardwood hammock forests are also present in the Florida Keys which is a chain of limestone islands that begins in Biscayne National Park and arcs west-southwest to Key West (Ross, Coultas \& Hsieh 2003). The size of hammock patches in Florida Keys also varies widely; among the largest is the continuous forest occupying an elongated, about $15-\mathrm{km}$ stretch in northern Key Largo (NKL) in the upper Florida Keys (Ross et al. 2001).

\subsubsection{Trait Selection}

Previous trait-based studies identified physiological and morphological traits that are strongly associated with plant growth and survival (Fonseca et al. 2000). Numerous traits have been employed because of a presumption that they were important for plant performance and represented relatively independent aspects of plant ecological strategy. Among these, six traits - specific leaf area (SLA), wood density (WD), maximum canopy height at maturity (HT), leaf nitrogen (TN), leaf phosphorus (TP), and leaf stable carbon isotope ratio $\left(\delta^{13} \mathrm{C}\right.$, representing the overall physiology of species in forests) - encompass 
many of the aspects of woody plant strategy (Westoby et al. 2002; Kraft, Valencia \& Ackerly 2008). The importance of each of these traits is summarized in Table 2.

\subsubsection{Study design and trait measurement}

Twenty-two permanent plots $\left(20 \times 20 \mathrm{~m}^{2}\right)$ were established across the south Florida landscape, representing four sub-regions (Figure 4). All trees greater than $1 \mathrm{~cm}$ DBH were included in the data set, but canopy height measurements were done only for trees greater than $5 \mathrm{~cm}$ DBH. Tree height was measured using a telescoping height pole to determine the shortest distance between the upper boundary of the main photosynthetic tissues on the plant and ground level (Cornelissen et al. 2003, Pérez-Harguindeguy et al. 2013). For leaf and wood traits (SLA, TN, TP, $\delta^{13} \mathrm{C}$, and WD), 3-5 replicates were taken from separate individuals of each species present in each plot. For leaf trait sampling, recently expanded sun leaves were sampled when possible, but in cases of understory species, the most illuminated leaves on the plant were sampled (Cornwell and Ackerly 2009). Specific leaf area (SLA, leaf area per unit mass) was quantified with a leaf area meter on leaves brought directly from the field to the lab, dried at $70^{\circ} \mathrm{C}$ for three days, and weighed. Wood density (WD) determined from 1-2 cm DBH branch samples was calculated as the oven-dry mass of the sample divided by the mass of water displaced by

its fresh (green) volume (Chave et al. 2006). Carbon isotope ratio $\left(\delta^{13} \mathrm{C}\right)$, leaf phosphorus content (TP), and leaf nitrogen content (TN) were obtained for each leaf measured for SLA. In general, measurements of plant traits followed well-established methods described by Pérez-Harguindeguy et al. (2013). 


\subsubsection{Environmental variables}

To capture the variation in environmental variables across the landscape and between sites, as well as to account for correlation among variables, I applied a principal component analysis to eight variables: ground water salinity, ground water depth relative to the surface, soil depth, soil nitrogen, soil phosphorus, soil $\mathrm{pH}$, soil organic matter, soil bulk density. Among these, soil depth was measured at 20 equidistant locations along a $20 \mathrm{~m}$ transect laid out through the middle of the permanent plot by probing to bedrock with a metal rod. For many Florida Keys' sites, ground water level, soil organic matter, bulk density, nitrogen, phosphorus, $\mathrm{pH}$ and groundwater salinity data were acquired from an earlier study by Ross et al. (2003). The same environmental data were acquired for marsh hammock sites by Ross and Sah (2011). Unfortunately, for a few sites (three in the Florida Keys and five in Long Pine Key), similar environmental data were not available. Thus, those sites were excluded from trait-environment relationship analysis. Altogether, 14 sites were used to represent the stress-productivity gradient, from dry and less productive forests (Florida Keys) to moist and more productive (marsh hammocks) (Ross et al. 2003; Ross \& Sah 2011).

\subsubsection{Statistical analysis}

\subsubsection{Community-weighted trait means}

To compare traits across sites, while accounting for species abundance, I used community-weighted means (CWM) (Violle et al. 2007; Hulshof et al. 2013):

$$
C W M_{p}=\sum_{s} \mu_{i} f_{i}
$$


where $\mathrm{p}=$ plot, $\mathrm{s}=$ species, and $\mu_{\mathrm{i}}$ and $\mathrm{f}_{\mathrm{i}}$ are the mean trait value and relative abundance of the species i (proportion of total tree density).

The CWM trait values were then compared across sub-regions, and linear regression analyses were performed to relate CWM traits and site-environmental parameters (site scores from principal component analysis). Significance was calculated using a Mantel test (R package vegan).

\subsubsection{Community assembly analysis across the hierarchical levels}

A suite of functional trait metrics exist in the literature (Aiba et al. 2013), but Tstatistics ("T" referring to traits) were used in this study, which are based on variance ratios that account for intra-specific variation relative to inter-specific variation (Violle et al. 2012). Since the relative importance of intra- and inter-specific trait variation is a key parameter of species coexistence, these variance ratios can test for internal and external filtering in a given community at different spatial and organizational scales (e.g., individual, species, whole community).

In this method, three T-statistics T_IP.IC, T_IC.IR, and T_PC.PR were calculated for each region and community, where I, P, C, and R represent individual, population, community, and region respectively. The T_IP.IC $\left(\sigma^{2}{ }_{\text {IP }} / \sigma^{2}{ }_{\text {IC }}\right)$ is the ratio of trait variance within single species (population) to the total variance of the community over all species; T_IC.IR $\left(\sigma_{\text {IC }}^{2} / \sigma_{\text {IR }}^{2}\right)$ is the ratio of trait variance of all individuals in a community to the

total variance in the regional pool; and T_PC.PR $\left(\sigma^{2}{ }_{P C} / \sigma^{2}{ }_{P R}\right)$ is the ratio of communitywide species variance to total variance in the regional species pool (inter-specific variance). 
Statistics T_IP.IC measures the strength of internal filters; that is, how strongly local processes, such as micro-environmental heterogeneity or density-dependent processes, act on community assembly. A completely non-overlapping trait niche would lead to a T_IP.IC close to 0 , while if community assembly occurs randomly in a community, T_IP.IC tends to be close to 1 . In contrast, T_IC.IR and T_PC.PR, measure the strength of external filters in the community at individual and species level, respectively. Statistics T_IC.IR considers the trait values of all individuals in the community and in the regional pool at the individual level, regardless of species identity, whereas T_PC.PR considers species (population) means within communities and the regional pool. When T_IC.IR and T_PC.PR are close to 1 , the community variance, is high in comparison to the total variance, indicative of relatively little external filtering (e.g. climatic constraints). Conversely, T_IC.IR and T_PC.PR close to 0 suggest that community collectively is strongly filtered by either abiotic stress or environmental filtering.

To determine the significance of the T-statistics, results from four sub-regions were compared to null models generated within the 'cati' package, using standardized effect sizes (SES), calculated as,

$\mathrm{SES}=\left(\mathrm{I}_{\mathrm{obs}}-\mathrm{I}_{\mathrm{sim}}\right) / \sigma_{\mathrm{sim}}$

where $\mathrm{I}_{\mathrm{obs}}$ is the observed trait value, $\mathrm{I}_{\text {sim }}$ is the mean of simulated trait values calculated with the null model and $\sigma_{\text {sim }}$ is the standard deviation of these simulated values (999 randomizations) (Table 3). 


\subsection{Results}

\subsubsection{Species diversity across the four sub-regions}

Species diversity varied by sub-region (Figure 5). Species diversity throughout the Florida Keys and Long Pine Key was high, while very few species were present in Everglades marsh hammocks. At the community (plot) level, species diversity exhibited a similar pattern of variation among sub-regions (Figure 5).

\subsubsection{Variation in community trait means along the gradient}

Principal component analysis (PCA) of the eight environmental variables demonstrated the overwhelming strength of the first component, which explained $47 \%$ of the variation (Table 4). High positive or negative weightings on the first axis of PCA were shared by all variables except soil nitrogen, which had a strong positive weighting on Axis 2. Along Axis 1, which represents the dominant environmental gradient based on ground elevation, soil depth, soil phosphorus, ground water salinity, and soil $\mathrm{pH}$, Lower Keys and North Key Largo sites are on the left side while Everglades sites are on the right (Figure 6). Axis 2, defined by soil nitrogen and bulk density, distinguishes the single Long Pine Key location from the other sites. Overall, the ordination displays a gradient from dry and low productive (Lower Keys) to moist and high productive sites (Everglades hammocks). Florida Keys sites have higher ground water salinity and lower soil depth, $\mathrm{pH}$, and phosphorus concentrations than hammocks in the Everglades marshes (Table 5). Furthermore, low elevation forests in some Florida Keys locations may experience water stress because of the proximity of brackish groundwater.

Community-weighted mean (CWM) traits showed significant trends along the environmental gradient for four of the six tested traits; the exceptions were leaf nitrogen 
(TN) and $\delta^{13} \mathrm{C}$ (Figure 7-12). The CWM of SLA, HT, and leaf phosphorus (TP) increased (Figure 7, 9, and 12), while that of WD decreased significantly from dry and lowresource sites (Florida Keys) to high resource sites in Everglades hammocks (Figure 8).

\subsubsection{Comparison of community weighted traits across regions}

The four sub-regions varied in their CWM trait values (Figure 13). Analysis of variance showed that CWM trait values of four of the six measured traits, i.e., SLA, HT, WD and TP, differed significantly across sub-regions (One way ANOVA, p<0.05). Specific leaf area in Lower Keys hammocks was lower than in the other three subregions. Concurrently, marsh hammocks in tree islands of the interior Everglades stood out in their low WD and high TP; in fact, CWM leaf TP in these islands was more than twice as high as in the next highest sub-region (Figure 13).

\subsubsection{Community assembly}

The departure of the T-statistics from the randomized distributions (through SES values) is plotted in the Figure 14. For all traits, the T_IP.IC metric, which reflects within-plot intra-specific to inter-specific variation, differed significantly from null expectations, indicating that a strong internal filtering on these traits determines local community assembly. Only for HT and TP, T_IC.IR, which measures the relative strength of external filtering on individuals, differed significantly from null expectations, indicating that the community collectively has been strongly filtered by either abiotic stress or external interactions. Differences between values of T_PC.PR and the null model, which reflects the relative strength of external filtering on species, were only observed for SLA, HT, and TP. 
In Everglades hammocks, T_IP.IC metric was significantly different than null expectation for three traits, which indicates that internal filtering is driven by competition associated with SLA, WD, and HT traits (Figure 15a). Statistics T_IC.IR and T_PC.PR in Everglades differed significantly from null expectations for only $\delta^{13} \mathrm{C}$ (Figure 15a) which suggests that species filtered in this sub-region had similar $\delta^{13} \mathrm{C}$ values. In the Lower Keys, T_IP.IC was significantly lower than null expectation for all six traits (Figure 15b). It means internal filtering within a community is strongly associated to competition for limiting resources in this sub-region. For external filtering, T_IC.IR differed significantly from the null expectation for $\mathrm{HT}, \delta^{13} \mathrm{C}$, and TP in Lower Keys, which indicates that individuals within a community are filtered by their similarities in these traits rather than by species; while T_PC.PR metric differed significantly only for SLA indicates that species in Lower Keys are similar in SLA. Similarly, in other two sub-regions, NKL and LPK, T_IP.IC metrics were significantly different than null expectation for three traits, namely SLA, WD, and HT, (Figure 15c and Figure 15d), more competition for resources at community level associated with these traits. For external filtering, both T_IC.IR and T_PC.PR differed significantly from the null expectation for two traits (HT and TP) in LPK sub-region (Figure 15c) i.e., species are filtered from regional pool by their similarity in height and leaf phosphorus. The observed significant different T_IC.IR and T_PC.PR metrics from the null expectations for only TP in NKL sub-region (Figure 15d) indicates that species are filtered on the basis on their response to phosphorus availability. 


\subsection{Discussion}

\subsubsection{Variation in community-weighted traits across the region}

The strong relationships observed between site characteristics and traits indicates that abiotic factors, mainly soil depth, soil phosphorus, soil $\mathrm{pH}$, and ground water salinity were the primary factors in explaining CWM trait variation across sites. Species with resource-acquisitive traits, such as high SLA, canopy height, and leaf nutrient (N and P) concentrations, occur more frequently or reach higher abundances in sites with high resource (moisture and nutrient) availability (Wright \& Westoby 2002; Garnier et al. 2004; Warren, Tausz \& Adams 2005; Cornwell \& Ackerly 2009; Shipley 2010; Baruch 2011; Katabuchi et al. 2012). In Everglades hammocks, trees certainly have greater access to soil nutrients and water compared to drier and resource poor sites in the Florida Keys and LPK. The very high leaf phosphorus observed in Everglades hammocks may be linked to exceptionally high soil phosphorus in this sub-region. At the abiotically stressful end of the south Florida gradient, environments with low resource availability appear to select for shorter trees with low SLA, and low leaf TN, and TP.

In contrast, an opposite pattern was observed along the environmental gradient in wood density. Dense wood is associated with low SLA, related to slow return on investment in assimilation (Wright et al. 2007; Chave et al. 2009). Moreover, wood density tends to be positively related to leaf lifespan (Ishida et al. 2008) and negatively to minimum leaf water potential (Ackerly 2004; Bucci et al. 2004; Santiago et al. 2004). The assumption is that trees with deeper roots will have better access to freshwater and thus lower minimum leaf water potentials (McElrone et al. 2004). In the Florida Keys, 
hammocks generally have very shallow soil depth (less than $30 \mathrm{~cm}$ ), lower annual precipitation than elsewhere in the region, and brackish ground water salinity. The high wood densities at the drier end of the environmental gradient (Lower Keys, NKL and LPK), may be associated with water and/or salt stresses, as fibers and thick-walled vessels found in dense wood have elsewhere been found to protect vessels from implosion when fresh water shortage creates strongly negative xylem potentials (Hacke et al. 2001).

The increase in community weighted means of SLA, HT, and TP, and the concomitant decrease in WD from the most stressful sites (Florida Keys) to those where resources were most plentiful (Everglades hammocks, Figures 7-9, and 12) represent a strong shift in CWM traits linked to fast-growth strategies. Therefore, the shift in CWM traits across sub-regions in South Florida supports the hypothesis that highly isolated resource-limited environments in coastal and pineland hammocks may select species whose strategy is to make a long-term investment in leaves and wood.

\subsubsection{Community assembly patterns across sub-regions}

\subsubsection{Internal filtering}

A significant lower value than the null expectation observed for T_IP.IC in Figure 14 suggests that competition within a community is an important process in determining local community assembly in each sub-region. However, the strength of internal filtering is not the same for all the traits in each sub-region. For example, SES values for $\mathrm{T}$ _IP.IC in all measured traits were significantly different than randomized values in the Lower Keys, while significantly low values were observed for only three 
traits (SLA, WD, and HT) in the other three sub-regions (Figure 15). Variation in filtering process between sub-regions might be the result of differences in biotic or abiotic conditions between sub-regions (Violle et al. 2012).

In Lower Keys, the observed pattern of strong internal filtering in all six traits may be a consequence of relatively high species diversity in association with stressful abiotic conditions. Species diversity in Lower Keys communities is very high compared to forests in Everglades marshes (Figure 5). As species number increases in a community, competition for limiting resources between co-existing species is also likely to increase (Paz, Mazer \& Martinez-Ramos 2005). Moreover, significantly low T_IP.IC values for all the traits in most Lower Keys sites is indicative of very low intra-specific trait variation (Violle et al. 2012), and emphasizes the importance of inter-specific competition in acquiring limited resources among co-existing species. It is also possible that as communities in this sub-region are mostly in isolated islands, the pattern of trait niche differentiation might be the reflection of adaptive radiation driven by competition for scarce resource (Cavender-Bares et al. 2004a). Therefore, environmental conditions in the Lower Keys may contribute to competition among species in local community assembly as species are likely to compete for limiting resources.

Similarly, significant internal filtering was also observed in other sub-regions: Upper Keys (NKL) and Long Pine Key (LPK) for three traits (SLA, WD, and HT) (Figure 15) because of inter-specific competition for resources. A high level of competition within dry and resource limited environment in NKL and LPK, which are somewhat similar to the biotic and abiotic conditions of the Lower Keys, was not unexpected, as species diversity in these sub-regions is as high as in the Lower Keys 
(Figure 5), and water and nutrients may be nearly as limiting (Ross et al. 2003). The lack of evidence for internal filtering for leaf nutrient traits $\left(\mathrm{TP}, \mathrm{TN}, \delta^{13} \mathrm{C}\right)$ in NKL and LPK, suggested by non-significant T_IP.IC values (Figure 15), may be because of their sensitivity to microhabitat variation within a community (Baraloto et al. 2010). Moreover, higher intra-specific variation in these traits may also contribute to low interspecific competition (Jung et al. 2010). Intra-specific variation in SLA, HT, and WD was observed to be very low compared to leaf nutrient traits (TP, TN, $\delta^{13} \mathrm{C}$ ) in hardwood hammock species in Florida Keys (see Chapter 3). Generally, high intra-specific trait variation results from trait plasticity in response to micro-environmental heterogeneity (Violle et al. 2012). For example, a few sites in NKL are slightly elevated, with a deeper soil layer that allows more access to water and nutrients. A study has shown that hardwood hammock species in LPK are highly dependent on access to groundwater, especially during the dry season (Ewe, Sternberg \& Busch 1999), and slight variations in elevation may influence the availability of freshwater. The evidence suggests that both inter-specific competition and individual response to micro-environmental heterogeneity are important processes for community assembly at local scale in these sub-regions.

Given the discussion above, it is interesting to observe similarities in the pattern at high resource sites, i.e., Everglades hammocks, where moisture and nutrients are abundant. Community weighted mean trait analysis (Figure 7-12) indicates that species in Everglades forest stands exhibit traits that allow them to grow rapidly in height (high SLA and HT, and low WD), resembling patterns reported for early successional species (Ross et al. 2016). However, canopy cover in Everglades hammocks is relatively high, so light availability at ground level is limited (personal observation). Resource availability is 
therefore more akin to moist closed canopy tropical forests (Poorter, Bongers \& Bongers 2006a), where competition for light has been shown to be an important determinant of species coexistence, particularly for canopy species at the seedling stage. Therefore, the observed internal filtering through competition in Everglades hammocks could relate to competition for light, perhaps affecting species selection among seedling and sapling stages (Spasojevic et al. 2014).

\subsubsection{External filtering}

In the Lower Keys, very low individual levels of trait variation was observed leading to a significantly lower $\mathrm{T} \_$IC.IR than null expectation in most sites for four traits (SLA, HT, TP, $\delta^{13} \mathrm{C}$ ), which could be the result of a very high environmental filtering. Local communities differing in edaphic or climatic factors across the region may create a strong environmental gradient (Cavender-Bares et al. 2006; Fine \& Kembel 2011). The Lower Keys represents the stressful end of such a gradient, caused by its relatively low rainfall, brackish groundwater, low nutrient availability, and salt stress associated with sea-water flooding. These conditions are likely to filter for individuals that have ability to thrive in such an environment, thus making them similar in traits. Trees in the Lower Keys arguably experience a drier environment than the hammocks in other areas because of low canopy cover, and selection therefore strongly favors for trees with increased capacity to tolerate drought. Moreover, freshwater species in the hardwood hammock community may have a limited ability to tolerate salt stress which is supported by the observed significant trait differences (lower SLA, higher WD, and shorter trees, Figures 7-9) in the Lower Keys compared to other sub- regions, in particular the Everglades 
hammocks. One might also expect that such a trait pattern would be paralleled by high leaf $\delta^{13} \mathrm{C}$, as this trait is often taken to reflect the ability to tolerate drought stress (Zhang et al. 2017). In contrast, no evidence of CWM leaf $\delta^{13} \mathrm{C}$ differences between sub-regions or along the environmental gradient (Figure 11) was observed in this study. Some studies have already shown that the leaf $\delta^{13} \mathrm{C}$ trait might not be useful at the community level because of its sensitivity to microhabitat variation (higher intra-specific variation) within a community (Baraloto et al. 2010) which is supported by the results presented in Chapter 4 of this dissertation, in which the bulk of variation in leaf $\delta^{13} \mathrm{C}$ across the hierarchical scales (leaf, individual tree, species, and sites) was concentrated at the leaf level, and the proportion of variation explained by the site level was very low. Observed significant external filtering on leaf $\delta^{13} \mathrm{C}$ occurs at the individual level (T_IC.IR metrics) (Figure 14 and 15) confirmed that trees were selected from the regional pool on the basis of their ability to tolerate dry conditions in Lower Keys hammocks

Similarly, in NKL and LPK sub-regions, community filtering based on height and phosphorus suggests that community assembly is driven by external factors (nutrient and freshwater availability), which are strongly controlled in these sub-regions by soil depth, ground elevation (distance to ground water table), and ground water salinity (Sternberg \& Swart 1987; Ewe et al. 1999). In LPK, rocky, skeletal soils (less than $20 \mathrm{~cm}$ ) and phosphorus-limited conditions may filter for trees with ability to tolerate these conditions. In NKL, trees may be limited by phosphorus (Redwine 2007, Subedi unpublished data) and their ability to tolerate or acquire phosphorus might determine their persistence in the local community. Similar patterns of external filtering at the species level (T_PC.PR) in NKL and LPK in TP (Figure 15c and Figure 15d) suggests further that environmental 
filtering acts on species in these locations as a consequence of their ability to tolerate phosphorus limiting environment. Furthermore, environmental filtering in height only at the individual level indicates that individuals in communities are found within a similar range of heights, irrespective their taxonomic identity.

External filtering in $\delta^{13} \mathrm{C}$ occurred at both individual and species levels (T_IC.IR and T_PC.PR, Figure 15a) in Everglades hammocks. They are located on islands embedded in peat-based marshes, but the hammock soils are high in carbonate minerals that allow phosphorus concentrations to reach extremely high levels. Species in Everglades marsh hammocks have relatively high stomatal conductance (Lin \& Sternberg 1992), which is likely associated with high growth rates, as indicated by high SLA, and low WD (Figure 13).

\subsection{Conclusions}

Both competition filtering and environmental filtering were found to influence local assembly. Both local and regional processes were contributed to the filtering of species from the regional species pool into local hardwood hammock communities. The important role of environmental filtering across sub-regions was observed primarily because of variation in edaphic and hydrologic variation across these areas. The observed shifts in trait values across the habitat gradient suggest that variation in individual physiology and morphology allows species to respond to differing external filters along environmental gradients. Stressful environments in coastal and pineland hammocks selected species with long-term investments in leaves and wood, while high-resource sites in Everglades hammocks filtered for species with fast-growth strategies. The 
external filtering process operated on the level of individuals instead of species, and only those individuals of a species with traits matching the local community should successfully establish in the presence of these filters. Furthermore, at local scale community assembly was driven by competition in all sub-regions. Therefore, the strong external filtering observed in the functional composition of South Florida hardwood forests contributes to the assembly of local communities. These local communities are defined by differing in access to freshwater, or to other edaphic or climatic factors, while, local community assembly is driven by inter-specific competition to acquire limited resources among co-existing species. Moreover, this study also supports the importance of incorporating intraspecific variation in community studies, as trees respond at the individual or the community level, depending on trait identity and site characteristics.

\section{Acknowledgement}

Thanks to South Florida Terrestrial lab (SOFTEL) for logistics and SOFTEL crews helping during the field and laboratory work, specially Bina Thapa, Rosario Valdes, and Susana Stoffella. Thankful to Everglades National Park, Florida State Park and US fish and Wildlife for allowing allow to access sites. Thanks to my coauthors Dr. Michael Ross, Dr. Jay P Sah, and Dr. Christopher Baraloto for their suggestions and reviews in this manuscript. Thanks to International Center for Tropical Botany (ICTB) for partial funding for laboratory analysis (stable isotope lab) through graduate student summer research. Also, thanks to Earth and Environment department (teaching assistantship), graduate school (FIU) for doctoral evidence acquisition fellowship (DEA), ICTB graduate student summer fellowship, and Everglades Tree Island Restoration 
Project (research assistantship) for helping directly and indirectly to accomplish the project. 
Table 2 Measured traits and their functional importance

\begin{tabular}{|l|l|}
\hline Trait & Functional importance \\
\hline Height (HT) & - Key determinant of competition for resources. \\
\hline $\begin{array}{l}\text { Specific leaf area } \\
\text { (SLA)- leaf } \\
\text { area/dry wt }\end{array}$ & $\begin{array}{l}\text { - Fast-growing species with cheap leaf construction } \\
\text { costs (High SLA) against slow-growing and stress-tolerant } \\
\text { species with expensive leaf construction costs (Low SLA). }\end{array}$ \\
\hline $\begin{array}{l}\text { Wood density } \\
\text { (WD) dry } \\
\text { wt/volume }\end{array}$ & $\begin{array}{l}\text { - Fast-growing species with low wood density against slow- } \\
\text { growing but stress-tolerant - i.e. high-survival - species with } \\
\text { high wood density }\end{array}$ \\
\hline $\begin{array}{l}\text { Leaf total } \\
\text { phosphorus (TP) }\end{array}$ & $\begin{array}{l}\text { Important for water and P-limited system like Florida Keys dry } \\
\text { tropical forest }\end{array}$ \\
\hline Leaf Nitrogen (TN) & $\begin{array}{l}\text { - A significant impact on primary productivity and nutrient } \\
\text { cycling in any ecosystem. }\end{array}$ \\
\hline $\begin{array}{l}\text { Leaf carbon stable } \\
\text { isotope ratios } \\
\left(\boldsymbol{\delta}^{13} \mathbf{C}\right)\end{array}$ & $\begin{array}{l}\text { - An indicator of the set point for leaf gas exchange regulation, } \\
\text { and reflects leaf-level water-use efficiency (WUE) and the } \\
\text { overall trade-off between carbon gain and water loss during } \\
\text { transpiration. }\end{array}$ \\
\hline
\end{tabular}

Source: Westoby et al. 2002; Kraft et al. 2008; Poorter et al. 2008; Reich et al. 1999; Wright et al. 2004; Poorter and Bongers 2006; King et al. 2005; Castro-Díez et al. 1998; Poorter et al. 2005. 
Table 3 Description of the null models used to calculate significance for T-statistics (adapted from Taudière \& Violle 2015)

\begin{tabular}{|l|l|l|l|}
\hline T- & Null hypothesis & Randomization & $\begin{array}{l}\text { Statistical } \\
\text { definition }\end{array}$ \\
\hline T_IP.IC & $\begin{array}{l}\text { No internal filtering. } \\
\text { Trait value distribution of all } \\
\text { the individuals within a given } \\
\text { community does not depend } \\
\text { on species identity }\end{array}$ & $\begin{array}{l}\text { Individuals trait values } \\
\text { are randomized within } \\
\text { the community }\end{array}$ & $\sigma^{2}{ }_{\mathrm{IP}} / \sigma^{2}{ }_{\mathrm{IC}}$ \\
\hline T_IC.IR & $\begin{array}{l}\text { No external filtering acting on } \\
\text { individuals. } \\
\text { Individual trait value } \\
\text { distribution is drawn } \\
\text { randomly from the regional } \\
\text { pool. }\end{array}$ & $\begin{array}{l}\text { Individual trait values } \\
\text { are randomized within } \\
\text { the regional pool, } \\
\text { keeping the number of } \\
\text { individuals in each } \\
\text { community constant. }\end{array}$ & $\sigma_{\mathrm{IC}}^{2} / \sigma_{\mathrm{IR}}^{2}$ \\
\hline T_PC.PR & $\begin{array}{l}\text { No external filtering } \\
\text { Species mean trait value } \\
\text { distribution is drawn } \\
\text { randomly from the regional } \\
\text { pool. }\end{array}$ & $\begin{array}{l}\text { Species trait mean } \\
\text { values are randomized } \\
\text { within the regional } \\
\text { pool, keeping the } \\
\text { number of individuals } \\
\text { in each community } \\
\text { constant. }\end{array}$ & $\sigma_{\mathrm{PC}}^{2} / \sigma_{\mathrm{PR}}^{2}$ \\
\hline
\end{tabular}


Table 4 Loadings contributed by each variable in PCA analysis.

\begin{tabular}{|l|l|l|}
\hline Environmental variable & PC1 & PC2 \\
\hline Ground elevation & 0.27 & -0.17 \\
\hline Ground water salinity & -0.32 & -0.31 \\
\hline Soil Depth & 0.39 & 0.12 \\
\hline soil nitrogen & -0.02 & 0.63 \\
\hline Soil phosphorus & 0.48 & -0.09 \\
\hline Soil pH & 0.42 & -0.12 \\
\hline Soil organic carbon & -0.39 & 0.38 \\
\hline Soil bulk density & -0.30 & -0.52 \\
\hline Variance explained & $47 \%$ & $24 \%$ \\
\hline
\end{tabular}

Table 5 Mean and standard deviation (in parenthesis) of each environmental variable across sub-regions.

\begin{tabular}{|c|c|c|c|c|}
\hline Variables & $\begin{array}{l}\text { Lower } \\
\text { Keys }\end{array}$ & NKL & LPK & Everglades \\
\hline $\begin{array}{l}\text { Ground elevation } \\
\text { (m) }\end{array}$ & $\begin{array}{l}1.86 \\
(0.27) \\
\end{array}$ & $\begin{array}{l}2.31 \\
(0.18) \\
\end{array}$ & 1.94 & $\begin{array}{l}2.35 \\
(0.03) \\
\end{array}$ \\
\hline $\begin{array}{l}\text { Ground water } \\
\text { salinity }(\mathrm{kg} / \mathrm{g})\end{array}$ & $\begin{array}{l}10.4 \\
(6.69) \\
\end{array}$ & $\begin{array}{l}8.3 \\
(4.95) \\
\end{array}$ & 0 & 0 \\
\hline $\begin{array}{l}\text { Soil Depth } \\
(\mathrm{cm})\end{array}$ & $\begin{array}{l}15.12 \\
(2.75) \\
\end{array}$ & $\begin{array}{l}23.45 \\
(2.42) \\
\end{array}$ & 14.13 & $\begin{array}{l}35.15 \\
(2.2)\end{array}$ \\
\hline soil nitrogen $(\%)$ & $\begin{array}{l}0.95 \\
(0.19) \\
\end{array}$ & $\begin{array}{l}1.16 \\
(0.30) \\
\end{array}$ & 2.24 & $\begin{array}{l}1.60 \\
(0.36)\end{array}$ \\
\hline $\begin{array}{l}\text { Soil phosphorus } \\
\text { (ppt) }\end{array}$ & $\begin{array}{l}0.82 \\
(0.08) \\
\end{array}$ & $\begin{array}{l}0.54 \\
(0.23) \\
\end{array}$ & 0.7 & $\begin{array}{l}342.02 \\
(178.63)\end{array}$ \\
\hline Soil pH & $\begin{array}{l}6.85 \\
(0.35) \\
\end{array}$ & $\begin{array}{l}7.16 \\
(0.39) \\
\end{array}$ & 7.05 & $\begin{array}{l}8.13 \\
(0.26)\end{array}$ \\
\hline $\begin{array}{l}\text { Soil organic } \\
\text { carbon }(\%)\end{array}$ & $\begin{array}{l}17.4 \\
(3.33)\end{array}$ & $\begin{array}{l}20.68 \\
(2.30)\end{array}$ & 31.66 & $\begin{array}{l}16.64 \\
(3.69)\end{array}$ \\
\hline $\begin{array}{l}\text { Soil bulk density } \\
\left(\mathrm{g} / \mathrm{cm}^{3}\right)\end{array}$ & $\begin{array}{l}0.33 \\
(0.04) \\
\end{array}$ & $\begin{array}{l}0.19 \\
(0.07) \\
\end{array}$ & 0.02 & $\begin{array}{l}0.11 \\
(0.04)\end{array}$ \\
\hline
\end{tabular}




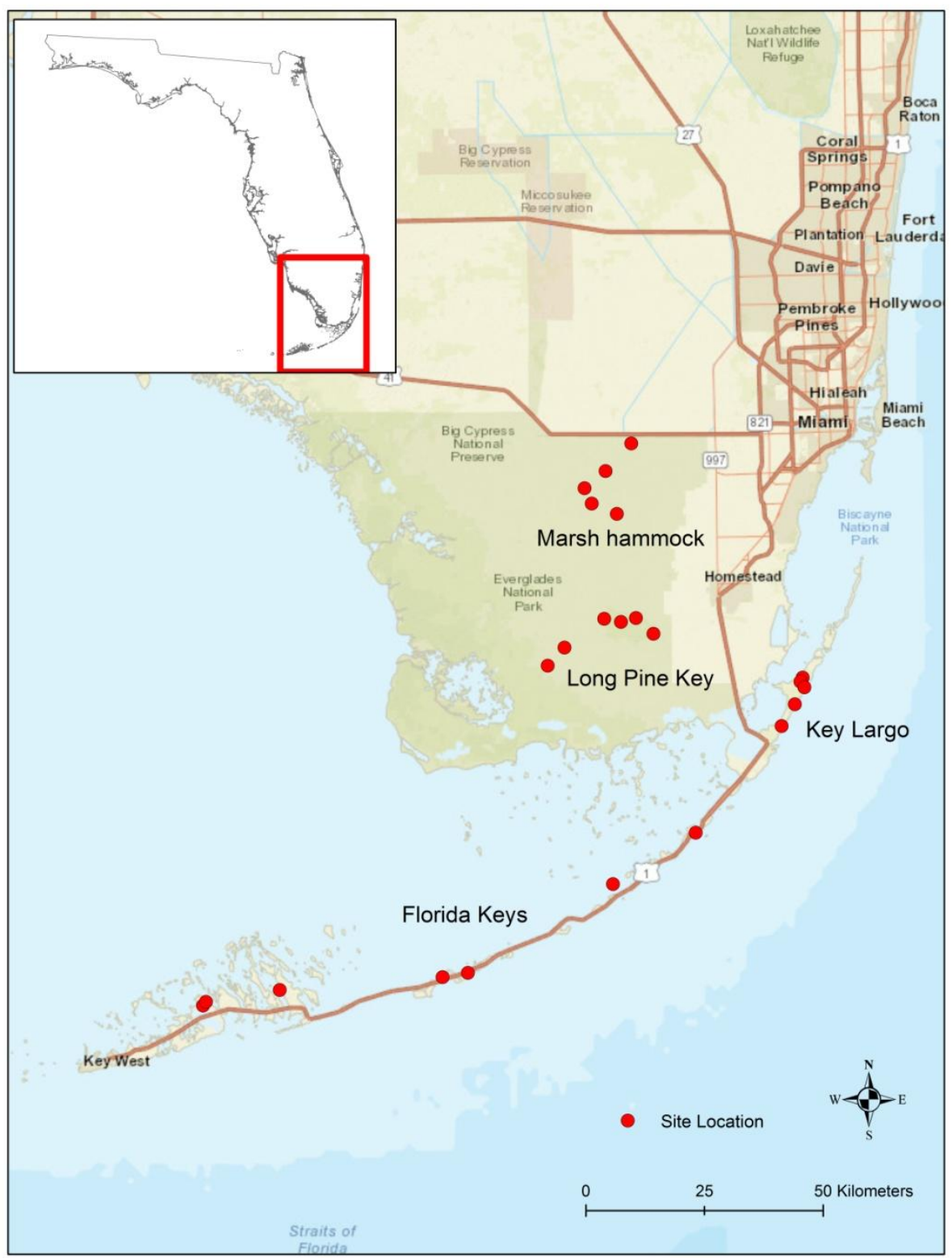

Figure 4 Study area

Figure 4 shows study sites distribution across four sub-regions (Everglades marsh hammock, pineland, Key Largo, and Florida Keys). 


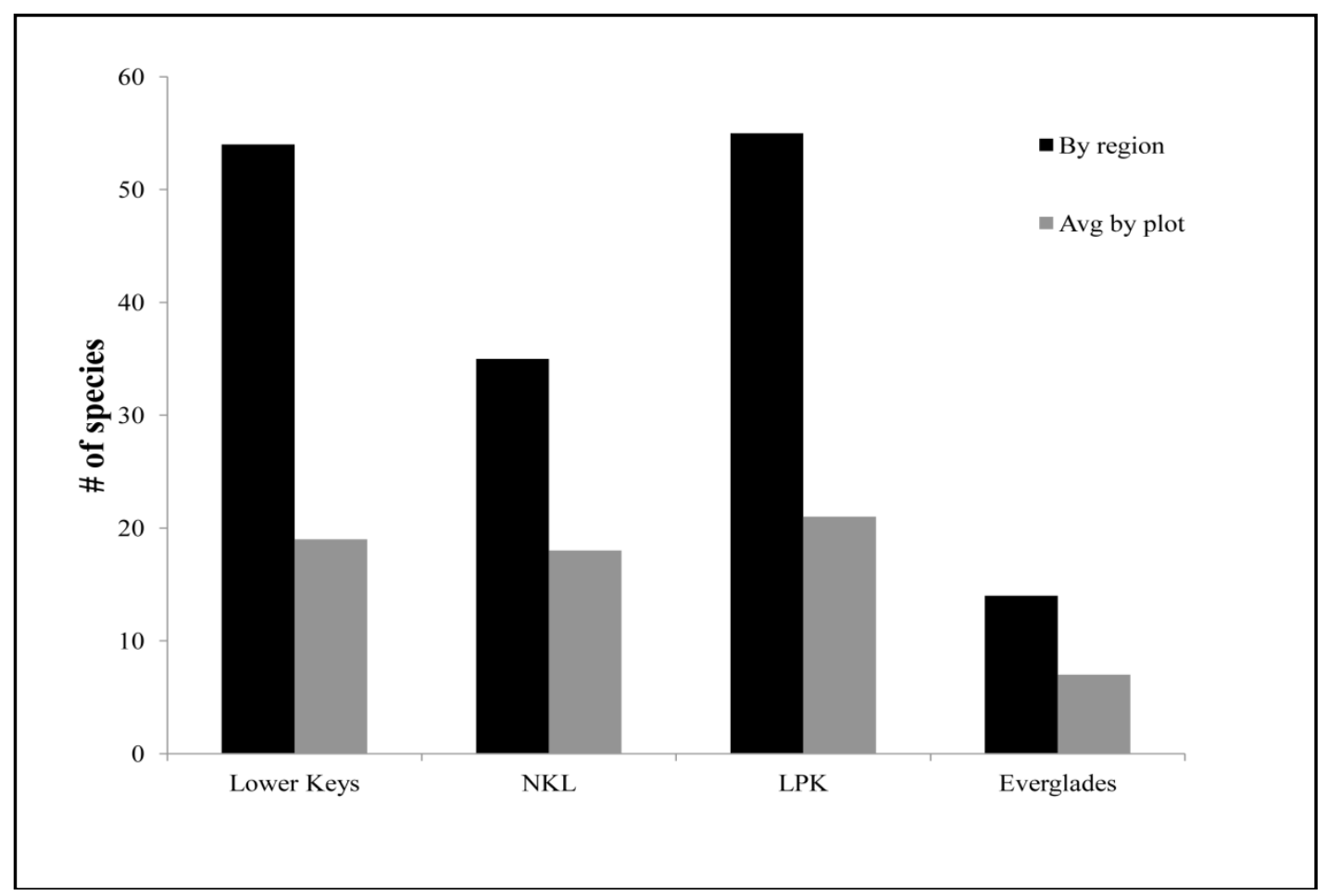

Figure 5 Tree species diversity across four sub-regions

Figure 5 shows tree species diversity across four sub-regions: Lower Keys, North Key Largo (Key Largo), Long Pine Key (LPK), and Everglades marsh hammocks. Species numbers (species richness) were calculated based on the unique species encountered across the plots $\left(20 \times 20 \mathrm{~m}^{2}\right)$ within each sub-region. 


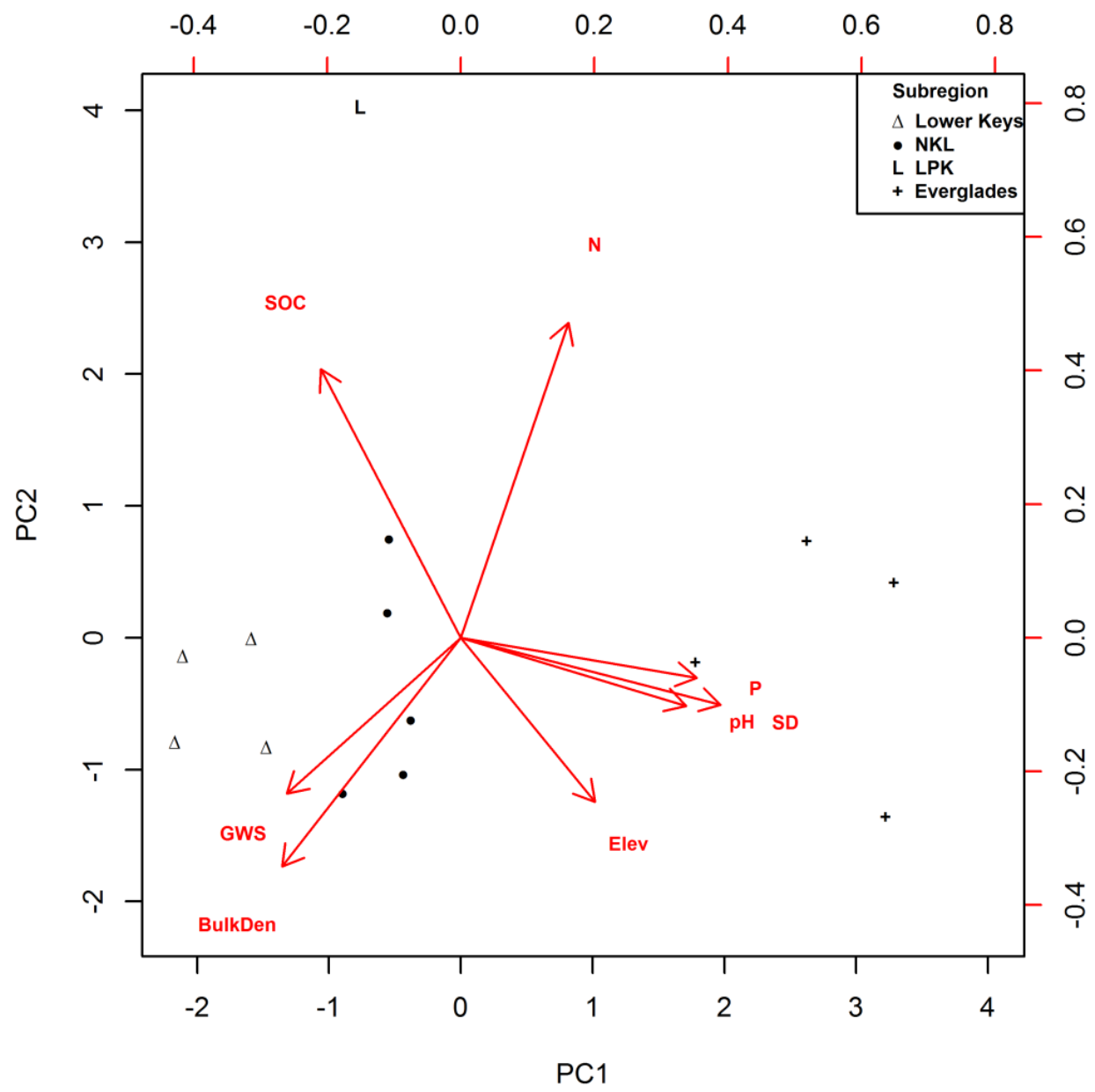

Figure 6 Bi-plot showing site variation across South Florida hammocks.

In Figure 6, environmental variables used for PCA analysis are Ground water salinity (GWS), soil depth $(\mathrm{SD})$, soil nitrogen $(\mathrm{N})$ and phosphorus $(\mathrm{P})$, soil $\mathrm{pH}$, soil organic carbon (SOC), bulk density (BD), relative elevation i.e., relative to ground water (Elev). 


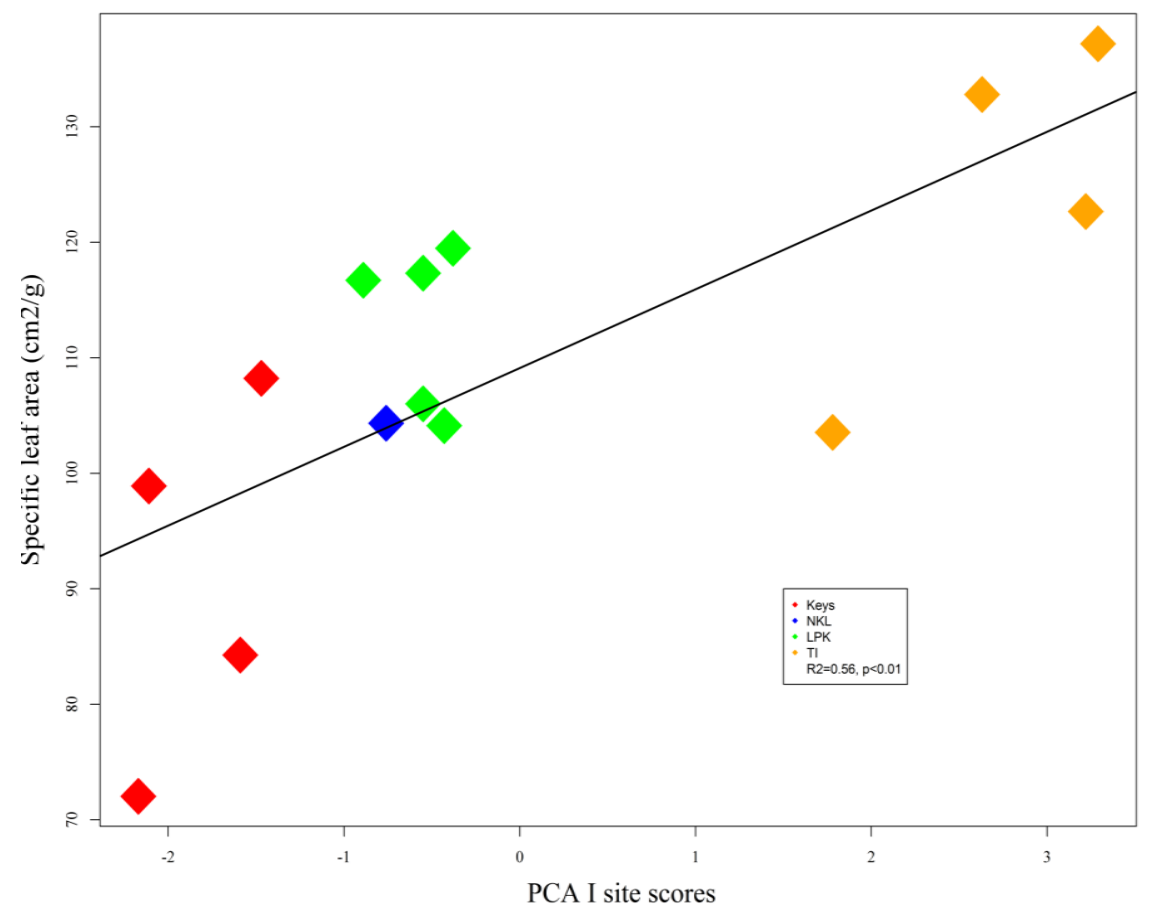

Figure 7 Relationship between CWM SLA and site characteristics.

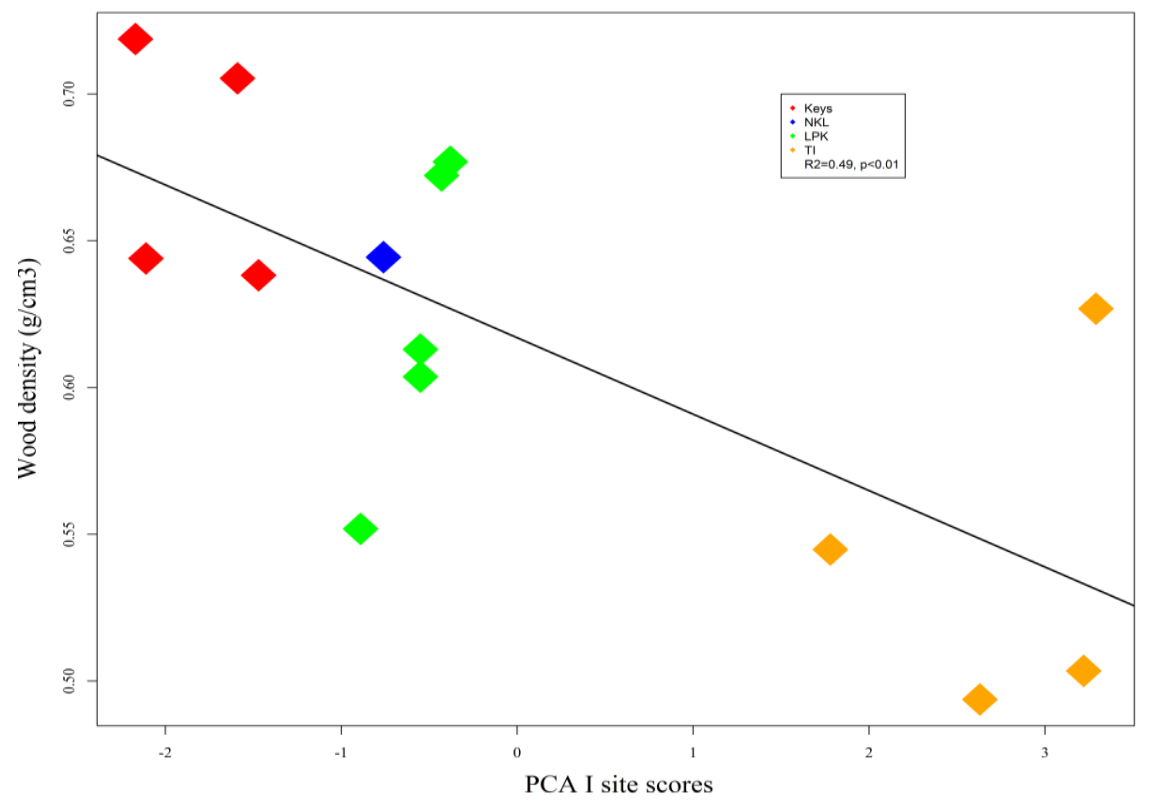

Figure 8 Relationship between CWM WD values and site characteristics 


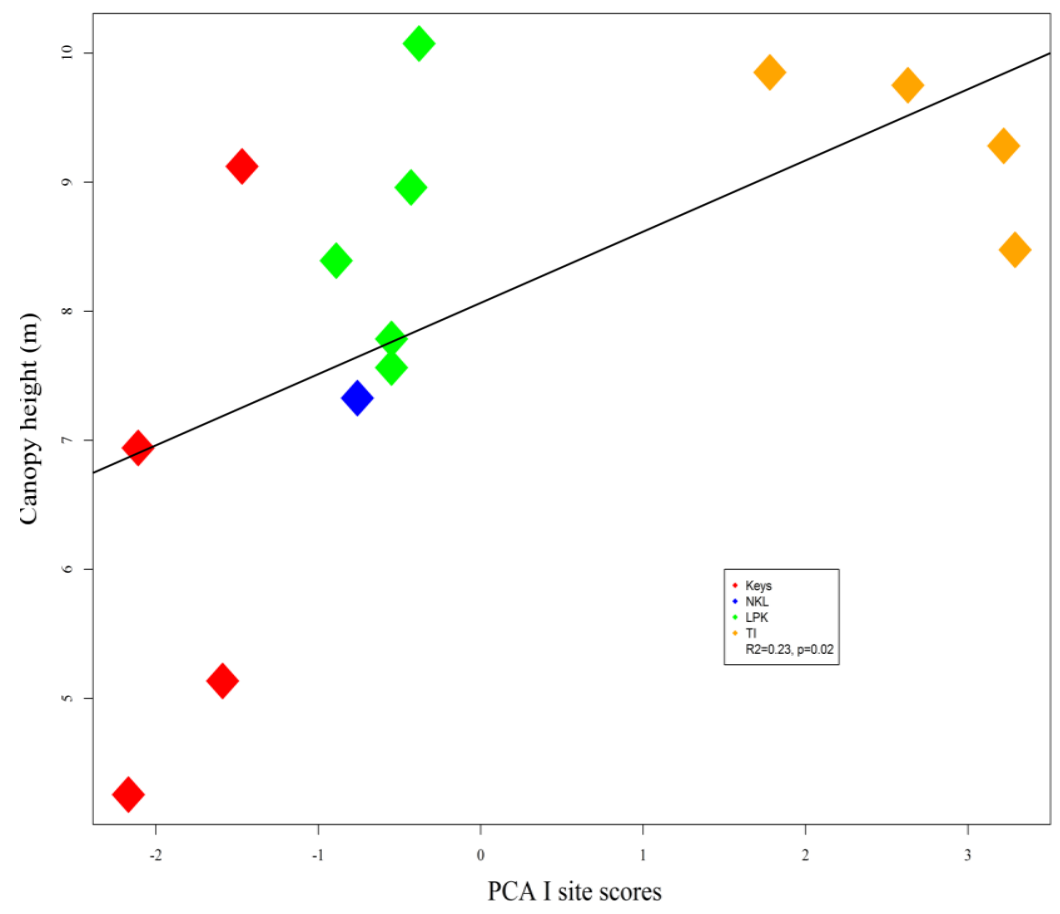

Figure 9 Relationship between CWM HT values and site characteristics

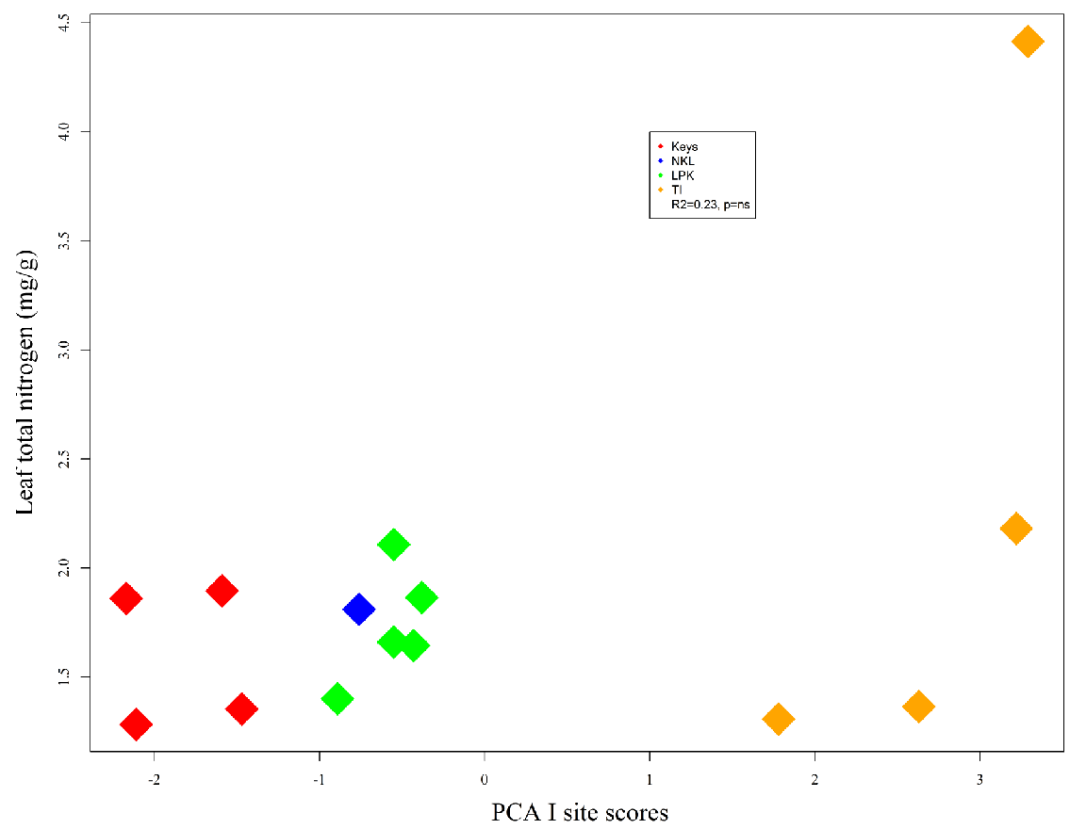

Figure 10 Relationship between CWM TN values and site characteristics. 


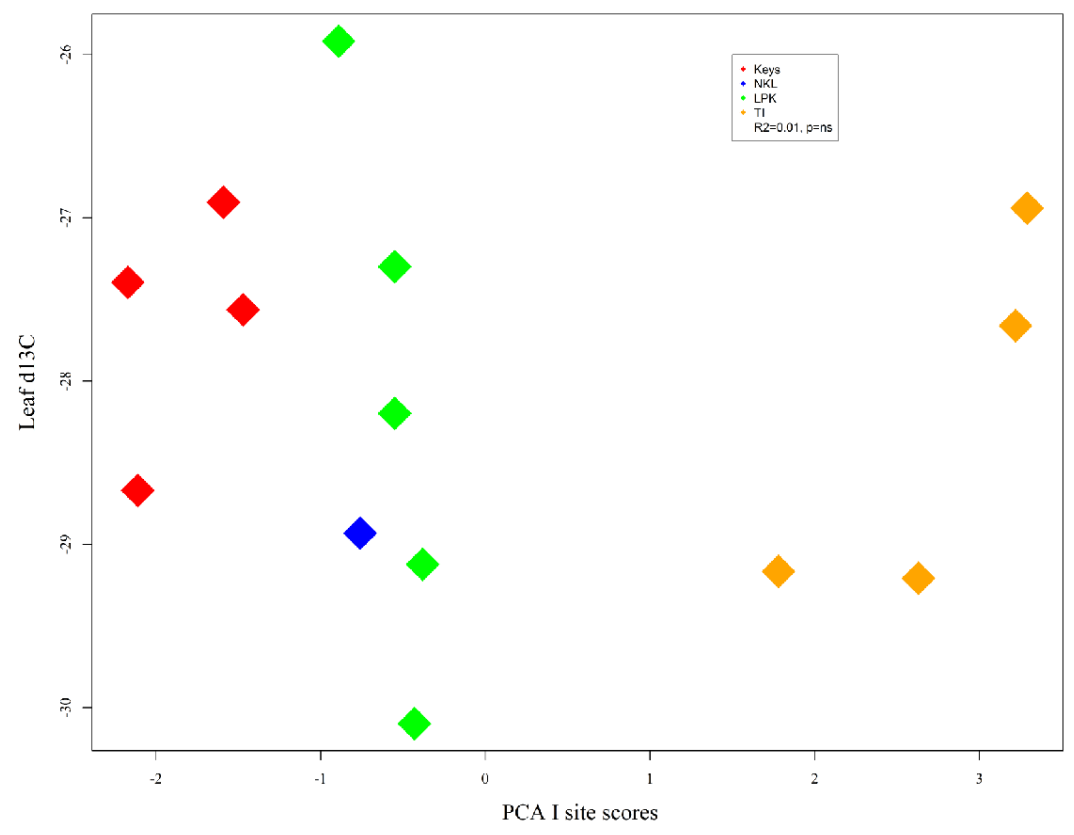

Figure 11 Relationship between $\mathrm{CWM} \delta^{13} \mathrm{C}$ trait values and site characteristics

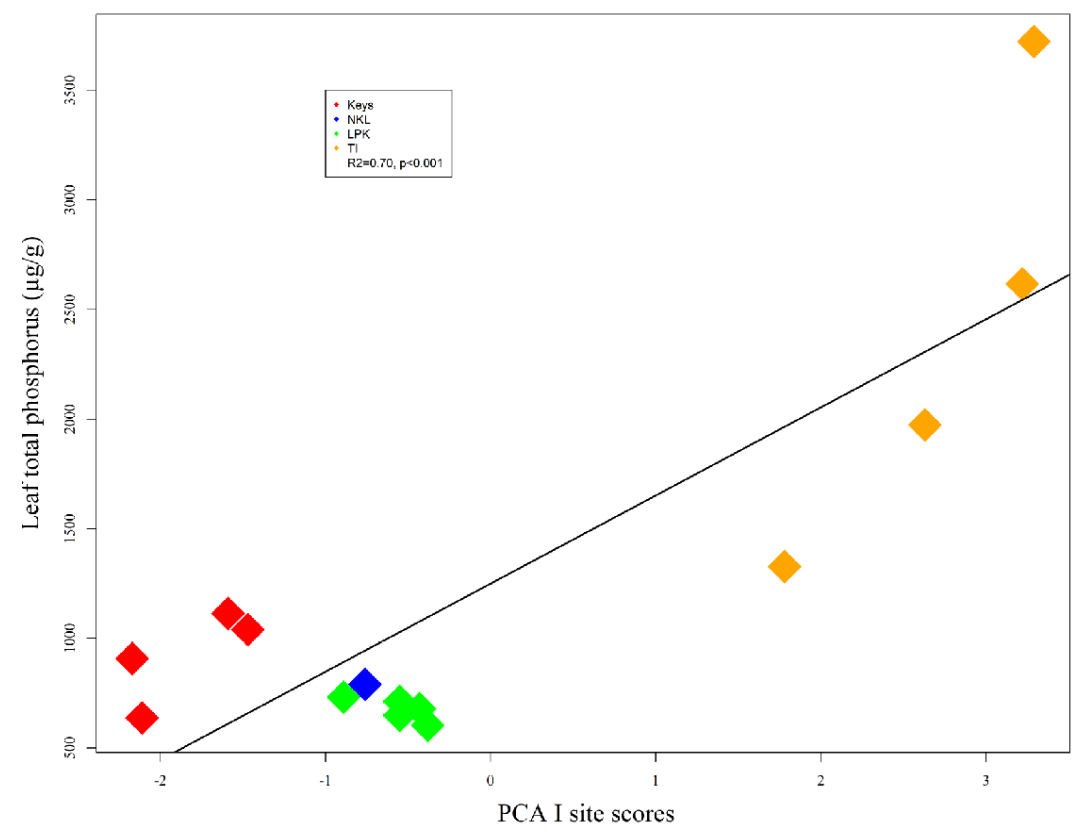

Figure 12 Relationship between CWM TP values and site characteristics 

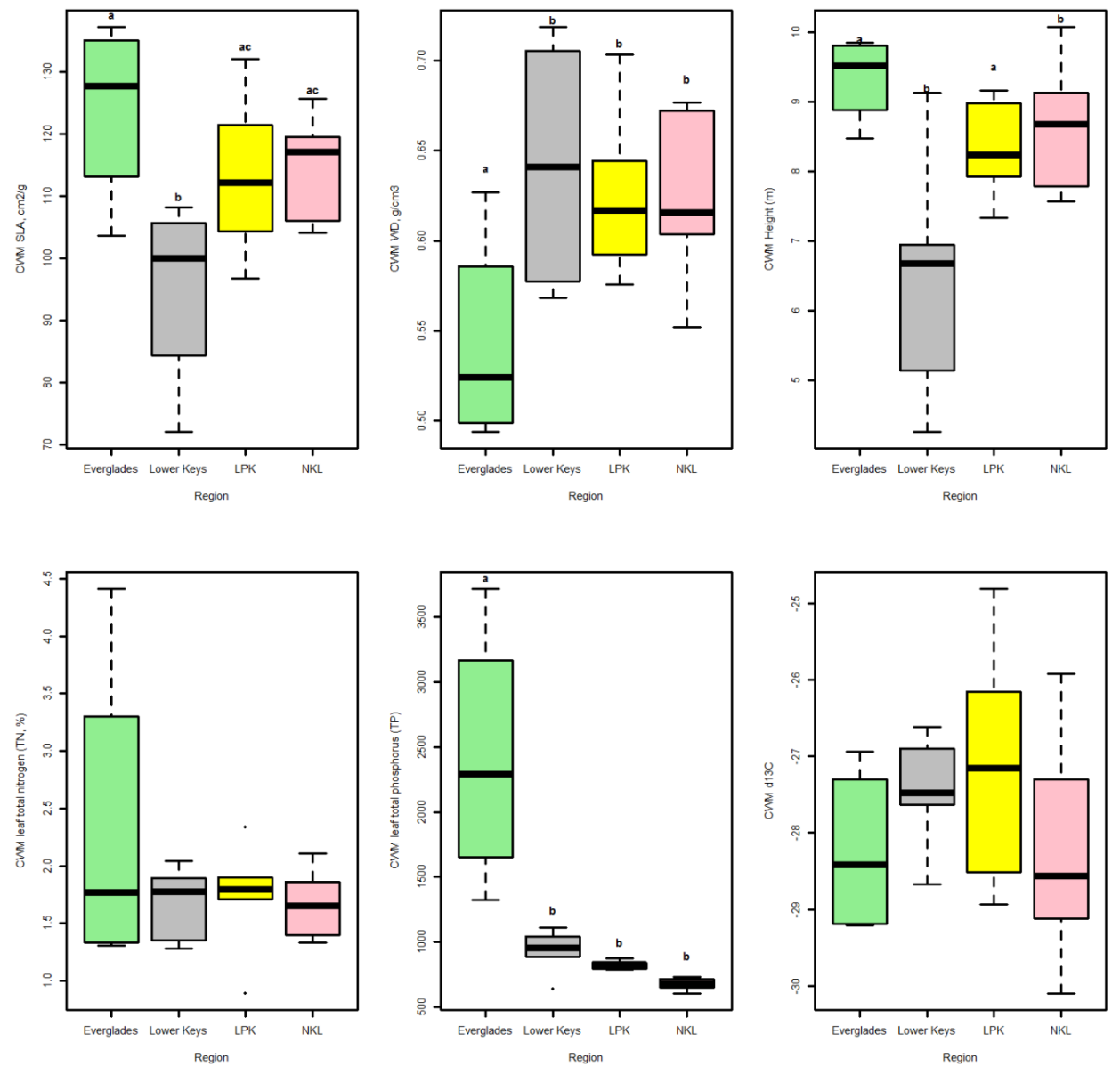

Figure 13 Box plots showing CWM trait variation across the sub-regions.

In Figure 13, community weighted mean (CWM) trait variation across the region:

Hammocks in Everglades, Lower Keys, Long Pine Key (LPK), and Upper Keys (NKL).

Common letter between regions are showing non-significant difference at $\mathrm{p}=.05$ level. 


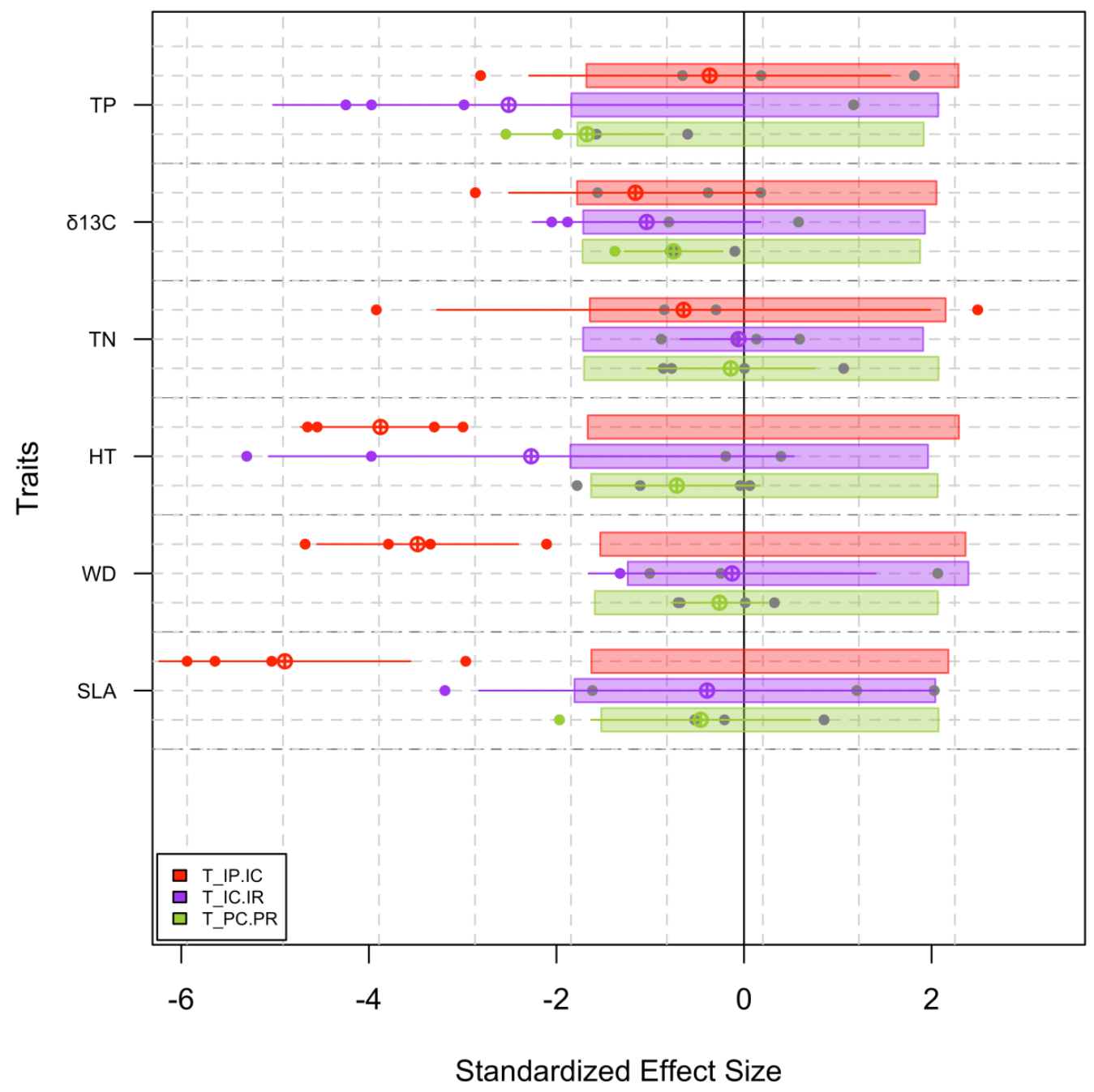

Figure 14 Standardized effect size (SES) of T-statistics of six traits

Figure 14 shows the Standardized effect size (SES) of T-statistics of six traits: (1) specific leaf area (SLA); 2) wood density (WD); 3) height (HT); 4) leaf nitrogen (TN); 5) stable carbon isotope ratio $(\delta 13 \mathrm{C})$; and 6 ) leaf phosphorus $(\mathrm{TP})$ across four sub-regions: Florida Keys, Key Largo, Long Pine Key, and Everglades marsh hammocks. Each dot represents the SES value for one sub-region. The circles and the segments represent, respectively, the mean and the standard deviation of the SES values for a given T-statistic (i.e., mean and standard deviation of regional values). Boxes delimit the confidence interval of the null model for the whole gradient; thus, for a given T-statistic, the mean of the SES (crossed circle) is significantly different from the null distribution if it is not embedded within the box. T_IP.IC: ratio of within-population variance to total withincommunity variance, T_IC.IR: community-wide variance relative to the total variance in the regional pool, and T_PC.PR: intercommunity variance relative to the total variance in the regional pool. 


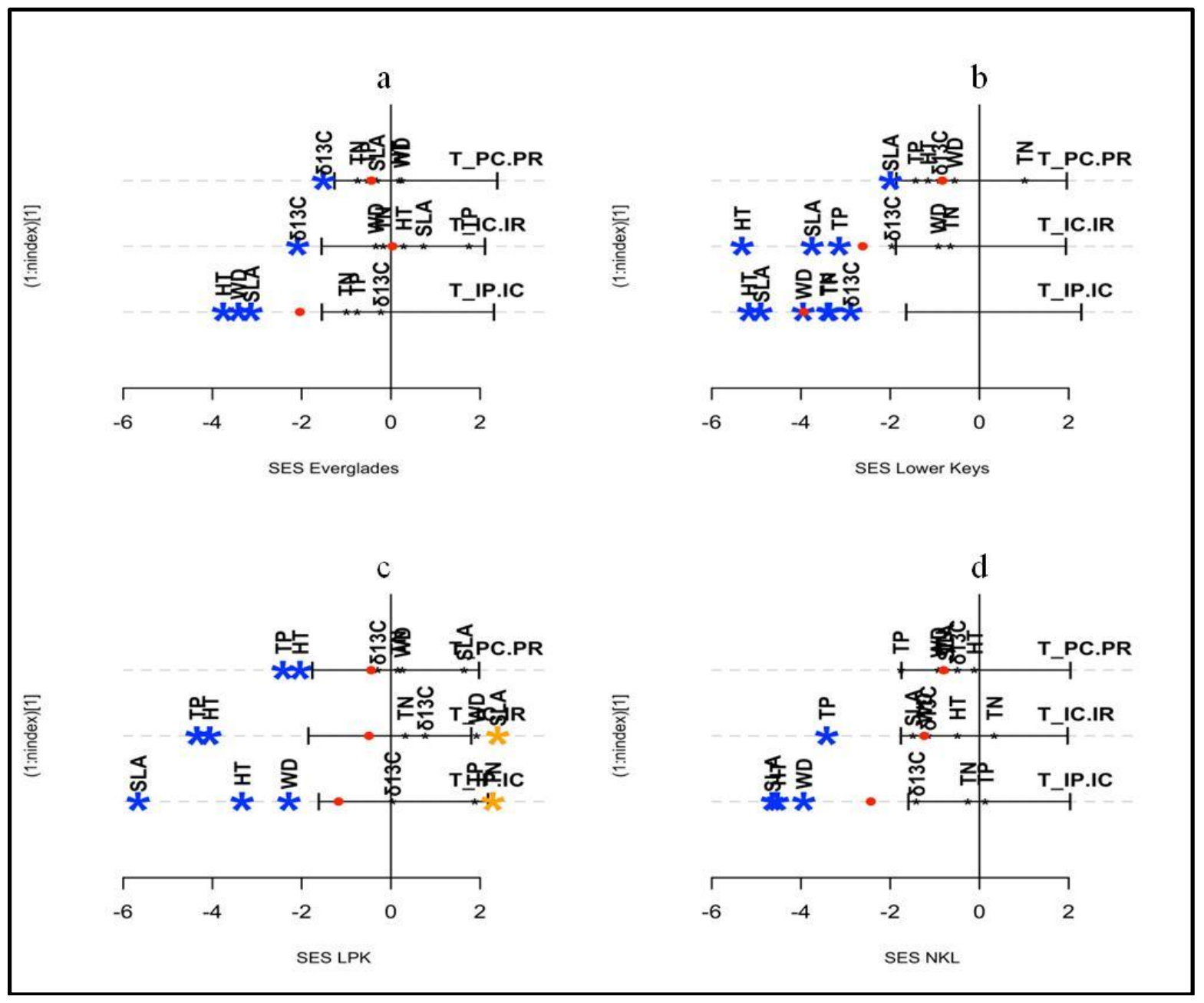

Figure 15 Standardized effect size (SES) of T-statistics by sub-region

Figure 15 shows standardized effect size (SES) of T-statistics by sub-region : a) Everglades marsh hammocks (Everglades), b) Lower Keys, c) Long Pine Key (LPK), and d) Key Largo (NKL). Specific leaf area (SLA); Wood density (WD); Height (HT); Leaf nitrogen (TN); Stable carbon isotope ratio $\left(\delta^{13} \mathrm{C}\right)$; and Leaf phosphorus (TP). Four sub-regions: Everglades marsh hammocks (Everglades); Lower Keys, Key Largo (NKL), and Long Pine Key(LPK). Each star represents the mean SES values for a given Tstatistic (i.e., mean of sub-regional values). Bar lines delimit the confidence interval of the null model for the whole gradient; for a given T-statistic, the mean of the SES (star) is significantly different from the null distribution if it is not fell within the line segment. The red dot represents the mean of the SES values for a given T-statistic. T_IP.IC: ratio of within-population variance to total within-community variance, T_IC.IR: communitywide variance relative to the total variance in the regional pool, and T_PC.PR: intercommunity variance relative to the total variance in the regional pool. 


\title{
CHAPTER 3
}

\section{Trait-based community assembly pattern along a forest succession gradient in seasonally dry sub-tropical forest, Florida Keys}

(To be submitted in journal of Vegetation Science)

\begin{abstract}
Succession is a community assembly process by which species are sorted through interactions with their biotic and abiotic environment. Community assembly is often assumed to represent the outcome of differing strengths of two opposing forces: environmental filtering (stress tolerance) and competitive interactions. Species interact with their environment through functional traits which reflect fundamental niche axes that characterize the leading dimensions by which plants differentiate from one another. Thirteen leaf, stem, reproductive, and architectural traits of resident tree species in a North Key Largo forest were measured that incorporated a broad range of successional stages. Our intent was to understand the underlying mechanisms that drive species assembly during forest succession in Florida dry sub-tropical forest. It was hypothesized that mean trait overlap among species in young stands would be relatively high because of environmental filtering, while in older stands, trait values among co-existing species would be more dissimilar, as a result of limiting similarity or competition for resources. Principal component analysis showed that specific leaf area, wood density, leaf phosphorus, leaf nitrogen, and the ratio of canopy height to crown length were the important traits that distinguished species along the successional gradient. Tests of null models to determine if species were evenly distributed across, or clustered within trait niche space showed a significant clustering among 26 species encountered in all plots.
\end{abstract}


When a subset of younger communities was tested, species also displayed significant clustering in their distribution across trait niche space. In contrast, species in mature plots displayed significant differentiation in their distribution across trait niche space in comparison to the null distributions. These results suggest that younger communities are shaped by environmentally driven processes, while mature communities are shaped by competitively driven processes. However, the overall trait similarities among species present in North Key Largo dry sub-tropical forest suggest that tree species are specialists on the local environment, and their ability to survive and grow in a stressful environment may be more important than competition for resources at larger scale.

Keywords: Community assembly, Plant traits, Florida Keys, Niche overlap, Succession, North Key Largo, Dry Tropical Forest.

\subsection{Introduction}

Community assembly is assumed to represent the outcome of differing strengths of two opposing forces: environmental filtering (stress tolerance) and competitive interactions (Spasojevic \& Suding 2012). Environmental filtering emphasizes the perspective that species occurring in the same community tend to share similar traits (Weiher \& Keddy 1995; Cornwell, Schwilk \& Ackerly 2006a; Navas \& Violle 2009), while competitive interactions arise from the idea of limiting similarity or niche partitioning, in which co-occurring species must maintain at least a minimum degree of dissimilarity if they are going to stably co-occur (MacArthur \& Levins 1967; Chesson 2000). From a functional trait perspective, functional similarity is indicative of similar resource use strategies among individuals or species. It means that species with similar 
traits should compete most directly, resulting in the exclusion of one or the other. Therefore, the expectation of limiting similarity theory is that co-occurring species will exhibit less functional similarity than they would occur by chance alone. In contrast, the environmental filtering concept posits that in stressful environments, species that cannot tolerate stress will be filtered out, resulting in a reduction in trait variation (similar stress tolerance ability among species) (Davis et al. 1999). These ideas have led to a widespread expectation that trait variation among species is low in regions of strong abiotic stress and increases in regions where competitive interactions are stronger than stressful regions (Weiher \& Keddy 1999). For example, in alpine tundra, abiotic filtering by wind and cold exposure reduce the variation in height and leaf area (Spasojevic \& Suding 2012). Functional niche concept was introduced to represent an n-dimensional hyper-volume in functional space, where niche axes are traits associated with different functional attributes (Rosenfeld 2002). The degree of overlap in these trait niche axes in a community may indicate the probability of co-occurrence of species in the same environment.

Succession is a sequential change over time in the relative abundance of dominant species (Shipley, Vile \& Garnier 2006). For example, shade intolerant species with fast growth rates and high resource acquisition rates are often replaced by shade-tolerant species with conservative trait syndromes during succession (Bazzaz 1996; Adler et al. 2013). Therefore, communities along a successional gradient can be distinctive on the basis of the dominance of plant functional types, representing distinct functional strategies for reproduction and resource capture (Baraloto et al. 2012). Early successional species tend to regenerate in a high light environment, and have inherently high growth rates compared with late successional species. Their high relative growth rates are 
attained through a high photosynthetic capacity and leaf area allocation (Poorter \& Bongers 2006). Changes in plant traits with forest age (e.g., high specific leaf area and leaf nitrogen content) acquiring external resources rapidly, which dominate the early stages following abandonment, while slower growing species (low specific leaf area and leaf nitrogen), tend to conserve internal resources more efficiently as succession proceeds (Bazzaz 1996). Therefore, species composition and associated functional strategies are likely to change throughout succession.

Functional traits can help define a species' fundamental niche, and that variation along well documented trait spectra (e.g., specific leaf area or maximum height, or seed mass) have been used to characterize the leading dimensions by which species differentiate from one another (Westoby et al. 2002; Wright et al. 2007). Most studies that have explored differences among co-occurring species have used controlled experiments, or phylogenetically constrained comparisons among closely related species (Valladares et al. 2000a; Davies 2001; Cavender-Bares, Kitajima \& Bazzaz 2004b; Sack \& Frole 2006; Niinemets 2015). The present study provides an example of a different approach by addressing hierarchical issues of landscape-scale trait variance in a seasonally dry sub-tropical forest where many tree species and families co-occur across the successional gradient within a mixed-age community mosaic. Moreover, in drytropical forest landscapes, our understanding of succession has been very limited (Vieira \& Scariot 2006; Bhaskar, Dawson \& Balvanera 2014), and community assembly processes may relate primarily to the availability of water and nutrient in addition to light which is more important in dry tropical forest, because of its overriding influence on species distributions (Balvanera, Quijas \& Perez-Jimenez 2011). 
Research on changes in species traits along successional gradients in dry tropical forests (DTFs), especially those in Florida, is not extensive. Ross et. al. (2001) described a successional sequence of species of DTF in Florida Keys using their abundance in stands that originated following clearing, catastrophic fire, or agricultural abandonment at different times. By sampling a set of forest patches that represent a chronosequence of time since they were cleared, Ross et al. (2001) could identify a change from dominance by deciduous species in early developmental stages to a predominance of evergreen species in mature stands. This transition appears to be associated with shifts in traits related to growth rate, leaf morphology, nutrient use efficiency, and nutrient content (Redwine 2007), a tradeoff between traits enhancing growth in early successional species (high specific leaf area, low wood density, and high concentration of nutrients in leaves) (King et al. 2006) and traits enhancing survival in late-successional species (long-lived leaves, large allocation to structural compounds) (Navas et al. 2010). Powers and Tiffin (2010) analyzed the potential to define ecologically meaningful groups among Costa Rican tropical dry forest species, and found that leaf habit alone was insufficient to distinguish plant functional groups. They argued that a database of functional traits must include other traits that are relevant to acquisition and use of resources in dry tropical forest. Therefore, the question of whether there is any pattern in important traits (stem, leaf, seed, architecture) along a successional gradient in DTF remains to be answered. Little is known about intraspecific variation in species traits as secondary succession proceeds. 
In this study, 13 traits among resident species were assessed, and I used these data to examine community-scale changes in traits along a successional gradient in the Florida Keys. Three primary research questions are:

1) How is trait variation distributed among inter- and intra-specific levels during forest succession in Florida DTF?

By decomposing the trait variation across ecological scales (community, species, individual), the dynamics of species response to environmental changes may be better understood.

2) Is there any pattern in community weighted mean traits across the successional gradient?

Comparisons of multiple trait patterns along an environmental gradient may advance understanding of the role of community assembly processes such as environmental filtering and competition (Spasojevic \& Suding 2012).

3) What is the underlying mechanism that drives species assembly during forest succession in Florida DTF?

Patterns in species niche overlap may explain much about the community assembly process. Early succcessional species in recently disturbed areas experience environmental adversity, thus habitat filtering is likely to structure early stage development. Environmental conditions may be improved (higher soil depth, moisture, nutrient, etc.) over time, causing density-dependent processes such as competition to increasingly dominate later stages of succession. Therefore, it is expected that younger stands and dominant early successional species will show similar trait values (higher 
niche overlap), whereas as community development proceeds, trait values among coexisting species will be more dissimilar (lower niche overlap).

\subsection{Materials and methods}

\subsubsection{Study Area}

A 15-km stretch of continuous forest in northern Key Largo, including portions of Crocodile Lakes National Wildlife Refuge and Key Largo Hammocks Botanical State Park, represents one of the most extensive remaining examples of DTF in southern Florida. This forest is composed of a diverse mixture of deciduous and evergreen tree species that are predominantly West Indian in origin (Tomlinson 1986). Soils rarely exceed $20 \mathrm{~cm}$ in depth, and elevations range from 0 to $5 \mathrm{~m}$ above sea level. Mean annual temperature is $25.1^{\circ} \mathrm{C}$, and mean annual precipitation is about $1200 \mathrm{~mm}$ (Ross et al. 2001). Although natural disturbances such as occasional ground fires and windstorms are parts of the disturbance regime, the relevant ecological history of these hammocks primarily includes clearance of some patches because of farming during the early 1900's. Aerial photos indicate that significant area of this forest has been under cultivation, or affected by roads, prospective residential development, oil exploration, or military use (Ross et. al. 2001).

\subsubsection{Study Design}

Species composition and density data were collected from 23 nested belt transects, 60-100 m in length, established by Ross et al (2001). The year that each patch was cleared is estimated on the basis of the appearance of the site on black and-white aerial photos between 1926-1985 (Ross et al. 2001). Trait data were collected from $20 \mathrm{x}$ 
$20 \mathrm{~m}^{2}$ plots established adjacent to ten of the Ross et al. (2001) transects: five in young forest, and five in mature stands, assumed to be at least 100 years old if not observed disturbed after 1926 photos (Figure 16).

Methods for measurement of plant traits followed those described by PérezHarguindeguy et al. (2013). Structural traits were determined for all trees greater than one $\mathrm{cm}$ diameter at breast height $(\mathrm{DBH})$ in 10 plots. Total height $(\mathrm{HT}), \mathrm{DBH}$, crown dimensions (length and width), and height to crown (first branch) from the ground were measured. Specific leaf area, leaf chemistry (nitrogen, phosphorus, $\delta^{13} \mathrm{C}$, and $\delta^{15} \mathrm{~N}$ ), and wood density of each species were collected from 3-5 separate individuals of each species present in each plot. Recently expanded sun leaves were sampled, or in cases of understory species, the most illuminated leaves on the plant were sampled (Cornwell and Ackerly 2009). Specific leaf area (SLA, leaf area per unit mass) was quantified using a leaf area meter (LI-3000C), and leaves were brought to the lab and dried at $70^{\circ} \mathrm{C}$ for three days in the oven before weighing. Wood density (WD) was determined from $1-2 \mathrm{~cm}$ DBH branch samples, and calculated as the ratio of the oven-dry mass of the wood sample divided by the mass of water displaced by its fresh (green) volume (Chave et al. 2006). Reproductive traits (seed mass and seed number) were assembled from several sources, including new field collections for most species, and literature sources for others for whom local seeds were not available.

\subsubsection{Trait selection}

The present study focused on 13 traits which were expected to be especially important in local environments (Table 6). Tropical dry forests in the Florida Keys are water and nutrient-limited systems (Redwine 2007; Saha et al. 2011) and frequently 
disturbed by storms and hurricanes. Given the frequency of disturbance and drought stress associated with the region's extended dry season, wood density (WD) is hypothesized to be an important functional trait in DTF tree species in South Florida given the role of wood density plays in determining resistance to wind damage during storm events, as well as the contribution of dense wood with small cells in maintaining high water potentials-a competitive advantage when water is scarce (Sperry 2003; Preston, Cornwell \& DeNoyer 2006; Swenson \& Enquist 2007; Chave et al. 2009). Specific leaf area (SLA), leaf nitrogen content $(\mathrm{TN})$, nitrogen stable isotope ratio $\left(\delta^{15} \mathrm{~N}\right)$, and leaf phosphorus (TP) of trees are correlated with primary productivity and nutrient cycling in all ecosystems (Reich et al. 1992; Cornelissen et al. 1999; Aerts and Chapin 2000), including water and P-limited forest ecosystems such as those in the Florida Keys (Redwine 2007). Another important trait in water limited forests is the carbon stable isotope ratio $\left({ }^{13} \mathrm{C} /{ }^{12} \mathrm{C}\right)$, expressed as $\delta^{13} \mathrm{C}$, which is an indicator of the strength of the diffusive gradient of $\mathrm{CO}_{2}$ during leaf gas exchange, and reflects how efficiently leaves utilize (often described as water use efficiency-WUE). Water use efficiency defines the leaf-specific trade-off between carbon gain and water loss during the interacting processes of photosynthesis and transpiration.

Architectural traits may be important indicators of the drought tolerance capability of trees in dry tropical forests, and they can be represented by allometric relationships (King 1996; Poorter et al. 2003; Bohlman \& O'Brien 2006). Three important architectural traits, diameter at breast height to crown area ratio (DBH:CA), height to diameter at breast height ratio (HT:DBH), and height to crown length ratio (HT:CL), were tested, which are often involved in physical and biotic interaction in a 
forest. For instance, interspecific differences in HT:CL might have important implications for light capture (Kohyama 1991), while DBH:CA and HT:DBH are associated with structural stability, mechanical strength, and crown support (Sterck \& Bongers 1998; King et al. 2006). Furthermore, when exposed to hurricanes or other types of windstorms, variation in such architectural traits may affect the relative likelihood of stem vs branch damage (Zimmerman et al. 1994). Basal diameter increases with wind exposure in trees of similar height (King 1996) which is particularly relevant in the Key Largo's DTF given the observed increased probability damage associated with larger individuals of certain early successional species associated with Hurricane Andrew (Ross et al. 2001). Multiple-stemmed trees tend to expand their canopy with minimum vertical growth and the frequency of multiple stem in DTF is related to environmental stresses such as drought and salt stress as well as periodic hurricane disturbances (Dunphy, Murphy \& Lugo 2000).

Finally, reproductive traits are important for the success of tree species in dry tropical environments. Some of these are, fruit type, seed number, or seed mass. Dispersal ability of a species is strongly influenced by the seed size and number and the dispersal vector (Westoby 1998; Khurana, Sagar \& Singh 2006). Smaller seeds disperse over longer distances and enjoy long periods of dormancy in soil seed banks compared to heavy and large seeds, but the seedlings produced by heavier, larger seeds tend to have greater competitive ability, enabling them to establish and survive under stresses brought on by competition, moisture, shading, disturbances, defoliation and herbivory (Westoby 1998). 


\subsubsection{Statistical analyses}

Trait means and standard deviations were calculated for each species encountered across the successional gradient. The general patterns of trait co-variation were analyzed using principal components analysis (PCA) at species and site levels. All measured traits were included in analyses for species and community levels (Table 6). At the species level, PCA analysis combined mean trait values for each trait in each individual plot. At the community level, community-weighted trait means (CWM) were calculated, with weightings using the relative densities of the species in each of the 23 permanent transects. To express the proportion of the total variance across three levels, i.e., site, species, and individual, linear mixed models were used for the subset of traits that were measured at all three levels (10 out of 13, see Table 6 ). Linear mixed models that specified random variables (site, species, and individual tree) for each trait were fitted using the "varcomp" function of R (R Developement Core Team 2015) with restricted maximum likelihood estimation.

Niche overlaps (NO's) and null models were computed using the $\mathrm{R}$ script provided by Geange et al. (2011). For each trait, a trait distribution was calculated using a kernel estimator (Mouillot et al. 2005b), which is a density function that assumes measurement error around each data point, and uses a smoothing function to estimate a distribution of all data for a given trait and community. Overlap is represented as the integral of the intersection of the species' respective kernel curves when overlaid on one another. The species kernels were then used to estimate pairwise niche overlaps in trait space for all the coexisting species. Overlap indices were calculated for two data sets: for

all species sampled across the ten plots, and within each successional category (young 
and mature). Maximum variance occurs when all niche overlaps are either 0 or 1 . To test community assembly processes, a test-statistic (n), i.e., the proportion of maximum variance (i.e., the coefficient of heterogeneity), was calculated to determine if the pattern in the data is random (the null model), clustered ( $\eta$ near 1$)$ or evenly spaced ( $\eta$ near 0 ) (see Geange et al 2011). If there are i species and t traits, each trait (as a niche axis) has

$\frac{(\mathrm{i}-1)}{2}$ niche overlap values, represented as $\mathrm{x}_{1}, \mathrm{x}_{2}, \ldots, \mathrm{x}_{\mathrm{n}}$, with $\overline{\mathrm{x}}$ and $\mathrm{s}^{2}$ representing mean niche overlap and variance.

$\eta=\sum \frac{s^{2}}{\bar{x}(1-x)}$

Once $\eta$ is calculated for each niche axis, examining the minimum and maximum values across all trait niche axes will indicate whether clustering occurs in one axis while there is even spacing in another. Finally, the average of $\eta$ over the $t$ niche axis gives an overall measure of clustering vs. regularity, or even spacing (Geange et al. 2011). All statistical analyses were carried out using R (R Developement Core Team 2015).

\subsection{Results}

\subsubsection{Variation in traits across the scales (intra-specific, inter-specific, and community)}

Trait responses differed dramatically across scales (Table 7). Overall trait variation attributable to site was very low, exceeding $2 \%$ only for architectural traits; the highest was $19.22 \%$ for $\mathrm{CA}: \mathrm{DBH})$. Variation was primarily attributable to species identity in five of the seven leaf-associated variables (SLA, WD, TN, N:P, and $\delta^{13} \mathrm{C}$, above $60 \%$ ). For five of the 10 traits, intra-specific variation was very low; while a considerable amount of intra-specific trait variation was observed in all three 
architectural traits along with TC, TP, and $\delta^{15} \mathrm{~N}$. For all the traits, a significant percentage of intraspecific variability occurred.

\subsubsection{Correlation between species traits among species}

The first three axes of the principal component analysis of twelve traits explained $53 \%$ of the total variation (Table 8). For simplicity, only the first two axes are presented in Figure 17. Deciduous and evergreen species were not grouped based on leaf habit on the first two principal component axes. Early successional, brevi-deciduous species (Guettarda scabra, G. elliptica, Bourreria ovata and Lysiloma bahamense) grouped together, while late successional, evergreen species (Simarouba glauca, Caliptranthes pallens, Drypetes diversifolia, D. lateriflora, Sideroxylon foetidissimum, Amyris elemifera, Krugiodendron ferreum, Nectandra coriacea) were scattered on the second principle component axis. Four traits (SLA, WD, \% of multiple stems, and HT:CL) were strongly corresponded to the first axis of the PCA. Vectors for leaf N:P and TP were nearly perpendicular to Axis 1 , and these traits were associated with the second axis of the PCA. Leaf TN was loaded highly on the third PCA axis. Thus, the first PCA axis combined stem, leaf, and architectural traits, while the second and third axes were strongly related to leaf nutrients. Addition of reproductive traits (seed mass, seed number) did not alter the overall structure of the analyses or reveal new axes of variation.

Early successional and late successional species were distributed on the opposite sides of the first principal component axis using differences in SLA, WD, percentage of multiple stem, and HT:CL (Figure 17). Early-successional species have lower wood density, shorter crown length, higher SLA, and fewer multiple stems than latesuccessional species (Table 9). On the basis on contribution of each traits in first three 
principal components, SLA, WD, TN, TP, and HT:CL represent the important trait niche axes among the species found along a successional gradient in the North Key Largo DTF. However, following trait analysis, there is no indication of any exclusive group of species such as deciduous vs evergreen, or canopy vs understory (Figure 17).

In the community-level analysis of functional traits, the first two principal components explained more than $90 \%$ of the total variation, $66 \%$ and $25 \%$ for first and $2^{\text {nd }}$ principal components, respectively (Table 9). Sites were grouped based on stand age in first principal component axis with young sites on the left side of the axis (Young1Young5), and mature sites (Mature1-Mature5) were on the right side (Figure 18). Mature sites grouped together; while young sites were scattered along y-axis. Most traits were associated with the first axis of the PCA: SLA, WD, TN, CA:DBH, and HT:CL; TP, $\delta^{13} \mathrm{C}, \%$ of multiple stems, HT:DBH were the main contributor to Axis 2 (Table 9).

\subsubsection{Pattern of trait variation across successional gradient}

Community-weighted mean (CWM) traits showed significant trends along the successional gradient for all of the traits except $\delta^{15} \mathrm{~N}, \mathrm{TP}$, and HT:DBH (Figure 19). The CWM of SLA, $\delta^{13} \mathrm{C}, \mathrm{TN}, \mathrm{N}: \mathrm{P}$, and HT:CL decreased with increasing stand age, while WD, \% of Mutiple Stem form, and CA:DBH increased significantly from young sites to mature sites (Figure 19).

\subsubsection{Niche overlap in important functional traits between species}

The PCA analysis showed that SLA, WD, TP, TN, and HT:CL were important niche axes and explained most of the variation among species for the first three principal components. Analysis of these five traits across the 26 tree species considered in Key Largo DTF yielded an average local realized niche overlap of 0.39 ( 0 is no overlap while 
1 is compete overlap) (Table 10). Exhibiting a mean niche overlap of 0.16, S. glauca was a conspicuous outlier among its associates. D. lateriflora $(0.31), D$. diversifolia $(0.32), F$. citrifolia (0.33), B. simaruba (0.33) were also notably dissimilar from their associates. Species with high mean niche overlaps were S. salicifolia (0.48), S. mahogany (0.47), M. toxiferum (0.46), C. pallens (0.46), and B. ovata (0.45), (Table 10).

To evaluate the community assembly patterns, mean niche overlap among species on traits in ten stands (five young and five old) was used. Species displayed significant clustering across the niche space in all plots (Table 11). When mean niche overlap was analysed separately for each trait, a significant clustering pattern was observed in three traits, i.e., SLA, WD, and TP whereas no departures from random expectations for overlap of other two traits (TN and HT:CL, Table 11) were observed. Similarly, when niche overlap was analysed separately for young stands, species also displayed significant clustering in their distribution across trait niche space. Community assembly patterns determining individual traits in young plots showed a significant clustering pattern in all five traits ( $\mathrm{p}$-value $<0.05$, Table 11). In contrast, species in mature plots differed significantly from the null model in their distribution across trait niche space. Individual trait community assembly patterns in mature plots showed significant niche differentiation in only one trait (leaf nitrogen, $\mathrm{TN}$ ), while no significant departure from random expectations was observed (Table 11).

\subsection{Discussion}

Plant success in any community depends on how intrinsic developmental qualities of an individual (a suite of traits) respond to the local environmental conditions (Grime 
2006b; Cornwell \& Ackerly 2009). In the Florida Keys, tree species must cope with a long dry season (4-6 months), as well as skeletal soils $<30 \mathrm{~cm}$ in depth. To a great extent, species success will therefore be determined by the species' strategy in coping with limiting resources, specially water and nutrient. Traits associated with resource capture and conservation strategies should thus be major drivers of species success in these forests.

\subsubsection{Intra-specific, inter-specific, and community sources of trait variation}

Except for architectural metrics, variance in traits using presence-absence data (i.e., all species weighted equally, not proportionally according to their abundance) was primarily observed at inter- and intra-specific levels, not across plots. Differences between individuals of the same species occupying different plots were of negligible importance for most traits. However, when weighted trait values (weighted by density in the plot) were used to compare between young and mature stands, notable change in trait means were observed, e.g., SLA decreased and WD increased from young stand to mature stands (Figure 18). Suggesting that environmental conditions in the forests of north Key Largo favor species with thicker leaves and denser wood as these forests develop following clearing. The general pattern may be relevant across the DTF of the Caribbean, given the predominant role of windstorms and nutrient limitation that occur in the region. Determining whether other DTF's in the world exhibit similar environmental filtering induced functional shifts presents an interesting opportunity for further research.

Intra-specific trait variation is attributable to differences between individuals of the same species occupying the same plots. Phenotypic plasticity can be expected to influence individual responses by trees to their immediate environment, including 
competitors and other biota, thereby allowing individuals to optimize resource acquisition (Sánchez-Gómez, Valladares \& Zavala 2006). Therefore, intra-specific variation should mostly represent any inherently plastic response that a species might exhibit because of localized environmental variability. The high intra-specific variation in a few traits, especially architectural characters, TP, and $\delta^{15} \mathrm{~N}$ indicates an individual variation in acquiring various resources, mainly light, phosphorus, and source of nitrogen within and across the sites. Furthermore, it is likely that competition for belowground resources, such as nutrients and water, is equal or greater in intensity than competition for light in Key Largo DTF, where canopy cover is generally not completely closed. Tree species can vary in tolerance to low nutrient availability ( $\mathrm{N}$ or $\mathrm{P}$ ) just as they can to low light. Clearly, intraspecific variation has the potential to have substantial impact on whole plant function. The variability in architectural traits particularly at the intraspecific level may reflect trees' plastic responses to the environments to which they are exposed, or to genetic variation among individuals within a local population. As these forests are standing on a skeleton of limestone bedrock, and sometimes disturbed by storms and hurricanes, tree architecture determines trees stability against static loading and mechanical stress by wind and branch fall at the individual level. Trees clearly interact with one another and their environment as individuals, not as species. The extraordinary variation in leaf TP at the individual level (about 79\%) may be associated with a strategy of managing with phosphorus limitation. It is well known that microbial associations with fungi and roots in soil can enhance the ability of plants to acquire nutrients from soil through several mechanisms. These include mycorrhizal associations that enhance root growth, branching and/or root hair development, $\mathrm{N}$-fixation, or stimulation of metabolic 
processes that mobilize nutrients from poorly available sources (Gyaneshwar et al. 2002; Barea et al. 2005; Richardson et al. 2009). These processes may contribute to plant nutrient availability and may vary at the individual, species, genus, or family level. As very few legume species present in this forest (about three species), little is known about below-ground processes for Key Largo species.

\subsubsection{Major trait niche axes among species in north Key Largo DTF forest}

The PCA results showed that linear combinations of multiple niche trait axes indicate important species-level differences across the forest patch age gradient that sampled in North Key Largo forest. The leaf economics spectrum of species from low to high TN and TP also constitutes a spectrum of increasing SLA, i.e., leaf nitrogen and phosphorus contents are considered to be traits highly correlated with SLA, which as a group are related to leaf lifespan (Reich et al. 1999; Wright et al. 2004). In general, low TN with low SLA are characteristics of species with long-lived leaves, while high TN with high SLA are associated with ephemeral leaves that live less than one year. In contrast, our results suggest an orthogonal relationship among SLA, TP, and TN (Table 8), suggesting that tree species response to nutrient limitation may be important in the Key Largo forest. The amount of contribution of leaf TP and TN to the second and third principal components for both species and communities indicates that forest patches are likely to exist on a nutrient availability spectrum, and reinforces the conclusion of Redwine (2007) that the north Key Largo forests are strongly phosphorus limited ecosystems.

A strong negative correlation between SLA and WD was also expected, as slow growing species with low SLA generally allocate photosynthate to dense wood (Reich $e t$ 
al. 2003). Whereas a slight negative correlation between these two was observed across all species in first axis of principal component analysis (Figure 17, Table 8), the correlation was not very strong. Both SLA and WD were low in common species such as D. diversifolia, S. mahogani, C. diversifolia, E. axillaris, and S. foetidissium, which do not belong exclusively to any one successional group, neither early nor late. Likewise, species like S. salicifolia, B. ovata, P. guapalensis, and Z. fagara were high in both SLA and WD. These contradictory results suggest that the coordination of traits is not a universal trend, with irregular patterns possible depending on the specific constraints of each ecosystem. Also, wood related traits may need to account for a few different trait axes. While the wood density spectrum was explored in this study, light woods can be either soft or brittle, and variation on this trait spectrum may contribute to a species' inherent capacity to resist windstorm damage and/or support multi-stem or spreading canopies.

Similarly, as a result of differences in light demand, among species variation in architectural traits may be important for resident species in the Key Largo forest. Shadeintolerant species, primarily early-successional in this case, tend to grow faster in height to gain access to the canopy. In many cases, they do so by developing a slender stem (high HT:DBH ratio, Poorter et al. 2003) and a narrow crown (high HT:CL ratio, King 1996; Poorter, Bongers \& Bongers 2006b). In contrast, shade-tolerant species tend to have wider and longer crowns that increase interception of diffuse light. Earlysuccessional species are thereby expected to grow quickly, overtopping neighbors and attaining or maintaining occupancy of the canopy following gap formation that results from storm and hurricane disturbance (Diamond \& Ross 2016). Shade-tolerant 
understory species that regenerate in shaded environments are likely to have wide, shallow crowns that allow the tree to intercept light over a large area while reducing selfshading (Givnish 1988). However, multivariate analysis showed that no simple pattern described differences between group of species, such as canopy vs. understory, or early successional vs. late successional, on each of the architectural traits measured in this study (data not shown). Therefore, variation in architectural traits in this forest may not directly relate to the light environment, but rather is perhaps a response to multiple limiting resources such as water, light, and nutrients.

The presence of complex interactions between traits and species composition indicates that no single trait adequately captures community dynamics, and highlights the importance of trait selection that captures multiple niche axes for the exploration of community assembly mechanisms. The PCA analyses help to determine important niche axes that correlate strongly with aspects of whole-plant performance. The orthogonality between key traits indicates that these functional traits may respond to different selective pressures of the environment (Liancourt et al. 2009). The most notable information is that there is no indication of any group of species such as deciduous vs evergreen, or canopy vs understory, on each of this trait niche axis at the species level (Figure 17). Therefore, a combination of plant architecture (HT:CL), wood density (WD), and leaf traits (SLA, TP, TN) can be considered to be key functional traits that are important for understanding community assembly process in Key Largo DTF. Furthermore, different assembly processes may be operating simultaneously along these distinct niche axes (Spasojevic \& Suding 2012), therefore, an understanding of the functional roles of each of these traits 
under study is important to interpret the relationships between niche axes and assembly processes.

\subsubsection{Community assembly processes}

Overall a significant clustering pattern in North Key Largo forest (Table 11) suggests strong abiotic filtering of trait values in this forest. Such trait similarity supports the expectation that differences in local environment influence which trait values, filtered out of the regional pool, perform best under local conditions. The overall finding of this study was mean trait niche overlap in young and mature stands to differ from each other. The significant trait similarity observed in younger stands was expected, and represents strong evidence of environmental filtering. It suggests that convergence toward trait values that maximize resource acquisition is the dominant assembly process in early stages of succession in Key Largo DTF. In contrast, a significant niche differentiation pattern in old stand indicates biotic filtering, in which resource competition acts to constrain local neighbourhoods to certain traits or trait combinations, producing lower niche overlap than expected by chance. On the basis of trait patterns, filtering at this end of the gradient was likely the result of competition for limiting resources, water and nutrient (high WD, low leaf TN, Figure 19). Therefore, as communities age, competition theory expects some level of limitation on functional similarity among co-occurring species.

Changes in the assembly processes can be further understood from individual trait patterns across the environmental gradient. Results from individual trait community assembly patterns (Table 11) showed a significant clustering pattern in only three traits (SLA, WD, and TP). Such patterns suggest an intense pressure for similar resource use 
strategy to acquire limiting resources. It was expected that water and nutrients were strongly limiting productivity in the Key Largo forest. Wood density is related to water acquisition strategies (Chave et al. 2009), with high wood density adaptive under lowwater availability conditions. Because fibers and thick-walled vessels found in denser wood may protect vessels from implosion when fresh water shortage creates strongly negative xylem potentials (Hacke et al. 2001). Similarly, a significant clustering pattern in all five traits in young communities suggests that dominant species in young forests have similar leaf, stem and architectural traits. Convergence in architectural traits in younger stands is expected, as early-successional species are predominantly shadeintolerant and grow faster in height to gain access to the canopy. Convergence in SLA, $\mathrm{WD}$, and leaf nutrient concentrations further indicates that there is intense pressure for similar resource use strategy to acquire limiting resources. As expected, young stands experience drier environments with plenty of sunlight (open canopy) and lower soil water (higher evaporation and shallow soil layer (less than $15 \mathrm{~cm}$ in this forest). With high SLA and low WD, species in young communities are fast-growing species (high SLA and low WD) that avoid drought by dropping leaves. Moreover, high photosynthetic rates are generally associated with high leaf nitrogen content. Indeed, a higher leaf nitrogen content in young stands (Figure 18) was observed. However, the only trait, leaf nitrogen (TN) showed a significant niche differentiation pattern, while the other four traits exhibited a random pattern among species (not different from null model). Previous study in this forest suggests that $\mathrm{N}$-fixing behavior is widespread (Redwine 2007) which may indicate that competition in capturing nitrogen or symbiotic association with n-fixing 
microorganism among coexisting species may be affecting for community assembly in mature forests.

In addition, trait differentiation among co-existing species in a community may be also caused by dispersal limitation (Hubbell 2006). However, one may assume that dispersal limitation is not important in explaining spatial patterning the NKL forest, as study is on $15-\mathrm{km}$ study area, populated mostly by tree species with fleshy fruits likely to be dispersed by birds and small animals (Redwine et al. 2007; Ross et al. 2016). Birds and animals can easily move across the whole forest and disperse seeds, meaning that most species can exploit most or all available habitat. Furthermore, our trait-species relationships were not strongly correlated with dispersal traits, i.e., seed mass and number (Figure 19). Similarly, abiotic filtering has been shown to generate phylogenetically clustered local communities because groups of closely related species share traits that allow them to persist in a given habitat (Webb et al. 2002; Cornwell, Schwilk \& Ackerly 2006b; Kraft et al. 2007). For example, among the most dominant early successional species, species such as B. ovata, G. scabra, and G. elliptica are phylogenetically very similar (http://www.phylotastic.org/). However, another dominant early-successional species, Lysiloma bahamense is not closely related phylogenetically with this group. Therefore, the future work needs to explore if abiotic conditions are filtering regional species to a smaller phylogenetic subset of taxa at different stand age as well as across the whole forest, or even the whole south Florida region. 


\subsection{Conclusions}

It can be concluded that younger stands are mostly shaped by environmental driven processes, and mature stands are shaped by competitively driven processes leading to limiting similarity at plot scale. This is because changes in abiotic conditions such as soil nutrients, water and light availability may favor different plant strategies as succession proceeds. Trees in younger sites (early successional species) tend to increase nutrient and water acquisition as they have less competition after disturbance in Key Largo DTF. Trees from mature sites (late successional species), in contrast, would compete for resources particularly nutrients as competition increases as stands age and become more diverse. The overall trait similarities among species presence in DTF in North Key Largo suggests that these species are specialists on local environment and species optimum tolerance for limiting resources such as nutrient and moisture may be more important than competition for resources at the regional scale.

\section{Acknowledgement}

I thank to South Florida Terrestrial lab (SOFTEL) crew for their help during the field and laboratory work, specially Susanna Stoffella, Rosario Vilades, and Bina Thapa. I also thank to my co-authors of this paper, Dr. Michael Ross, Dr. Jay P Sah, and Dr. Jed Redwine for their valuable contributions and suggestions. I am also thankful to the Florida State Parks and the U.S. Fish and Wildlife Service for allowing access to the sites. This project was partially supported by graduate student research project funded from the International Center for Tropical Botany (ICTB). 


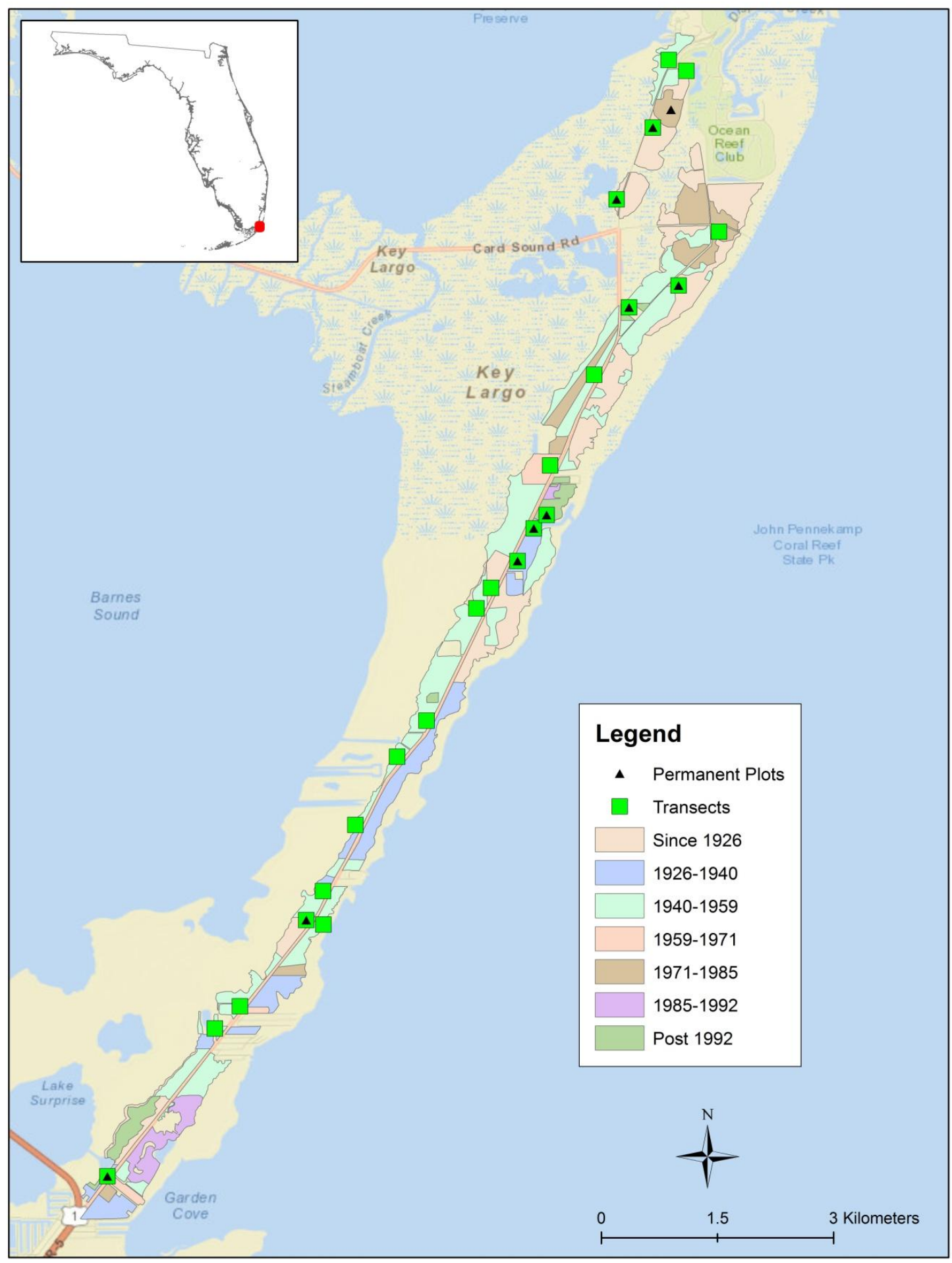

Figure 16 Study area and location of plots and transects with stand age. 
Table 6 List of traits measured at different scales.

\begin{tabular}{|l|l|l|l|}
\hline Trait & Site & Species & Individual \\
\hline Specific leaf area (SLA) & $\mathrm{X}$ & $\mathrm{X}$ & $\mathrm{X}$ \\
\hline Wood density (WD) & $\mathrm{X}$ & $\mathrm{X}$ & $\mathrm{X}$ \\
\hline Leaf total phosphorus $(\mathrm{TP})$ & $\mathrm{X}$ & $\mathrm{X}$ & $\mathrm{X}$ \\
\hline Leaf total nitrogen $(\mathrm{TN})$ & $\mathrm{X}$ & $\mathrm{X}$ & $\mathrm{X}$ \\
\hline Leaf stable carbon isotope ratio $\left(\delta^{13} \mathrm{C}\right)$ & $\mathrm{X}$ & $\mathrm{X}$ & $\mathrm{X}$ \\
\hline Leaf stable nitrogen isotope ratio $\left(\delta^{15} \mathrm{~N}\right)$ & $\mathrm{X}$ & $\mathrm{X}$ & $\mathrm{X}$ \\
\hline Leaf N:P ratio $(\mathrm{N}: P)$ & $\mathrm{X}$ & $\mathrm{X}$ & $\mathrm{X}$ \\
\hline Seed number $(\mathrm{SN})$ & $\mathrm{X}$ & $\mathrm{X}$ & \\
\hline Seed Mass $(\mathrm{SM})$ & $\mathrm{X}$ & $\mathrm{X}$ & \\
\hline Crown area:Diameter at breast height $(\mathrm{CA}: \mathrm{DBH})$ & $\mathrm{X}$ & $\mathrm{X}$ & $\mathrm{X}$ \\
\hline Height:Diameter at breast height $(\mathrm{HT}: \mathrm{DBH})$ & $\mathrm{X}$ & $\mathrm{X}$ & $\mathrm{X}$ \\
\hline Height:Crown length $(\mathrm{HT}: \mathrm{CL})$ & $\mathrm{X}$ & $\mathrm{X}$ & $\mathrm{X}$ \\
\hline Percentage of multiple stem $(\mathrm{MS} \%)$ & $\mathrm{X}$ & $\mathrm{X}$ & \\
\hline
\end{tabular}

Table 7 Percentage of trait variation at three different scales (site, species, and individual), unweighted (presence-absence matrix).

\begin{tabular}{|l|l|l|l|}
\hline Trait & Site & Species & Individual \\
\hline SLA & $<1.00$ & 90.37 & 9.23 \\
\hline WD & 1.91 & 80.86 & 17.22 \\
\hline TN & $<1.00$ & 99.88 & $<1.00$ \\
\hline TP & $<1.00$ & 20.95 & 78.64 \\
\hline$\delta^{13} \mathrm{C}$ & $<1.00$ & 96.90 & 3.07 \\
\hline$\delta^{15} \mathrm{~N}$ & $<1.00$ & 9.57 & 90.42 \\
\hline HT:DBH & 6.83 & 46.58 & 46.58 \\
\hline CA:DBH & 19.22 & 35.41 & 45.35 \\
\hline HT:CL & 4.24 & 12.47 & 83.27 \\
\hline
\end{tabular}


Table 8 Trait contribution to first three components contributed by each factor.

Trait contribution to first three components contributed by each factor. Percentage of variation explained by each component was provided in parenthesis. Asterisk $\left(^{*}\right)$ sign was added to one that contributed significantly in each PCA axis.

\begin{tabular}{|l|l|l|l|}
\hline Trait & $\begin{array}{l}\text { Comp.1 } \\
\mathbf{( 2 2 \% )}\end{array}$ & $\begin{array}{l}\text { Comp.2 } \\
\mathbf{( 1 7 \% )}\end{array}$ & $\begin{array}{l}\text { Comp.3 } \\
\mathbf{( 1 4 \% )}\end{array}$ \\
\hline SLA & $0.42^{*}$ & 0.17 & $<0.01$ \\
\hline WD & $-0.45^{*}$ & 0.18 & $<0.01$ \\
\hline TP & -0.13 & $0.52^{*}$ & -0.24 \\
\hline$\delta^{13} \mathrm{C}$ & 0.12 & -0.26 & $<0.01$ \\
\hline TN & 0.12 & 0.27 & $-0.52^{*}$ \\
\hline CA:DBH & $<0.01$ & 0.30 & 0.35 \\
\hline HT:DBH & -0.15 & 0.25 & -0.29 \\
\hline HT:CL & $0.48^{*}$ & $<0.01$ & $<0.01$ \\
\hline $\begin{array}{l}\text { Multiple } \\
\text { Stem }\end{array}$ & -0.27 & 0.12 & $<0.01$ \\
\hline Seed mass & -0.14 & -0.15 & 0.38 \\
\hline $\begin{array}{l}\text { Seed } \\
\text { number }\end{array}$ & 0.12 & $<0.01$ & -0.17 \\
\hline$\delta^{15} \mathrm{~N}$ & 0.26 & $<0.01$ & $<0.01$ \\
\hline
\end{tabular}

Table 9 Community weighted trait contribution to first two components contributed by each factor. Asterisk (*) sign was added to one that contributed significantly in each PCA axis.

\begin{tabular}{|l|l|l|}
\hline Trait & Comp.1(66\%) & Comp.2 (25\%) \\
\hline Stand age & $0.36^{*}$ & 0.15 \\
\hline SLA & $-0.36^{*}$ & 0.23 \\
\hline WD & $0.32^{*}$ & 0.28 \\
\hline TP & 0.18 & $-0.57^{*}$ \\
\hline$\delta^{13} \mathrm{C}$ & -0.29 & $-0.36^{*}$ \\
\hline TN & $-0.33^{*}$ & 0.31 \\
\hline HT:DBH & -28 & $0.36^{*}$ \\
\hline CA:DBH & $0.37^{*}$ & 0.15 \\
\hline HT:CL & $-0.39^{*}$ & $<0.02$ \\
\hline Multiple Stem & 0.21 & $0.39^{*}$ \\
\hline
\end{tabular}


Table 10 Mean niche overlap between species occurred across the successional gradient.

Species are arranged according to their abundance across the succesional gradient published by Ross et al. (2011). Signature earlyand late-successional species are assigned with different color, i.e. green and orange, respectively. Species pairs statistically not different as identified by null model tests are highlighted by blue color $(\mathrm{P}>0.05)$. Mean nicheoverlap across all associate species are given in last row of the table.

\begin{tabular}{|c|c|c|c|c|c|c|c|c|c|c|c|c|c|c|c|c|c|c|c|c|c|c|c|c|c|c|}
\hline sp & GS & $\mathrm{BO}$ & LB & GE & SM & FC & SS & PG & ARE & MT & PP & $\mathrm{ZF}$ & BS & EA & GD & EF & $\mathrm{CD}$ & AME & $\mathrm{AL}$ & $\mathrm{NC}$ & $\mathrm{KF}$ & SF & DL & DD & $\mathrm{CP}$ & SG \\
\hline GS & & .48 & .32 & .41 & .48 & .24 & .47 & .32 & .32 & .46 & .39 & .64 & .34 & .44 & .40 & .44 & .46 & .35 & .46 & .38 & .31 & .37 & .34 & .34 & .46 & .11 \\
\hline $\mathrm{BO}$ & & & .47 & .49 & .48 & .35 & .62 & .38 & .44 & .56 & .59 & .49 & .44 & .39 & .48 & .29 & .35 & .50 & .32 & .40 & .37 & .46 & .24 & .37 & .45 & .15 \\
\hline LB & & & & 0.49 & .35 & .26 & .42 & .33 & .43 & .50 & .59 & .24 & .44 & .33 & .55 & .23 & .36 & .35 & .22 & .34 & .38 & .38 & .16 & .21 & .29 & .14 \\
\hline $\mathrm{GE}$ & & & & & .57 & .27 & .66 & .39 & .45 & .48 & .41 & .44 & .43 & .51 & .38 & .29 & .42 & .45 & .27 & .32 & .44 & .47 & .28 & .41 & .49 & .11 \\
\hline SM & & & & & & .45 & .52 & .42 & .52 & .66 & .37 & .58 & .29 & .46 & .42 & .50 & .57 & .53 & .37 & .46 & .38 & .41 & .32 & .43 & .64 & .11 \\
\hline $\mathrm{FC}$ & & & & & & & .36 & .23 & .37 & .46 & .35 & .34 & .30 & .29 & .25 & .26 & .32 & .34 & .30 & .34 & .30 & .19 & .28 & .27 & .45 & .11 \\
\hline SS & & & & & & & & .42 & .47 & .52 & .53 & .49 & .41 & .56 & .45 & .33 & .46 & .50 & .31 & .37 & .43 & .62 & .33 & .40 & .53 & .20 \\
\hline PG & & & & & & & & & .44 & .38 & .38 & .46 & .22 & .37 & .38 & .36 & .35 & .48 & .40 & .47 & .44 & .49 & .28 & .29 & .39 & .05 \\
\hline ARE & & & & & & & & & & .53 & .50 & .35 & .31 & .40 & .44 & .27 & .43 & .51 & .40 & .40 & .49 & .41 & .22 & .30 & .44 & .14 \\
\hline MT & & & & & & & & & & & 0.52 & .51 & .40 & .43 & .45 & .44 & .53 & .61 & .33 & .35 & .36 & .34 & .25 & .36 & .56 & .15 \\
\hline PP & & & & & & & & & & & & .37 & .43 & .32 & .54 & .23 & .34 & .41 & .35 & .44 & .48 & .44 & .18 & .24 & .35 & .14 \\
\hline ZF & & & & & & & & & & & & & .27 & .37 & .33 & .50 & .37 & .42 & .57 & .47 & .31 & .35 & .35 & .38 & .60 & .05 \\
\hline BS & & & & & & & & & & & & & & .39 & .30 & .21 & .27 & .33 & .22 & .20 & .27 & .26 & .27 & .26 & .31 & .23 \\
\hline EA & & & & & & & & & & & & & & & .36 & .41 & .53 & .50 & .31 & .29 & .38 & .44 & .43 & .31 & .59 & .22 \\
\hline GD & & & & & & & & & & & & & & & & .34 & .49 & .35 & .31 & .53 & .46 & .49 & .17 & .17 & .37 & .17 \\
\hline $\mathrm{EF}$ & & & & & & & & & & & & & & & & & .50 & .52 & .40 & .45 & .27 & .37 & .37 & .34 & .50 & .13 \\
\hline $\mathrm{CD}$ & & & & & & & & & & & & & & & & & & .49 & .32 & .40 & .39 & .34 & .27 & .22 & .48 & .16 \\
\hline AME & & & & & & & & & & & & & & & & & & & .36 & .33 & .40 & .46 & .27 & .46 & .47 & .14 \\
\hline $\mathrm{AL}$ & & & & & & & & & & & & & & & & & & & & .45 & .46 & .28 & .42 & .26 & .52 & .06 \\
\hline $\mathrm{NC}$ & & & & & & & & & & & & & & & & & & & & & .49 & .40 & .37 & .18 & .42 & .05 \\
\hline $\mathrm{KF}$ & & & & & & & & & & & & & & & & & & & & & & .45 & .29 & .23 & .39 & .12 \\
\hline SF & & & & & & & & & & & & & & & & & & & & & & & .25 & .33 & .36 & .16 \\
\hline $\mathrm{DL}$ & & & & & & & & & & & & & & & & & & & & & & & & .24 & .45 & .14 \\
\hline $\mathrm{DD}$ & & & & & & & & & & & & & & & & & & & & & & & & & .40 & .17 \\
\hline $\mathrm{CP}$ & & & & & & & & & & & & & & & & & & & & & & & & & & .09 \\
\hline \multicolumn{27}{|l|}{ SG } \\
\hline Overall & .41 & .45 & .37 & .43 & .47 & .33 & .48 & .39 & .41 & .47 & .42 & .43 & .33 & .42 & .40 & .38 & .41 & .44 & .37 & .39 & .39 & .40 & .31 & .32 & .46 & .16 \\
\hline
\end{tabular}

Note: Species abbreviation will be provided in the appendix. 
Table 11 Measures of the evenness vs. clustering of community assembly

Table 11 shows the measures of the evenness vs clustering of all the plots, young stands, and mature stands of Key Largo tree species across niche space incorporating five functional traits: (1) SLA; 2) WD; 3) TP; 4) TN; 5) HT:CL; with the average coefficient of heterogeneity over the five traits giving an overall measure of clustering vs. even spacing. Statistically significant evenly spaced or clustered distributions, as identified by null model tests, are indicated in bold $(\mathrm{P}<0.05)$. Asterisk $(*)$ sign was added to the significant patterns at 0.05 level (*), 0.01 level (**), and 0.001 level (***).

\begin{tabular}{|c|c|c|c|c|c|c|c|}
\hline Source & Test & Overall & SLA & WD & $\mathrm{TP}$ & TN & HT:CL \\
\hline \multirow[b]{2}{*}{ All plots } & Evenness & ns & ns & ns & ns & ns & ns \\
\hline & Clustering & $<0.01 * *$ & $0.01 * *$ & $0.02 *$ & $0.001 * * *$ & ns & ns \\
\hline \multirow[b]{2}{*}{ Young } & Evenness & ns & $\mathrm{ns}$ & ns & ns & ns & ns \\
\hline & Clustering & $<0.01 * *$ & $0.02 *$ & $0.03 *$ & $0.03 *$ & $0.04 *$ & $0.02 *$ \\
\hline \multirow[b]{2}{*}{ Mature } & Evenness & $0.03 *$ & $\mathrm{~ns}$ & ns & $\mathrm{ns}$ & $0.03 *$ & ns \\
\hline & Clustering & $\mathrm{ns}$ & ns & ns & ns & ns & ns \\
\hline
\end{tabular}



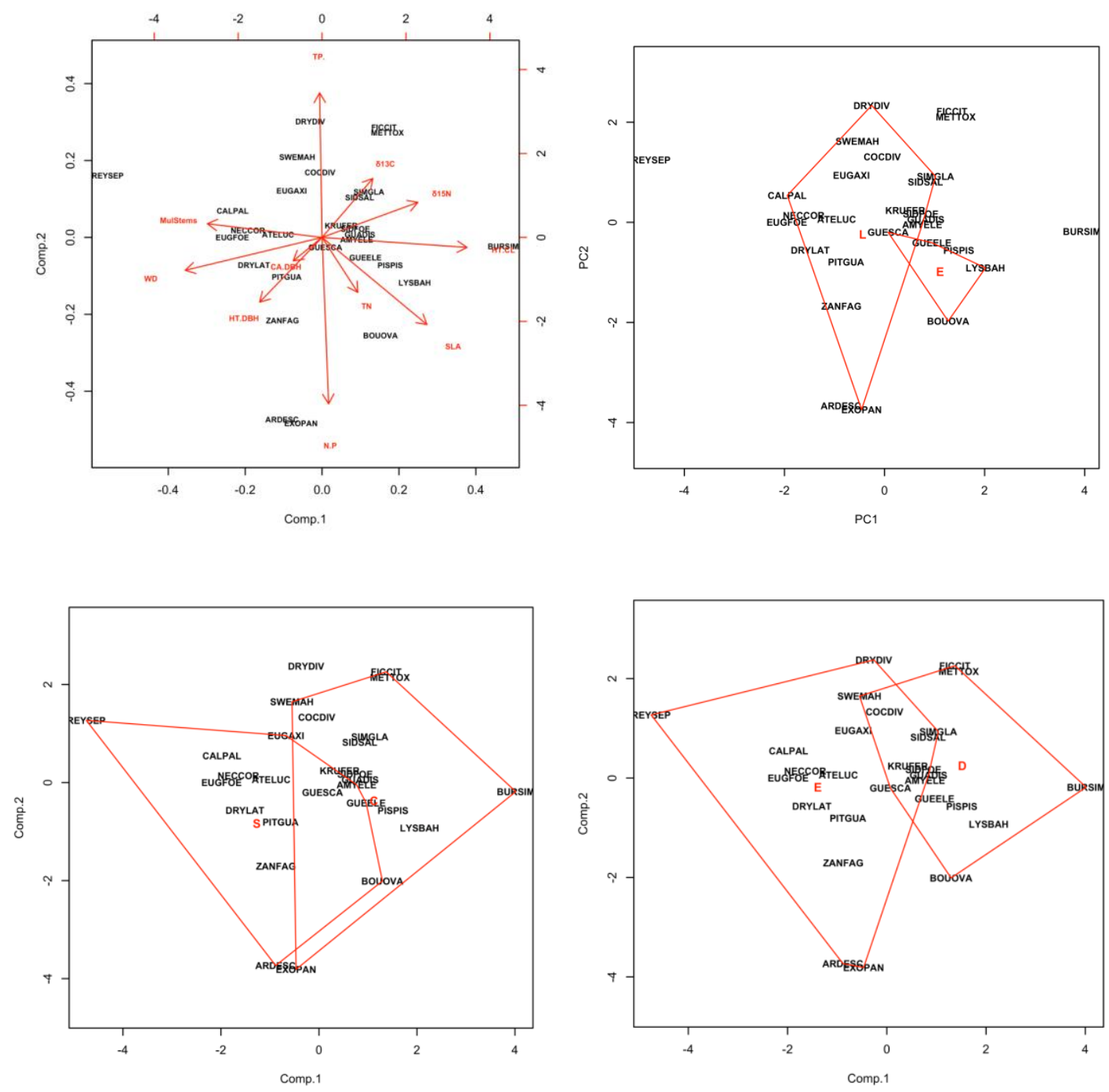

Figure 17 Species-trait bi-plot for PCA of Key Largo dry tropical forests

Species-trait bi-plot for PCA of Key Largo dry tropical forests: a) without grouping species (top left); b) grouping by stand age group ( $\mathrm{L}=$ late successional and $\mathrm{E}=$ earlysuccessional species) (top right); c) grouping by canopy position ( $\mathrm{S}=$ sub-canopy or understory, $\mathrm{C}=$ canopy) (bottom left); and $\mathrm{d}$ ) grouping by leaf habit $(\mathrm{E}=$ evergreen, $\mathrm{D}=$ deciduous) (bottom right). Data levels are six-letter codes (first three letters of genus, first three letters) of species. The ordination is based on 12 functional traits (see Table 8), un-weighted by species abundances. 


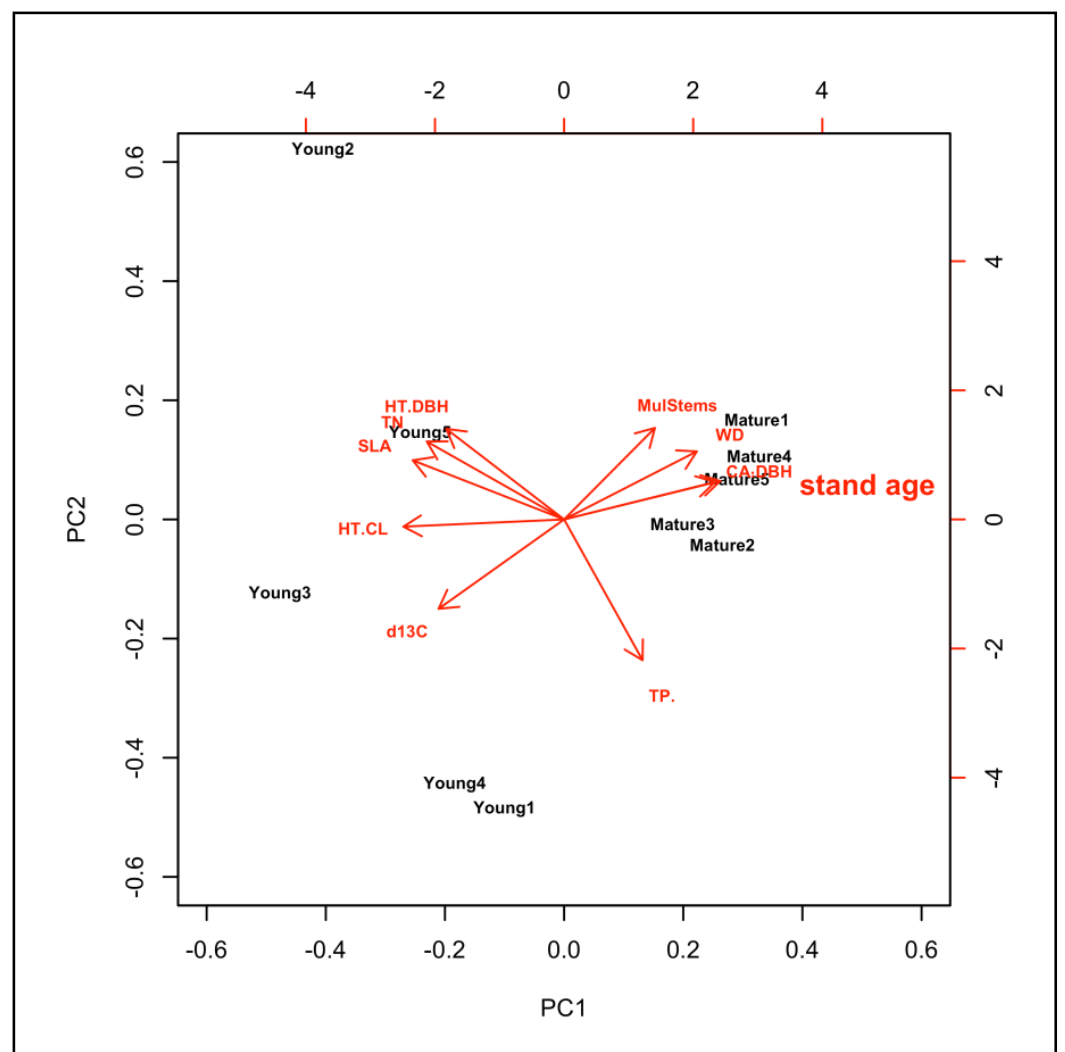

Figure 18 Community-weighted trait bi-plot for PCA of Key Largo dry tropical forests.

Data levels are six-letter codes for plots. The ordination is based on community-weighted mean (CWM) traits, traits weighted for each species by its relative abundance in the community. 


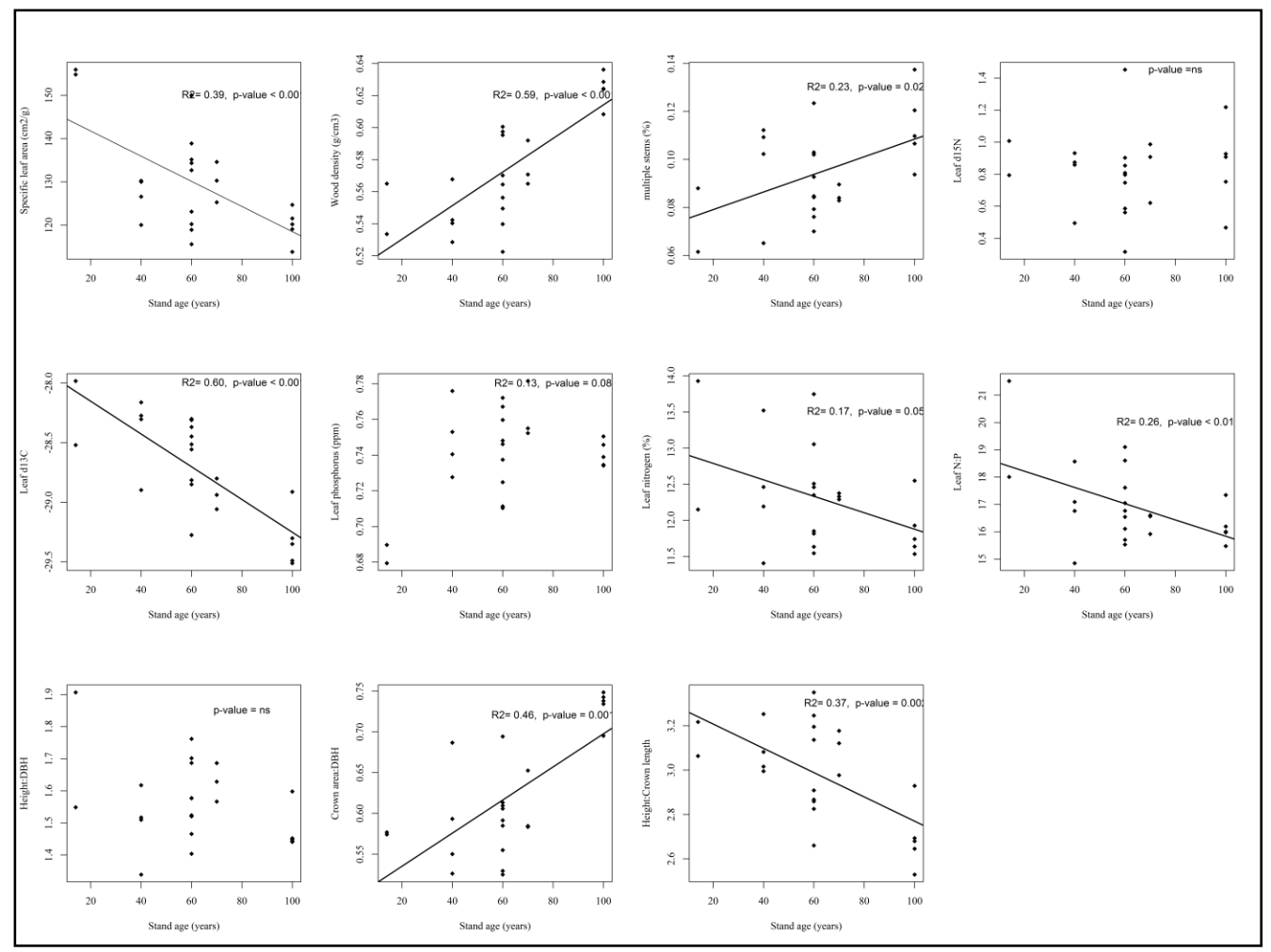

Figure 19 Relationship between trait and stand age.

Each point represents one of 23 sites in a $15-\mathrm{km}$ continuous secondary forest in North Key Largo. The dependent variables are the community-weighted mean trait values of the vegetation at that site. The linear regression line is shown only for traits exhibiting significant pattern $(\mathrm{p}=<0.05)$. 


\title{
CHAPTER 4
}

Variation in functional characteristics of Bursera simaruba (L.) Sarg., a dominant tree species of tropical hardwood hammock forest across a habitat gradient in the Florida Keys

(Reviewed in Functional Plant Biology journal)

\begin{abstract}
:
Tree species in the coastal forests may exhibit specialization or plasticity in coping with drought by changing in their stomatal morphology or activity, allowing for a balance between gas exchange and water loss in a periodically stressful environment. We sought to answer two primary research questions: a) how is variation in $B$. simaruba's stomatal traits partitioned across hierarchical levels, site, tree, and leaf and b) does variation in its stomatal traits reflect physiological stress expressed across the habitat gradient of Florida Keys forests? At eight sites distributed throughout the Keys, three mature trees were randomly selected and five leaves were collected from each for stomatal analysis. Leaf carbon stable isotope ratio $\left(\delta^{13} \mathrm{C}\right)$ was determined to infer the changes in water use efficiency caused by physiological stress experienced by each tree. The results showed that substantial proportions of the total variance in three traits (stomatal density, stomatal size, and $\delta^{13} \mathrm{C}$ ) were observed at all levels, suggesting that processes operating at each scale are important in determining trait values. A significant negative correlation between stomatal density and size, and a positive correlation between leaf $\delta^{13} \mathrm{C}$ and stomatal density were observed across scales. A significant interaction between elevation and ground water salinity was observed for both response variables (stomatal density and length). Small and densely distributed stomates in tandem seems to represent a strategy
\end{abstract}


that allows $B$. simaruba to conserve water under physiological drought induced by higher ground water salinity or increased elevation.

Keywords: Bursera simaruba, dry tropical forest, Florida Keys.

\subsection{Introduction}

The impacts of stress in plants growing in saline or flooded environments are similar to the ones faced by plants growing in dry environments (Carrow \& Duncan 1998), and are collectively referred to as physiological drought. Like drought stress, saltinduced stress occurs when water intake is limited, in this instance when salt concentrations in the soil solution rise above a critical level (Chartzoulakis et al. 2002). Both salt and drought stress lead to cellular dehydration, which causes osmotic stress (Bartels \& Sunkar 2005). The effects of osmotic stress can harm woody plants through cavitations of water columns within the xylem, or by toxicity of salts on biochemical processes (Sternberg \& Manganiello 2014). Flooding stress likewise is detrimental to most terrestrial plants, resulting in dramatically reduced gas exchange between plants roots and the soil environment during flood events. Physiological responses to flooding stress resemble those brought on by drought stress; cellular $\mathrm{O}_{2}$ levels may decline to concentrations that restrict aerobic respiration, causing stomatal conductance to slow down (Sojka 1992).

Plant evolution in a heterogeneous environment leads to one of two alternatives: specialization to a fraction of the environmental heterogeneity (evolutionary specialization); or generalized adaptation to a broad range of environments (i.e., phenotypic plasticity) (Bazzaz 1996; Van Kleunen \& Fisher 2001; Agrawal 2001). One 
way that plants may exhibit specialization or plasticity in dealing with drought is by changes in stomatal morphology or activity, allowing for a balance between gas exchange and water loss in stressful environments. Species adapted to a broad range of environments may respond to spatial and temporal environmental heterogeneity by plasticity in stomatal traits. In contrast, species or genotypes specialized in drought environment are less plastic in stomatal traits as evolution of these traits are specific to a given environment (Valladares et al. 2000b).

Tropical dry forests of the Florida Keys occupy a wide range of physical settings, including flood-stressed, salt-stressed, and water-limited environments. Trees in these forests have two distinct sources of water: rainwater stored in an organic-rich soil layer and groundwater present at some depth in the bedrock. The organic soil layer is typically thin $(<30 \mathrm{~cm})$, causing trees to depend in varying degree on groundwater as their water source (Sternberg et al. 1991, 2007). Trees located at relatively low elevations have more access to the groundwater because of their proximity to the water table, while trees at higher elevations may become drought-stressed when soil water is exhausted. Although these forests (locally known as hammocks) are infrequently flooded, those situated at very low elevations (almost at the sea level) may suffer flooding stress when high rainfall and/or high tides inundate the surface for brief periods. The third potential stressor is the salinity of the water available to Florida Keys trees, which is affected not only by elevation and source (rainfall or tides), but also by bedrock geology (Halley, Vacher \& Shinn 1997). In the easternmost (Upper) Keys, even the water closest to the surface is brackish, because the coralline limestone that forms these islands is extremely permeable, allowing groundwater to mix freely with surrounding seawater (Lapointe, O'Connell \& 
Garrett 1990). In the lower Florida Keys, where a less permeable oolitic limestone overlies the coralline rock formation, a freshwater lens operating under Ghyben-Herzberg dynamic influences near the groundwater surface (Langevin, Stewart \& Beaudoin 1998). These geologic factors are critical, as both the salinity of the groundwater and the proximity of tree roots to it may determine the magnitude of water stress and the nature of plant response.

A hypothetical alignment of physiologic stresses and leaf characteristics is illustrated graphically for a single mesophytic tree species in the Florida Keys (Figure 20Figure 21). The independent curve of stress with distance to the water table is concave, with highest levels close to the water table and far above it, and lowest stress at intermediate elevations (Figure 20). In contrast, stress increases monotonically with increasing salinity, all else being equal. Tendencies in leaf architecture have not been examined within a single tree species, where plasticity in stomatal density or size may be expressed across sites, among trees within a site, or even among leaves within a tree, depending on the scale at which the operative stress is expressed.

Stomatal traits are not the only leaf characters affected by physiological drought. In many instances, carbon fixed in the leaves of physiologically stressed plants have been shown to be enriched in the heavier isotope ${ }^{13} \mathrm{C}$ compared with the lighter isotope ${ }^{12} \mathrm{C}$ (Farquhar et al. 1982; Brugnoli \& Lauteri 1991; Lin \& Sternberg 1992). When plants are stressed, the rate of photosynthetic $\mathrm{CO}_{2}$ assimilation decreases as a result of reduced stomatal conductance and consequent restriction in the availability of $\mathrm{CO}_{2}$ for carboxylation. Therefore, ${ }^{13} \mathrm{C} /{ }^{12} \mathrm{C}$ ratios (expressed as $\delta^{13} \mathrm{C}$, after standardization) may track the trajectories of stomatal density and size in response to hydrologic conditions. It 
is expected that the response in leaf $\delta^{13} \mathrm{C}$, as a direct reflection of plant stress, to follow suit, varying with both the salinity of the groundwater table and its distance below the soil surface.

Some studies have argued that an increase in stress caused by drought or salinity causes plants to produce fewer and larger stomates to minimize their water loss by transpiration under dry or saline conditions (Woodward \& Kelley 1995; Franks, Drake \& Beerling 2009; Barbieri et al. 2012; Orsini et al. 2012; Sternberg \& Manganiello 2014). In contrast, other studies have shown that drought stress and arid climatic conditions causes an increase in stomatal density and a decrease in stomatal size because plants with larger stomata are slower to close and demonstrated a greater potential for hydraulic dysfunction under drought (Gindel 1969; Hetherington \& Woodward 2003; Galmés et al. 2007). Based on these two views, two alternative patterns are illustrated for a single mesophytic tree species in the Florida Keys (Figure 21). If an increase in physiological stress is associated with fewer and larger stomates, leaf $\delta^{13} \mathrm{C}$ and stomatal density are expected to exhibit a linear negative correlation (Figure 21A). On the other hand, if an increase in physiological stress is associated with many and smaller stomates, leaf $\delta^{13} \mathrm{C}$ and stomatal density are expected to exhibit a linear positive correlation (Figure 21B). However, most studies that have explored differences among co-occurring species have used controlled experiments, or comparisons among closely or distantly related species. This study provides an example of a different approach by addressing hierarchical issues of landscape-scale stomatal trait variance in a species with wide distribution in dry subtropical forest where populations occur across the environmental gradient. Moreover, in dry-tropical forest, our understanding of stomatal trait variation has been very limited, 
and physiological traits including stomatal traits are influenced by different processes operating across distinct spatial scales ranging from regional environmental factors such as climate, geology, elevation, groundwater salinity, to localized factors such as light and soil environment (Gillison 2016). Identifying which scales cause the most variation in traits provides important information regarding the patterns and processes that are ecologically most critical at that scale (McGill 2008). For example, the primary factors that drive trait variation across the sites may include topography, disturbance, edaphic, and hydrological factors, while factors that drive trait variation within a population (site) are mainly because of phenotypic plasticity in response to micro-environmental heterogeneity.

In this chapter, stomatal size and density in Bursera simaruba, a common tree species in tropical dry forests of the Florida Keys were observed. Sampling leaves from eight forests, I determined how small differences in environmental conditions such as elevation, geology, and groundwater salinity affected both stomatal structure and physiological stress, as reflected by carbon isotope ratios. In the process, variance in stomatal traits were quantified across a hierarchy of scales: site, tree, and leaf levels. Identifying which scales account for most of the variation in these traits can provide a focus on patterns and processes at the spatiotemporal scales that are ecologically most important (McGill 2008). Two primary research questions were answered: a) how is the variance in stomatal traits (size and density) partitioned across the hierarchical levels? and b) at the site level, does variation in B. simaruba (L.) Sarg. stomatal traits reflect physiological stress expressed across the habitat gradient of Florida Keys forests? 


\subsection{Materials and methods}

\subsubsection{Field sites and experimental design}

The Florida Keys are a $210 \mathrm{~km}$ chain of islands running southwest from Soldier Key, near the Florida mainland, to Key West. Conditions become progressively drier and warmer with increasing distance from the mainland (Ross et al. 1992). The highest elevation is only $5.5 \mathrm{~m}$ above the sea level, while most of the land area is below $2 \mathrm{~m}$. Eight study sites were chosen: three in the lower Keys, two in the middle Keys, and three in the upper Keys (Figure 22). In each site a well was drilled to allow sampling of ground water salinity and distance to water table, which was conducted at monthly intervals during 1989-1992 (Ross, O’Brien \& Flynn 1992). While subsequent research has shown some increases in groundwater salinity since 1992 (Ogurcak 2016), these changes have been small, especially in the interior locations where most of the study sites were located. Because of the difference between the mean ground water level and mean sea level very low $(<30 \mathrm{~cm})$ in the Florida Keys, ground elevation can be used as an proxy to distance to the water table (Ross et al. 2003). Soil depth was measured by probing to bedrock with a metal rod during Aug-Dec 2014. Mean soil depth was calculated by averaging 20 equidistant measurements along a $20 \mathrm{~m}$ transect near the center of the hammock.

B. simaruba was chosen as the study species because of its local abundance and wide distribution within the study area. A tree pruner was used to collect newly matured healthy, leaves from all eight sites during July-October 2014. To control for trait variation because of light variation, leaves were collected only from outer canopy, fully exposed to sun. Since, all data were collected during one wet season (July-October), temporal variation in traits that occurs between seasons and years was minimized. 
Similarly, the youngest fully expanded leaves were collected to control for trait variation associated with leaf development and aging. Three trees per site were selected randomly and five leaves per tree were collected. Altogether, 120 leaves were sampled from 24 trees.

\subsubsection{Stomatal density and size measurement}

Using clear nail polish, leaf imprints were made, lifted off by tape, and placed on a slide. Digital images of three randomly selected views of each leaf were taken under a compound microscope. Stomatal density and size were analyzed in ImageJ (Rasband 2012). For stomatal density, the total area counted was $0.275 \mathrm{~mm}^{2}$ at $160 \mathrm{X}$ magnification and later converted to number of stomata per $\mathrm{mm}^{2}$ for analysis. A total of 345 captured fields of view were used. Imprint images that had visible leaf veins, which lacked stomata, required a correction to the total area viewed (Vialet-Chabrand \& Brendel 2014). Using the polygon-drawing tool in ImageJ, veins were digitized, and their area calculated and subtracted from the total observed grid area. Stomatal size was determined by measuring guard cell length i.e., the length between the junctions of the guard cells at each end of the stomata (Xu \& Zhou 2008), which represents the maximum potential opening of the stomatal pore rather than the actual aperture (Maherali et al. 2002). Stomatal length was measured using a compound microscope at 1000X magnification.

\subsubsection{Carbon isotope analysis}

We used the foliar stable carbon isotope ratio to infer the underlying variation in physiological stress experienced by each tree. ${ }^{13} \mathrm{C}$ content of leaves was determined with data expressed in "delta" notation $\left(\delta^{13} \mathrm{C}\right)$ as:

$\delta^{13} \mathrm{C}=[($ Rsample $/$ Rstandard $)-1] \times 1000$ 
where $\mathrm{R}_{\text {sample }}$ and $\mathrm{R}_{\text {standard }}$ are the ratios ${ }^{13} \mathrm{C}:{ }^{12} \mathrm{C}$ of the sample and standard, respectively, and $R_{\text {standard }}$ for carbon is of marine fossils of the Pee Dee Belemnite.

Sample processing was done by drying at $65{ }^{\circ} \mathrm{C}$ to constant weight, grinding the samples to a fine powder, and combusting 2-3 mg subsamples in an elemental analyzer (Carlo Erba) coupled to an isotope ratio mass spectrometer (IRMS Delta Plus, Finnigan Mat, San Jose, CA, USA) operating in the continuous flow mode at Southeast Environmental Research Center stable isotope laboratory, Florida International University, Miami, USA .

\subsubsection{Data Analysis}

We used a linear mixed model to partition the variance in stomatal traits and leaf

$\delta^{13} \mathrm{C}$ among the following levels: across sites, among trees within a site, and among leaves within a tree. Mixed models that specified this nested structure were fitted using the 'varcomp" function in 'nlme' library of R (R Developement Core Team 2015) with restricted maximum likelihood estimation. The code used in $\mathrm{R}$ to calculate the variance partitioning of the stomatal density trait across the nested scales for the full model was:

$$
\begin{aligned}
& \text { Varcomp.SD<- varcomp(lme(stomatal density } 1, \quad \text { random= } 1 \mid \text { Site/Tree/Leaf, } \\
& \text { na.action }=\text { na.omit })
\end{aligned}
$$

The same model was applied to stomatal size and leaf $\delta^{13} \mathrm{C}$. The variance attributable to each hierarchical level was expressed as a percentage of the total variance. We also plotted and calculated the linear correlations between stomatal traits and leaf $\delta^{13} \mathrm{C}$.

Multiple regression analysis was used to observe stomatal trait response to environmental variables (ground elevation and ground water salinity). Environment variables were log-transformed before analyses to make normal distribution, while 
stomatal density and stomatal length were normally distributed and used as response variables in multivariate analyses without transformation.

\subsection{Results}

\subsubsection{Variation in environmental variables across sites}

Environmental variables (ground elevation, distance to water table, soil depth, and GWS) varied across sites (Table 12). Ground water salinity ranged from (2 to $24 \%$ ), maximum in Key Largo site (23.44\%, KL3) and followed by Lignumvitae Key $(20.42 \%$, LV1), while lowest in Sugarloaf Key (2.78\%, SL2). Similarly, distance to water ranged from $38 \mathrm{~cm}$ (SL1) to $328 \mathrm{~cm}$ (KL3), and ground elevation ranged from $66 \mathrm{~cm}$ in Sugarloaf Key (SL1) to $379 \mathrm{~cm}$ in Key Largo (KL3). Mean soil depth across sites ranged from $10 \mathrm{~cm}$ to $21 \mathrm{~cm}$ (Table 12).

\subsubsection{Variance Partitioning in leaf traits}

Results of the decomposition of the total variance in stomatal density, stomatal size, and leaf $\delta^{13} \mathrm{C}$ among the hierarchical levels are shown in Table 13. For stomatal density, the proportion of the total variance was well distributed across the three scales, with the highest proportion at the site level $(41 \%)$ and the lowest percentage at the leaf level $(21 \%)$. However, the bulk of the variation in both stomatal size and leaf $\delta^{13} \mathrm{C}$ was found at the leaf level (61\% and $76 \%$, respectively), while variation at tree and site levels was very low (12\% and 9\%, respectively).

\subsubsection{Relationships among leaf traits}

Stomatal density ranged from 350 to $1017 \mathrm{~mm}^{-2}$, and stomatal size ranged from 14 to $32 \mu \mathrm{m}$. Despite considerable variation within sites, stomatal density exhibited an 
inverse relationship (negatively correlation) with stomatal length at the site level $(r=-$ $0.64, \mathrm{p}<0.05$, Figure 23).

Leaf $\delta^{13} \mathrm{C}$ ranged from (-33.13 to -25.12$)$. Leaves in three upper Keys sites, underlain by brackish groundwater, were most enriched in the heavy carbon isotope (high $\delta^{13} \mathrm{C}$ ), indicating relatively high stress; in turn, lower Keys sites with fresher groundwater showed more depleted carbon signatures. Leaf $\delta^{13} \mathrm{C}$ was positively correlated with stomatal density $(\mathrm{r}=0.61, \mathrm{p}=0.02$; Figure 24$)$.

\subsubsection{Stomatal traits and environmental variables}

Multiple regression analyses were used to exhibit how stomatal traits co-vary with ground elevation and ground water salinity (Table 14). A significant interaction between elevation and GWS was observed for both response variables (stomatal density and length). Furthermore, a significant linear relationship between stomtal traits was observed with GWS but no significant linear pattern was observed for ground elevation for both stomatal traits (Table 14). Stomatal density was observed higher at very low elevation. The density decreased in the middle, but slowly increased with increase in elevation (Figure 25). While stomatal density linearly increased with ground water salinity. Similarly, stomatal length linearly decreased with increase in GWS, while it was higher at low elevation and slowly increased and again decreased at very high elevations, a hump-shaped pattern was observed (Figure 26). 


\subsection{Discussion}

\subsubsection{Stomatal trait partitioning across scales}

Variance in leaf traits was observed at all levels, suggesting that processes operating at all three scales are important in determining trait values. Site level variation might arise from adaptations to environmental differences across the study area. Dry tropical forests in the Florida Keys are water-limited ecosystems in which trees go through a long (usually more than five months) dry period each year. Sites vary in freshwater availability, depending on factors such as soil depth, geographical location, proximity to the water table, and ground water salinity (Table 12). The conceptual models presented in Figure 20 and Figure 21 outline our expectations if trait variation is driven primarily by broad differences among sites in three environmental characteristics (soil depth, elevation, and GWS). Depending on their strength, sources of among- and within-tree variation are likely to obscure these relationships.

Though we attempted to minimize this source of variation by sampling fully developed and healthy leaves from the upper canopy (dark green with no visible damages as a result of herbivory or disease), a large amount of trait variation was observed at leaf level for all three traits $(>21 \%$, Table 13$)$. The origin of trait variation at the leaf level may be biological or physical. In the first category, the phenomenon of apical dominance arises out of interference competition. The apical meristem produces auxin, a growth substance that diffuses downward through tissue and inhibits the growth of lateral meristems. During branching, the apical meristems of a plant compete with one another for resources (light, water, nutrients, Keddy 2001). Height growth in fast-growing trees such as B. simaruba may be effectuated by a few meristems, which suppress the 
development and elongation of lateral shoots. Therefore, variation in leaf traits within a tree might be expressions of internal competition between branches for limited resources. Likewise, all portions of the crown do not experience the same environment, especially with respect to access to sunlight. Branch shading within a crown is likely to create asymmetric within-canopy competition for resources between individual branches. In addition, leaves of tall trees like $B$. simaruba are susceptible to occasional airborne small doses of salt spray brought by wind and wave activities in coastal environments, and salt deposition may be unevenly distributed within the canopy. The effect of salt spray is even more pronounced where water availability is limited (Griffiths \& Orians 2003), as it is in the Florida Keys' forests. Salt deposition on leaves during and/or after leaf development may create physiological stress, and contribute to variation in leaf structure or function.

Our analysis of variance partitioning suggests that the leaf traits we examined in B. simaruba differed in their responses to short-term or fine-scale environmental variation; the overwhelming concentration of variance in stomatal size and $\delta^{13} \mathrm{C}$ at the leaf level contrasted sharply with the large proportion of variance in stomatal density found at the site level. Variation in stomatal traits among trees within a site, and among leaves within a tree is likely to be affected by both environmental and biological factors. Within-site variability in plant traits may result from microtopographic differences. In Florida Keys' dry tropical forests, physical and chemical erosion has produced a rough karst surface characterized by peaks and valleys that can vary by decimeters to meters over very short distances. On well-drained sites in the lower Keys, trees at lower elevations may be favored by better access to fresh groundwater than those on higher ground. Biological factors such as neighbor effects are also likely to come into play at 
this level, as a result of competition among trees for resources in limited supply (water, light, nutrients). Similarly, within-site variation may also occur because of genetic variation among the individual trees. B. simaruba seeds are generally dispersed by birds, which are likely to disperse fruits to nearby islands, resulting in mixing of the seedling pool, while allowing for genetic segregation among distant population clusters may point to differences in plasticity among traits (Franks, Weber \& Aitken 2014). The large proportion of variance in stomatal density among populations at the site level may indicate that variation in this trait may result from a long-time selective pressure in environments with different water availability (Dunlap \& Stettler 2001; Abbruzzese et al. 2009), and therefore might comprise adaptive responses to persistent differences in freshwater availability across sites. In contrast, variation in stomatal size and leaf $\delta^{13} \mathrm{C}$ may be reflective of plastic responses to microenvironment. For instance, leaf $\delta^{13} \mathrm{C}$ is considered a short-term response to the current environment, as it carries a temporally integrated signature of foliar photosynthesis and stomatal conductance (McDowell et al. 2011). Similarly, in a shade-house experiment, Aasamaa et al. (2001) observed significant changes in stomatal length of tree species subjected to water stress over short periods, while stomatal density varied only slightly among the same trees. Therefore, changes in stomatal size and leaf $\delta^{13} \mathrm{C}$ in $B$. simaruba seem to be short-term plastic responses to changes in microenvironment expected at the tree or leaf levels, while changes in stomatal density might be in response to relatively long-term or macro-scale environmental changes (Schoch, Zinsou \& Sibi 1984; Casson et al. 2009; Haworth, Elliott-Kingston \& McElwain 2011). 


\subsubsection{Stomatal traits and plant stress}

The relationship between stomatal size and density is mainly determined by two factors: ontogenetic process and leaf size (Beerling \& Chaloner 1993). Stomatal density may be affected by ontogenetic process causing cell expansion or shrinkage during leaf development stages (Ceulemans, Praet \& Jiang 1995). For instance, increases in leaf size with increasing moisture and/or nutrient availability (Cunningham, Summerhayes \& Westoby 1999; Fonseca et al. 2000) may cause decreases in stomatal density because of increases in the size of both epidermal and stomatal guard cells. In contrast, drought and high irradiance can reduce leaf area (Lee et al. 2000; Schurr et al. 2000), causing stomata to be packed more densely. Therefore, a high stomatal density could be the outcome of either the formation of a larger number of stomatal cells in the epidermis during leaf development, or of the failure of the leaf to expand fully, leaving a fixed number of stomates within a smaller leaf. Alternatively, low stomatal density might be the result of rapid cell growth, which would increase the distance between stomates and decrease their density, or a product of low stomate formation. In present study, total leaf size was not measured on the same leaves analyzed for stomatal traits. However, in a parallel study at the same sites, leaf area on 3-5 leaves from 1-3 B. simaruba trees per plot were measured (Subedi unpublished manuscript), and no significant difference in leaf size was observed among sites $(\mathrm{p}=0.54)$. It suggests that the inverse relationship between stomatal density and size found in the present study may not be a result of shrinkage of the leaves, and is more likely the result of an ontogenetic process.

The inverse relationship between stomatal density and stomatal size is generally explained as a coordinated response to management of stomatal conductance and 
transpiration under stressful conditions (Gindel 1969; Franks \& Farquhar 2001; Uprety et al. 2002; Sternberg \& Manganiello 2014). To explain the inverse relationship between stomtal density and size, we proposed two opposing patterns in our study species based on contrasting views (Figure 21A and B). Our results more closely matched the second hypothesis (Figure 21B), as we observed a positive correlation between leaf $\delta^{13} \mathrm{C}$ and stomatal density (Figure 24). The rationale often proposed for such results is that plants with large stomates are less proficient at regulating stomatal closure and opening, and hence respond poorly to drought (Aasamaa, Sõber \& Rahi 2001; Hetherington \& Woodward 2003; Drake, Froend \& Franks 2013), while being well suited for more favorable moisture conditions (Hetherington and Woodward, 2003). Further support for this view may be drawn from observations of stomatal density increase with ground elevation and ground water salinity (Figure 25). As we expected, slight variation in elevation in trees' position might have significantly influenced the availability of freshwater in Florida Keys. Observed higher stomatal density and lower stomatal size in trees located at lower elevations might have more access to the groundwater because of their proximity to the water table, when ground water is fresher. High stomatal density and low stomatal size with increase in elevation and ground water salinity might be associated with an increase in drought stress. Studies reporting contrasting results (Figure 21A) were mostly on the basis of comparisons among species or functional groups (Woodward \& Kelley 1995; Franks et al. 2009; Barbieri et al. 2012; Orsini et al. 2012; Sternberg \& Manganiello 2014), rather than within individual species. For instance, salttolerant species mangroves were reported to have fewer and larger stomates than freshwater species (Sternberg \& Manganiello 2014) which could be the result of 
evolutionary specialization to a consistently stressful environment. Studies have shown that species specialized in less favorable environments often lack plasticity (e.g., Valladares et al. 2000a). Therefore, a wide variation in stomatal traits across the habitat gradient is likely to be the result of adaptive plasticity across the heterogeneous environments.

B. simaruba, the subject of our investigation, is a freshwater species with a wide geographical distribution across the environmental gradient, but possibly with limited ability to tolerate salt stress, as observed in other hammock species (Sternberg \& Swart 1987). It is a tall canopy tree, often reaching $15 \mathrm{~m}$, with high growth rate, very low wood density $\left(0.30 \mathrm{gcm}^{-3}\right)$, and high specific leaf area $\left(300 \mathrm{~cm}^{2} \mathrm{~g}^{-1}\right)$. Though trees growing on surfaces in close proximity to brackish groundwater did exhibit some evidence of hydraulic stress, in a parallel study at the same sites showed a non- significant structural differences (height, crown dimensions, diameter at breast height, leaf area) among $B$. simaruba populations (Subedi et al. unpublished manuscript). Therefore, regardless of any habitat differences that might affect resource availability, all sampled populations had sufficient hydraulic and stomatal conductance to enable the good supply of water and $\mathrm{CO}_{2}$ needed for growth. Canopy species in dry habitats are known to be opportunistic, capable of high stomatal conductance and photosynthetic capacity that enables rapid growth during short periods of water availability (Hetherington \& Woodward 2003). $\delta^{13} \mathrm{C}$ can be used as an indirect measure of water use efficiency and stomatal conductance during drought stress (Hultine \& Marshall 2000; Franks et al. 2009), a positive correlation between leaf $\delta^{13} \mathrm{C}$ and stomatal density may signify that one effect of physiological drought is an increase in stomatal density in $B$. simaruba leaves. It seems 
that a trade-off between many and small stomates in stressful environments, and large and few stomates in less stressful environments may be a strategy pertinent to rapidly growth canopy species across the environmental gradient. Small stomates have the ability to open and close rapidly, and their association with high stomatal density may provide the capacity for rapid increases in the stomatal conductance of a leaf during favorable conditions (Hetherington \& Woodward 2003).

\subsection{Conclusions}

Results suggest that stomatal characteristics may be viewed as adaptive traits that play an important role in water relations for B. simaruba populations. The observed variation in stomatal size and density in B. simaruba individuals could determine the capacity of the trees to adapt to various levels of physiological stress. Stomatal density and size of B.simaruba trees may change with the level of physiological stress, as expected in plants with the capacity for phenotypic plasticity in heterogeneous environments (Valladares, Gianoli \& Gómez 2007). The present study suggests that B.simaruba has the ability to alter its stomatal traits in response to environmental changes, as a result of plasticity under drought conditions. Production of the combination of small and densely distributed stomates seems to represent a strategy that allows $B$. simaruba to conserve water under conditions of periodic physiological drought by maintaining stomatal control. This variability may be called upon as the coastal forests that it inhabits are exposed to the higher salinity and locally droughty conditions that will accompany global warming and sea-level rise. Furthermore, repeating this analytical 
approach on individuals subjected to serial changes in drought intensity may confirm this pattern.

\section{Acknowledgements}

The authors thank to Leah Ramnath for her help during the field and laboratory work. The authors also thank to Dr. Jennifer Richards for important insight at the beginning of the project, and for providing lab facilities. I am also thankful for graduate student research project funded from the International Center for Tropical Botany (ICTB). Thanks for co-authors (Michael S Ross, Rosario Vidales, Jay P Sah, Leonel Sternberg), and Dr. Jed Redwine for their reviews and suggestions. This is contribution \#XXX from the Southeast Environmental Research Center. 
Table 12 Environmental variation across sites.

Sites with mean ground water salinity (GWS), ground elevation, and soil depth. Site ID's: KL = Key Largo, LV = Lignumvitae Key, BPK = Big Pine Key, SL = Sugarloaf Key.

\begin{tabular}{|l|r|r|r|r|}
\hline Site & GWS (\%) & \multicolumn{2}{|l|}{ Distance to water } & \multicolumn{2}{l|}{ Elevation } & Soil depth (cm) \\
\hline KL1 & 3.80 & 47.29 & 69.71 & 12 \\
\hline KL2 & 15.25 & 121.26 & 156.48 & 10 \\
\hline KL3 & 23.44 & 328.46 & 379.54 & 10.2 \\
\hline LV1 & 20.42 & 258.48 & 291.27 & 10.3 \\
\hline LV2 & 13.83 & 49.07 & 73.62 & 12.7 \\
\hline SL1 & 9.81 & 38.23 & 66.1 & 15.2 \\
\hline SL2 & 2.78 & & & \\
\hline BPK & 4.65 & 59.81 & 78.60 & 15.3 \\
\hline
\end{tabular}


Table 13 Decomposition of the total variation in stomatal density, stomatal length, and leaf $\delta^{13} \mathrm{C}$ traits across three hierarchical levels (site, tree, and leaf)

\begin{tabular}{|l|l|l|l|}
\hline Groups & Stomatal density $(\%)$ & Stomatal size $(\%)$ & Leaf $\delta 13 \mathrm{C}(\%)$ \\
\hline Site & 41 & 12 & \\
\hline Tree & 30 & 17 & 9 \\
\hline Leaf & 23 & 61 & 5 \\
\hline Residual & 6 & 10 & 76 \\
\hline
\end{tabular}


Table 14 Multiple regression analyses results.

Table 14 showing multiple regression analyses results esponse variables (stomatal density and length) and independent variables as ground water salinity (GWS) and elevation and their interaction (Elevation $*$ GWS ).

\begin{tabular}{|c|c|c|c|}
\hline $\begin{array}{c}\text { Response } \\
\text { variable }\end{array}$ & Predictors & $r^{2}$ & $\mathrm{p}$-value \\
\hline \multirow{5}{*}{$\begin{array}{l}\text { Stomatal } \\
\text { density }\end{array}$} & $\begin{array}{l}\text { Log Elevation + Log GWS+ Elevation* } \\
\text { GWS }\end{array}$ & 0.58 & $<0.001$ \\
\hline & Log Elevation + Log GWS & 0.37 & $<0.01$ \\
\hline & Log Elevation & 0.07 & ns \\
\hline & Log GWS & 0.36 & $<0.001$ \\
\hline & Log Elevation* Log GWS & 0.39 & $<0.01$ \\
\hline \multirow{5}{*}{$\begin{array}{l}\text { Stomatal } \\
\text { length }\end{array}$} & $\begin{array}{l}\text { Log Elevation + Log GWS+ Elevation* } \\
\text { GWS }\end{array}$ & 0.60 & $<0.01$ \\
\hline & Log Elevation + Log GWS & 0.27 & $<0.05$ \\
\hline & Log Elevation & 0.09 & $\mathrm{~ns}$ \\
\hline & Log GWS & 0.26 & $<0.01$ \\
\hline & Elevation* GWS & 0.33 & $<0.05$ \\
\hline
\end{tabular}




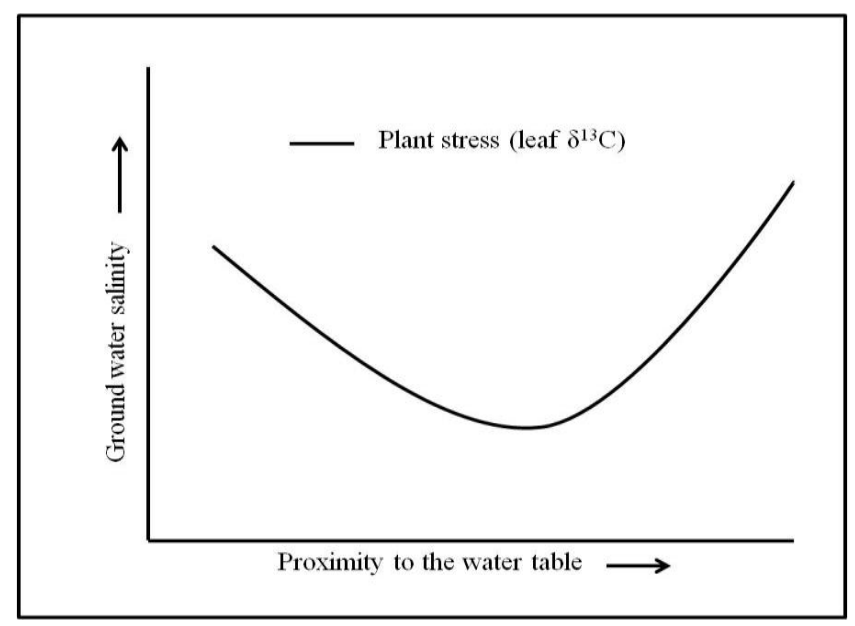

Figure 20 Plant stress in response to distance from the ground water table and salinity
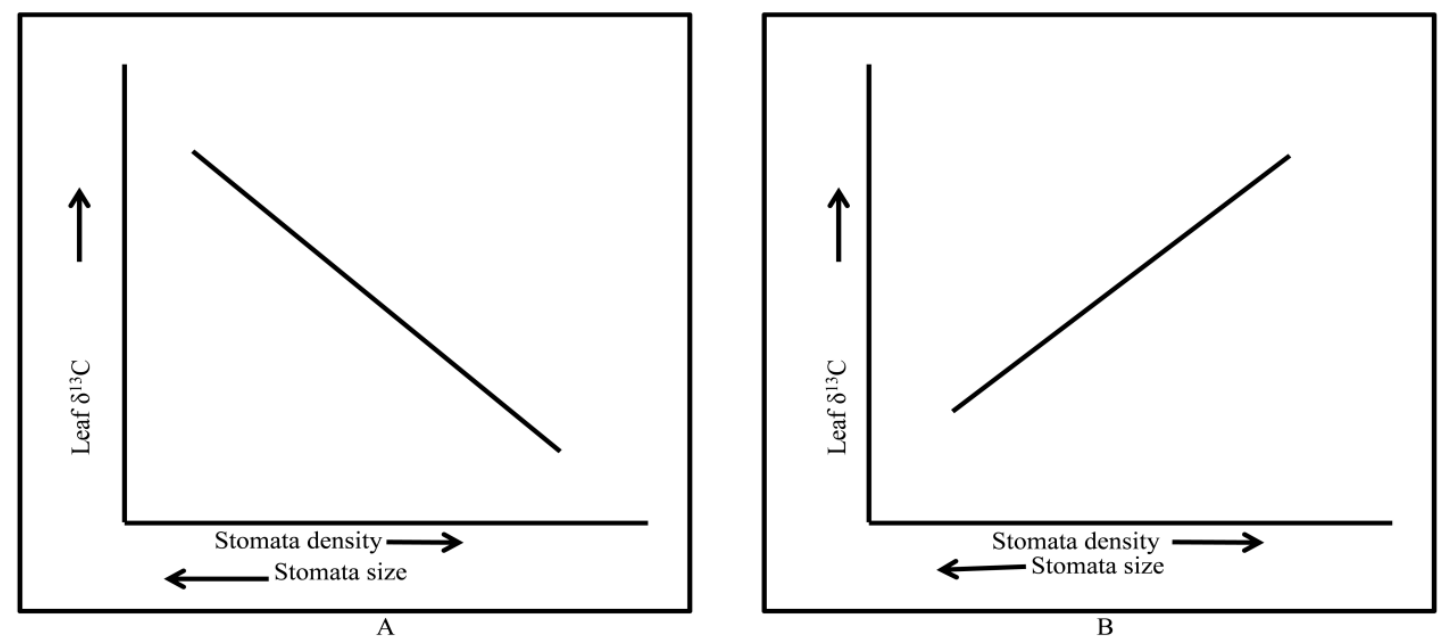

Figure 21 Hypothesized two alternative models in response to plant stress

A) stomatal density decreases with increase in stress $\left(\delta^{13} \mathrm{C}\right)$, B) stomatal density increases with increase in $\delta^{13} \mathrm{C}$. 


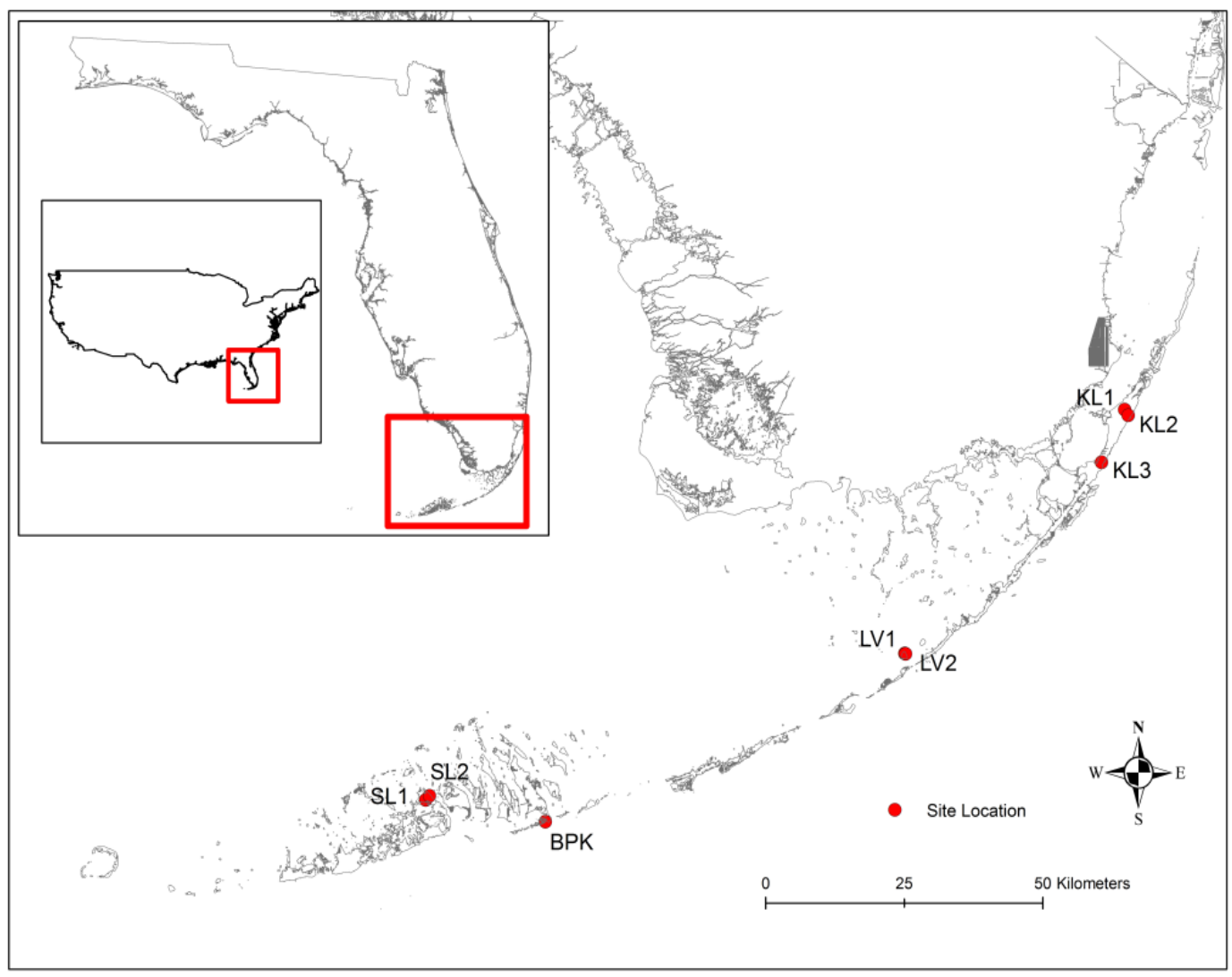

Figure 22 Map showing study locations. 


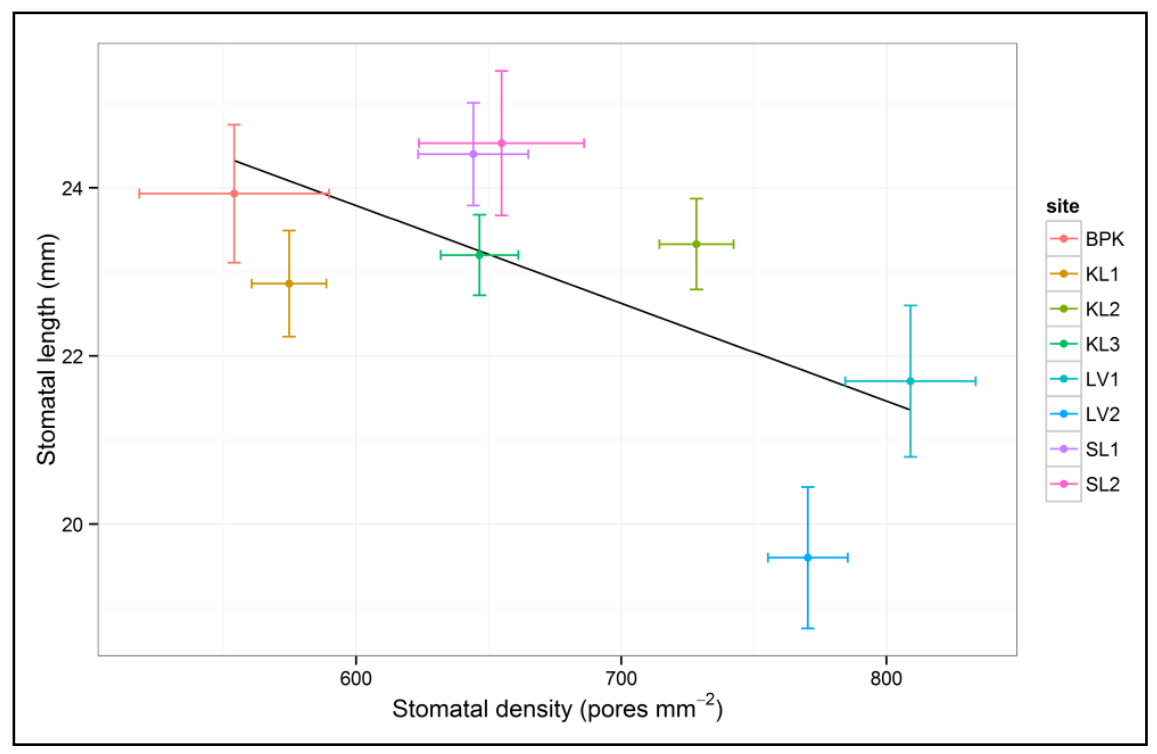

Figure 23 Relationship between stomatal density and stomatal length at site level.

The regression line is fit to site level means. Error bars represent standard errors of mean $(n=15$ for each site).

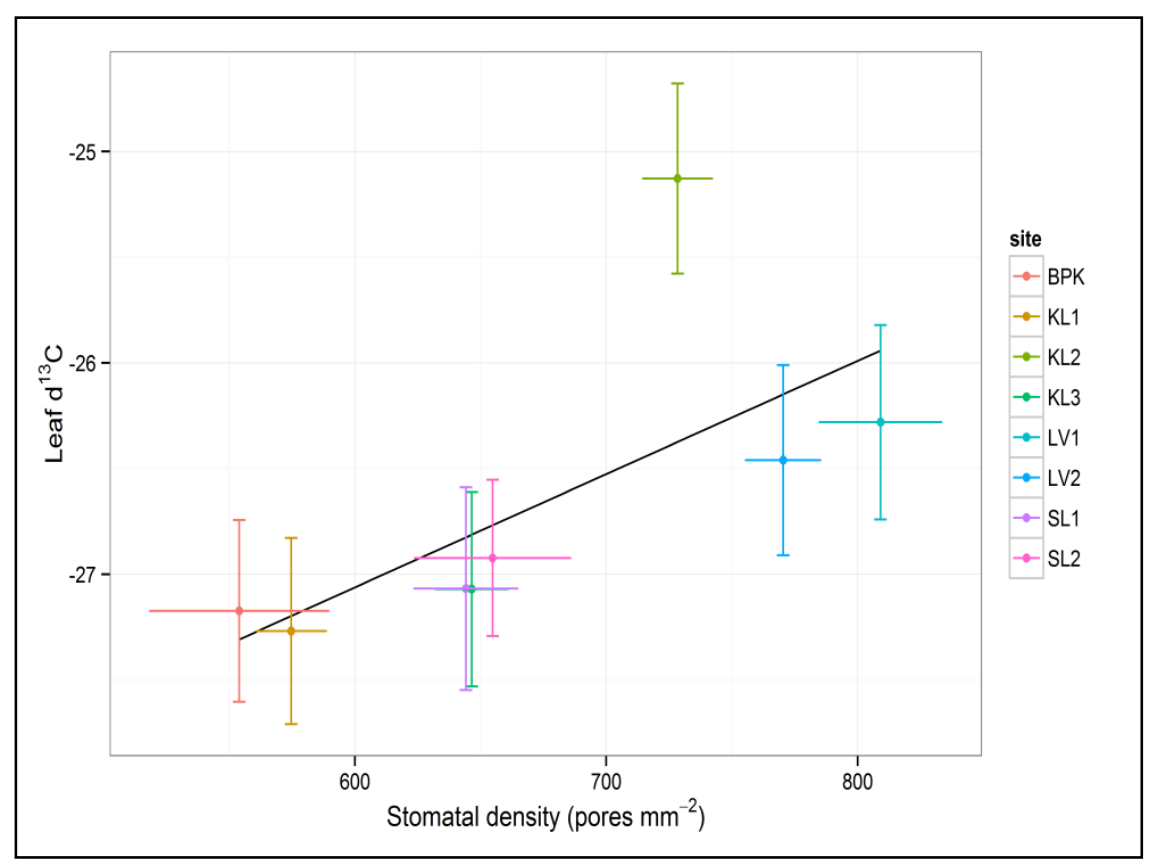

Figure 24 Relationship between stomatal density and leaf $\delta^{13} \mathrm{C}$.

The regression line is fit to site level means. Error bars represent standard errors of mean $(n=15$ for each site). 


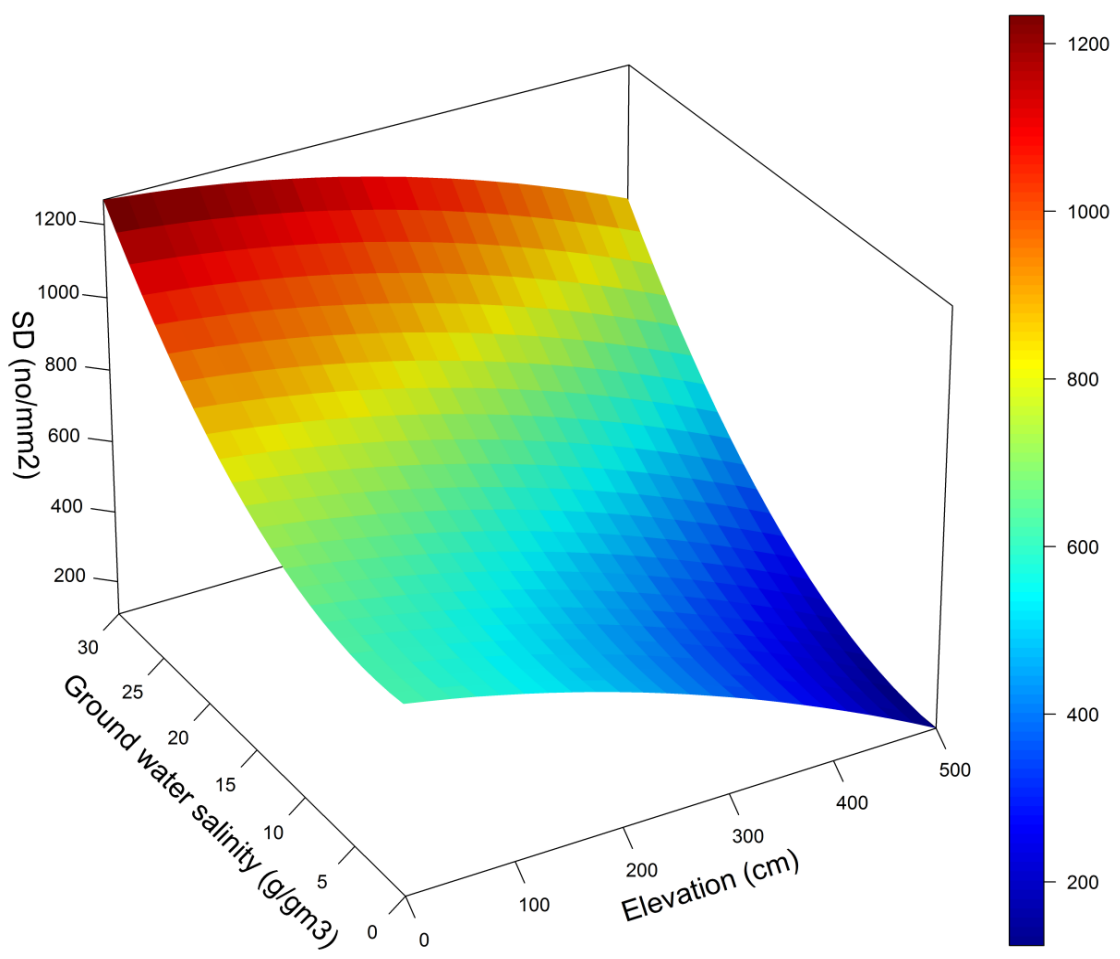

Figure 25 Surface plot showing stomatal density co-variation with GWS and elevation

Figure showing a 3-D surface plot resulted from quadric fit by using multiple regression showing stomatal density (SD, no $\mathrm{mm}^{-2}$ ) as a function of ground elevation (Elevation) and ground water salinity (GWS). 


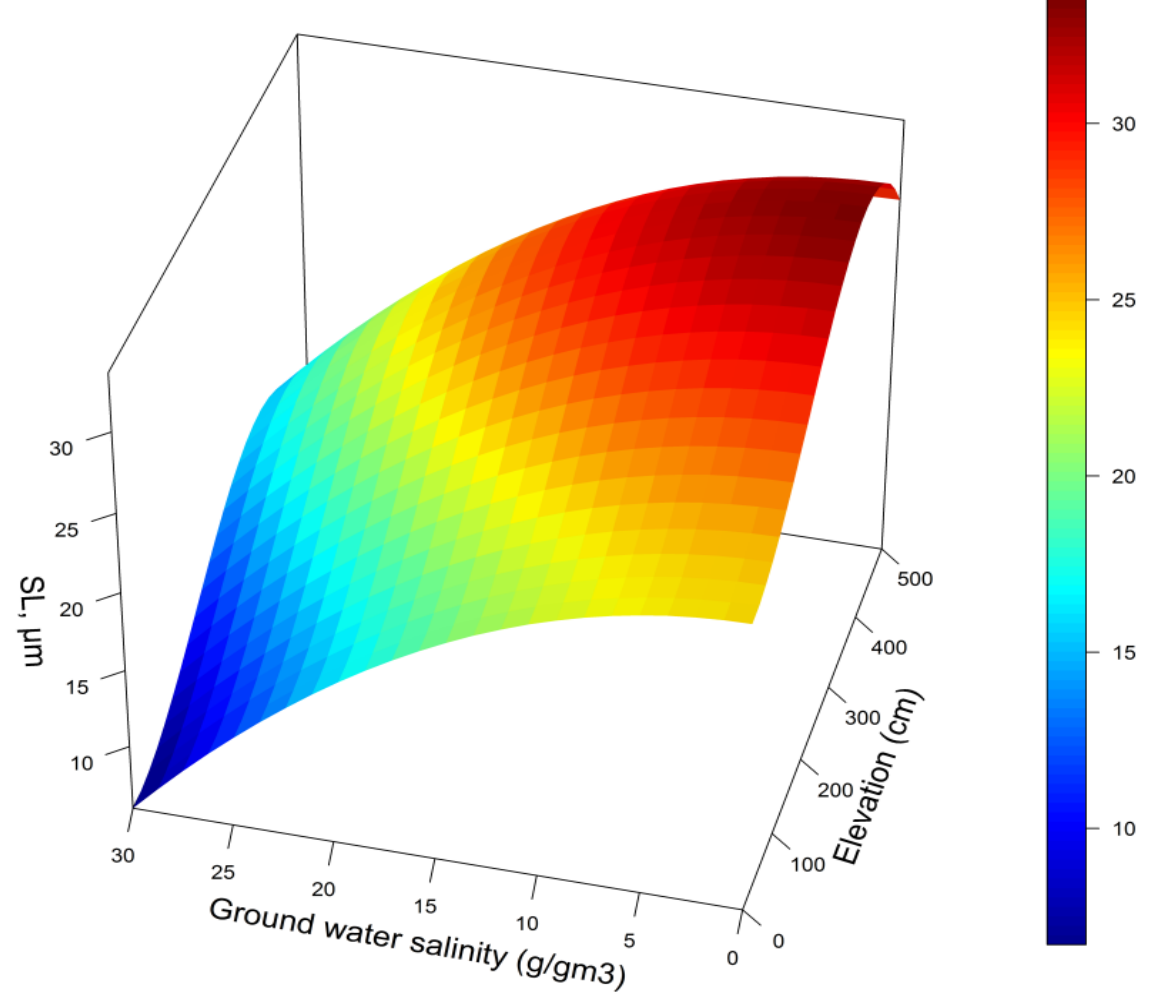

Figure 26 3-D surface plot showing stomatal length co-variation with GWS and elevation Figure showing 3-D surface plot resulted from quadric fit by using multiple regression showing stomatal length (SL, $\mu \mathrm{m})$ as a function of ground elevation (Elevation) and ground water salinity (GWS). 


\section{CHAPTER 5}

\section{SYNTHESIS}

This dissertation provides an investigation into the predominant patterns of trait variation across south Florida and Florida Keys hardwood hammock communities. The present work is focused on the role of plant functional traits in community assembly and structure. In this study of the environment-species-trait relationship, I find four main results, discussed in brief below.

First, there are significant, deterministic community assembly rules that influence the hardwood hammock forest community. Both local and regional processes influence the filtering of species from the regional species pool into local communities. The shifts in trait values across the habitat gradient appear to indicate that variation in individual physiology and morphology allow individuals to better respond to differing external filters. For most traits and sub-regions, the external filtering process functions on the level of individuals instead of species. Individuals with traits matching the local community are successful in establishing under a community's external filters. I observed a significant change in community weighted mean trait values across the environmental gradient, from fertile sites with high nutrient and moisture availability to dry and highly isolated resource-limited environments in coastal and pineland hammocks. The strong shift in community traits along the environmental gradient is linked to alternative strategies, from resource-acquisitive characteristics such as large maximum height, low wood density, and high specific leaf area on the one hand, to short canopies, high wood density, and low specific leaf area, suggesting a strategy of long-term investments in leaves and wood. 
Second, community assembly rules differ between young (habitat filtering) vs mature hammock (competition, trait differentiation) forests. Shifts in community weighted trait means across the successional gradient suggests that the axes on which species are differentiated also shift with the abiotic and biotic environment during the process of succession. The age of communities influences species filtering, indicating that community assembly and the relative importance of different filters change in successional time. Young forests are shaped by environmentally driven processes, while mature communities were shaped by competitively driven processes.

Third, my work shows that trends in trait variation across the environment are the result of both intra- and inter-specific variation within a community, with intra-specific shifts playing a key role for a few traits, particularly leaf nutrient traits: TN, TP, and $\delta^{13} \mathrm{C}$. My study is the first to combine measures of both intra- and inter-specific trait variation within plots across the habitat gradient represented by coastal, pineland, and marsh matrices that surround south Florida hammocks. Though understanding of how both intra- and inter-specific variation change over environmental gradients is currently limited, my findings showed that trait variation at both levels influence community assembly patterns at regional and local scales.

Fourth, the pairing of small and densely distributed stomates seems to represent a strategy that allows DTF species, represented here by B. simaruba, to conserve water under physiological drought. Trees in coastal areas may exhibit specialization or plasticity in coping with drought by changes in their stomatal morphology or activity, allowing for a balance between gas exchange and water loss in a periodically stressful environment. Species in hardwood hammocks might have the ability to modulate 
physiological response to environmental change, by altering the size and number of their stomates in response to a wide range of physical stresses, including flooding, drought, and salt water. Plasticity in stomatal architecture seems to represent a strategy that allows local species to conserve water under conditions of periodic physiological drought.

\subsection{Significance of the work}

The hardwood hammock community is a forest ecosystem that, in the United States, occurs only in extreme south Florida. Hardwood hammock is a rare forest type which is characterized by high plant diversity of trees and shrubs of West Indian origin. In the Florida Keys, hardwood hammocks provide important habitat for many federallylisted and state-listed endangered plants and animals (USFWS 1999). Hardwood hammock functions are involved in physical, chemical and biological processes that sustain the whole Everglades ecosystem. Examples of hammock function include provision of habitat for different animal species (biotic), and a nutrient sink that permits the oligotrophic characteristic of most other Everglades plant communities to be maintained (Ross et al. 2006; Wetzel et al. 2009). These forests are under intense development pressure, particularly because of their presence on high elevation sites that are relatively safe from flooding. While several studies have focused on the ecology of plant species in these forests, none have attempted to identify mechanisms of community assembly, which are extremely important if the remaining forest habitat is to be conserved by (Feeley 2003; Mouillot et al. 2005a).

Trait-based community assembly rules allow a more insightful interpretation of shifts in species composition and functions along the environmental gradient. This 
understanding helps to address several fundamental issues in community ecology, including questions about the degree to which community patterns reflect abiotic and biotic interactions, driven by resource limitation and competition, respectively. My work can contribute to the identification of community/species' traits that can serve as reliable indicators of alterations of environment quality. Thereby they can contribute towards timely actions aimed at preserving the habitat function and biodiversity.

The functional-trait approach promises a better prospect to understand the filtering process across hierarchical levels. The global changes expected to occur in the next century will possibly modify environmental filters at all scales, including climate, disturbance regime and biotic interactions (Díaz, Hector \& Wardle 2009). Given a certain scenario of future climatic conditions, and assuming consistent trait-environment linkages, the present distribution of plant traits in space, particularly along the south Florida stress-productivity gradient, may be used a proxy for changes in time. Since plant traits are found to strongly influence ecosystem functioning (Diaz et al. 2004), this study may be also seen as a first step towards a trait-based prediction of fundamental community and ecosystem processes in this region, applicable at a range of spatial and temporal scales. Similarly, variability observed at hierarchical scales may soon be called upon, as the coastal settings that hardwood hammocks inhabit are exposed to the higher salinity and locally droughty conditions that will accompany global warming and sealevel rise. My study supports the notion that understanding species co-existence requires knowledge of the individual level of trait variability. Furthermore, both abiotic stress and biotic interactions together appear to drive changes in community functional composition. 
An additional benefit of the study is the contribution of plant trait data for South Florida to global data systems. Filling this information gap will aid in placing the region's vegetation within a broader context. This work also creates a foundation for future experimental work. Connecting my analyses of shifts in species traits and community composition to mechanistic thinking on how plant communities are constructed, function, and interact will aid in many ways for forest management.

\subsection{Potential future Research}

The dissertation concludes by offering thoughts on the most pressing and instructive directions for future study of hardwood hammock forests in South Florida.

My analyses include four different sub-regions within a landscape that differs in a number of ways, including regionally variable environmental factors such as rainfall, freshwater availability, and soil qualities. Future studies are needed to relate traits to direct measurement of local environmental variables, especially from the Long Pine Key area which are missing from this study, in order to disentangle the effects of potentially confounding abiotic and biotic factors (Körner 2007; Malhi et al. 2010).

Below ground traits have barely been studied, let alone how those traits might figure into DTF community responses to anthropogenic impacts or restorative actions. When only above-ground traits are accounted for, conclusions about variation in ecological strategies for woody species in South Florida are limited, and how belowground strategies differ across spatial scales, life forms or taxa could not inferred. Findings from leaf nutrient analysis in this study showed extraordinary variation in leaf nutrient concentrations at the individual level (chapter 4), i.e., between trees of the same 
species within the same community; this variability may be part of a strategy that also involves below-ground traits that affect the degree of nutrient limitation, e.g., fine root production, mycorrhizal association, root branching, or root diameter, etc. (Laliberté 2017). Therefore, extending the work I've reported to include below ground traits will certainly help to further understanding of community assembly patterns across various habitat gradients.

To more strongly link traits to plant fitness, testing for abiotic and biotic filters through a trait-based approach should be expanded to include experimental and demographic analyses (Cornwell \& Ackerly 2009; Hillerislambers et al. 2012).

Plant invasions are a serious threat to natural and managed ecosystems in south Florida and worldwide. The number of species involved and the extent of existing invasions renders the problem virtually intractable, and it is likely to worsen as more species are introduced to new habitats and more invaders move into a phase of rapid spread. Compared to non-invasive species, invasive plants generally have higher values for performance-related traits characterizing physiology, leaf-area allocation, shoot allocation, growth rate, size and fitness (Van Kleunen, Weber \& Fischer 2010). Although only a handful of invasive non-native individuals were found in a few sites in my study, perhaps because my network of sites was in remote areas far from human disturbances, hardwood hammock communities in south Florida suffer from a high invasion rate by a range of tropical ornamental and agricultural plants. One factor affecting the vulnerability of hammocks is a result of highly-disturbed hydrologies, brought about by water management (Brooks, Lockwood \& Jordan 2013). Hammocks present in disturbed areas are severely invaded from invasive plant species such as Brazilian Pepper (Schinus 
terebinthifolius), Australian pine (Casuarina equisetifolia), Melaleuca (Melaleuca quinquenervia), and Lygodium microphyllum (a vine) which are gradually approaching remote and pristine areas where their presence is still very low. Thus, it is important to study whether different traits favor invasion in different habitat types, for instance urban areas, pinelands, marsh, and coastal environments, or are effective in undisturbed natural habitats or highly disturbed anthropogenic habitats. Future studies need to explicitly address whether traits associated with invasiveness differ among habitat types. In addition, study of seedling growth rates of invasive tree species and native tree species under different conditions might increase our understanding of the traits that are consistently associated with invasiveness, and under which conditions they can be more successful in replacing native species.

Studies carefully designed to examine how traits vary over time, space, and phylogeny would tell us a great deal about the ecological and evolutionary importance of traits and help us build a more predictive framework of principles and models. Species traits offer a potentially powerful lens for understanding outcomes of biotic interactions, across a broad spectrum of abiotic contexts. As discussed in this study, there is concrete evidence that environmental habitat filtering and limiting similarity are the two dominant processes that underlie community assembly. However, the contemporary interpretation of habitat filtering and competition in community ecology also relies on the use of phylogenetic clustering (trait similarity) and phylogenetic over-dispersion (trait differentiation, Webb et al. 2002; Willis et al. 2010). The prevalence of one assembly pattern over the other in a community therefore may also depend on the evolutionary conservatism or convergence among ecologically relevant traits (Cavender-Bares et al. 
2004a). Therefore, future work needs to explore if the reflection of one assembly pattern over the other in a community depends on evolutionary conservatism or convergence among ecologically relevant traits, using community phylogenetics across various subregions, or even the whole South Florida region. 


\section{LIST OF REFERENCES}

Aasamaa, K., Sõber, A. \& Rahi, M. (2001) Leaf anatomical characteristics associated with shoot hydraulic conductance, stomatal conductance and stomatal sensitivity to changes of leaf water status in temperate deciduous trees. Functional Plant Biology, 28, 765-774.

Abbruzzese, G., Beritognolo, I., Muleo, R., Piazzai, M., Sabatti, M., Scarascia Mugnozza, G. \& Kuzminsky, E. (2009) Leaf morphological plasticity and stomatal conductance in three Populus alba L. genotypes subjected to salt stress. Environmental and Experimental Botany, 66, 381-388.

Ackerly, D. (2004) Functional strategies of chaparral shrubs in relation to seasonal water deficit and disturbance. Ecological Monographs, 74, 25-44.

Adler, P.B., Fajardo, A., Kleinhesselink, A.R. \& Kraft, N.J.B. (2013) Trait- based tests of coexistence mechanisms. Ecology Letters, 16, 1294-1306.

Agrawal, A.A. (2001) Phenotypic plasticity in the interactions and evolution of species. Science (New York, N.Y.), 294, 321-326.

Aiba, M., Katabuchi, M., Takafumi, H., Matsuzaki, S.I.S., Sasaki, T. \& Hiura, T. (2013) Robustness of trait distribution metrics for community assembly studies under the uncertainties of assembly processes. Ecology, 94, 2873-2885.

Albert, C.H., Thuiller, W., Yoccoz, N.G., Soudant, A., Boucher, F., Saccone, P. \& Lavorel, S. (2010) Intraspecific functional variability: Extent, structure and sources of variation. Journal of Ecology, 98, 604-613.

Anderson, M.J., Crist, T.O., Chase, J.M., Vellend, M., Inouye, B.D., Freestone, A.L., Sanders, N.J., Cornell, H. V., Comita, L.S., Davies, K.F., Harrison, S.P., Kraft, N.J.B., Stegen, J.C. \& Swenson, N.G. (2011) Navigating the multiple meanings of?? diversity: A roadmap for the practicing ecologist. Ecology Letters, 14, 19-28.

Le Bagousse-Pinguet, Y., De Bello, F., Vandewalle, M., Leps, J. \& Sykes, M.T. (2014) Species richness of limestone grasslands increases with trait overlap: Evidence from within- and between-species functional diversity partitioning. Journal of Ecology, 102, 466-474.

Balvanera, P., Quijas, S. \& Perez-Jimenez, a. (2011) Distribution Patterns of Tropical Dry Forest Trees Along a Mesoscale Water Availability Gradient. Biotropica, 43, 414-422.

Baraloto, C., Hardy, O.J., Paine, C.E.T., Dexter, K.G., Cruaud, C., Dunning, L.T., Gonzalez, M.A., Molino, J.F., Sabatier, D., Savolainen, V. \& Chave, J. (2012) Using 
functional traits and phylogenetic trees to examine the assembly of tropical tree communities. Journal of Ecology, 100, 690-701.

Baraloto, C., Paine, C.E.T., Poorter, L., Beauchene, J., Bonal, D., Domenach, A.M., Hérault, B., Patiño, S., Roggy, J.C. \& Chave, J. (2010) Decoupled leaf and stem economics in rain forest trees. Ecology Letters, 13, 1338-1347.

Barbieri, G., Vallone, S., Orsini, F., Paradiso, R., De Pascale, S., Negre-Zakharov, F. \& Maggio, A. (2012) Stomatal density and metabolic determinants mediate salt stress adaptation and water use efficiency in basil (Ocimum basilicum L.). Journal of Plant Physiology, 169, 1737-1746.

Barea, J.M., Pozo, M.J., Azc??n, R. \& Azc??n-Aguilar, C. (2005) Microbial co-operation in the rhizosphere. Journal of Experimental Botany, pp. 1761-1778.

Bartels, D. \& Sunkar, R. (2005) Drought and salt tolerance in plants. Critical Reviews in Plant Sciences, 24, 23-58.

Baruch, Z. (2011) Leaf trait variation of a dominant neotropical savanna tree across rainfall and fertility gradients. Acta Oecologica, 37, 455-461.

Bazzaz, F.A. (1996) Plants in Changing Environments: Linking Physiological, Population, and Community Ecology. Cambridge University Press.

Beerling, D.J. \& Chaloner, W.G. (1993) Evolutionary responses of stomatal density to global CO2 change. Biological Journal of the Linnean Society, 48, 343-353.

De Bello, F., Lepš, J. \& Sebastia, M.-T. (2005) Predictive value of plant traits to grazing along a climatic gradient in the Mediterranean. Journal of Applied Ecology, 42, 824-833.

Bhaskar, R., Dawson, T.E. \& Balvanera, P. (2014) Community assembly and functional diversity along succession post-management. Functional Ecology, 28, 1256-1265.

Bohlman, S. \& O'Brien, S. (2006) Allometry, adult stature and regeneration requirement of 65 tree species on Barro Colorado Island, Panama. Journal of Tropical Ecology, 22, 123-136.

Bolnick, D.I., Amarasekare, P., Araújo, M.S., Bürger, R., Levine, J.M., Novak, M., Rudolf, V.H.W., Schreiber, S.J., Urban, M.C. \& Vasseur, D.A. (2011) Why intraspecific trait variation matters in community ecology. Trends in Ecology and Evolution, 26, 183-192.

Brooks, W.R., Lockwood, J.L. \& Jordan, R.C. (2013) Tropical paradox: A multi-scale analysis of the invasion paradox within Miami Rock Ridge tropical hardwood hammocks. Biological Invasions, 15, 921-930. 
Brugnoli, E. \& Lauteri, M. (1991) Effects of Salinity on Stomatal Conductance, Photosynthetic Capacity, and Carbon Isotope Discrimination of Salt-Tolerant (Gossypium hirsutum L.) and Salt-Sensitive (Phaseolus vulgaris L.) C(3) NonHalophytes. Plant Physiology, 95, 628-635.

Bryant, J.A., Lamanna, C., Morlon, H., Kerkhoff, A.J., Enquist, B.J. \& Green, J.L. (2008) Microbes on mountainsides: Contrasting elevational patterns of bacterial and plant diversity. Proceedings of the National Academy of Sciences, 105, 11505-11511.

Bucci, S.J., Goldstein, G., Meinzer, F.C., Scholz, F.G., Franco, A.C. \& Bustamante, M. (2004) Functional convergence in hydraulic architecture and water relations of tropical savanna trees: from leaf to whole plant. Tree Physiology, 24, 891-899.

Carrow, R.N. \& Duncan, R.R. (1998) Salt-Affected Turfgrass Sites: Assessment and Management. John Wiley \& Sons.

Casson, S.A., Franklin, K.A., Gray, J.E., Grierson, C.S., Whitelam, G.C. \& Hetherington, A.M. (2009) phytochrome B and PIF4 Regulate Stomatal Development in Response to Light Quantity. Current Biology, 19, 229-234.

Castro-Díez, P., Puyravaud, J.P., Cornelissen, J.H.C. \& Villar-Salvador, P. (1998) Stem anatomy and relative growth rate in seedlings of a wide range of woody plant species and types . Oecologia, 116, 57-66.

Cavender-Bares, J., Ackerly, D.D., Baum, D.A. \& Bazzaz, F.A. (2004a) Phylogenetic Overdispersion in Floridian Oak Communities. The American naturalist, 163, 823843.

Cavender-Bares, J., Keen, A. \& Miles, B. (2006) Phylogenetic structure of Floridian plant communities depends on taxonomic and spatial scale. Ecology, 87.

Cavender-Bares, J., Kitajima, K. \& Bazzaz, F.A. (2004b) Multiple trait associations in relation to habitat differentiation among 17 Floridian oak species. Ecological Monographs, 74, 635-662.

Ceulemans, R., Praet, L. \& Jiang, X.N. (1995) Effects of CO2 enrichment, leaf position and clone on stomatal index and epidermal cell density in poplar (Populus). New Phytologist, 131, 99-107.

Chartzoulakis, K., Loupassaki, M., Bertaki, M. \& Androulakis, I. (2002) Effects of NaCl salinity on growth, ion content and CO 2 assimilation rate of six olive cultivars. Scientia Horticulturae, 96, 235-247.

Chave, J., Coomes, D., Jansen, S., Lewis, S.L., Swenson, N.G. \& Zanne, A.E. (2009) Towards a worldwide wood economics spectrum. Ecology Letters, 12, 351-366.

Chesson, P. (2000) Mechanisms of maintenance of species diversity. Annual Review of Ecology and Systematics, 31, 343-+. 
Cingolani, A.M., Cabido, M., Gurvich, D.E., Renison, D. \& Díaz, S. (2007) Filtering processes in the assembly of plant communities: Are species presence and abundance driven by the same traits? Journal of Vegetation Science, 18, 911-920.

Cornelissen, J.H.C., Lavorel, S., Garnier, E., Díaz, S., Buchmann, N., Gurvich, D.E., Reich, P.B., Steege, H., terMorgan, H.D., Heijden, M.G.A., van der Pausas, J.G. \& Poorter, H. (2003) A handbook of protocols for standardized and easy measurement of plant functional traits worldwide. Australian Journal of Botany, 51, 335-380.

Cornwell, W.K. \& Ackerly, D.D. (2009) Community assembly and shifts in plant trait distributions across an environmental gradient in coastal California. Ecological Monographs, 79, 109-126.

Cornwell, W.K., Schwilk, D.W. \& Ackerly, D.D. (2006a) A trait-based test for habitat filtering: Convex hull volume. Ecology, 87, 1465-1471.

Cornwell, W.K., Schwilk, D.W. \& Ackerly, D.D. (2006b) A trait-based test for habitat filtering: Convex hull volume. Ecology, 87, 1465-1471.

Cunningham, S.A., Summerhayes, B. \& Westoby, M. (1999) Evolutionary divergences in leaf structure and chemistry, comparing rainfall and soil nutrient gradients. Ecological Monographs, 69, 569-588.

Davies, S.J. (2001) Tree mortality and growth in 11 sympatric Macaranga species in Borneo. Ecology, 82, 920-932.

Diamond, J.M. (1975) Assembly of species communities. Ecology and evolution of communities (eds M.L. Cody \& J.M. Diamond), pp. 342-444. Harvard Univ. Press, Cambridge, Massachusetts, USA.

Diamond, J.M. \& Ross, M.S. (2016) Canopy gaps do not help establish pioneer species in a South Florida dry forest. Journal of Tropical Ecology, 32, 107-115.

Díaz, S., Hector, A. \& Wardle, D.A. (2009) Biodiversity in forest carbon sequestration initiatives: not just a side benefit. Current Opinion in Environmental Sustainability, 1, 55-60.

Diaz, S., Hodgson, J.G., Thompson, K., Cabido, M., Cornelissen, J.H.C., Jalili, A., Montserrat- Martí, G., Grime, J.P., Zarrinkamar, F. \& Asri, Y. (2004) The plant traits that drive ecosystems: evidence from three continents. Journal of Vegetation Science, 15, 295-304.

Díaz, S. \& Cabido, M. (2001) Vive la difference: plant functional diversity matters to ecosystem processes. Trends in Ecology \& Evolution, 16, 646-655.

Drake, P.L., Froend, R.H. \& Franks, P.J. (2013) Smaller, faster stomata: Scaling of stomatal size, rate of response, and stomatal conductance. Journal of Experimental Botany, 64, 495-505. 
Duckworth, J.C., Kent, M. \& Ramsay, P.M. (2000) Plant functional types: an alternative to taxonomic plant community description in biogeography? Progress in Physical Geography, 24, 515-542.

Dunlap, J.M. \& Stettler, R.F. (2001) Variation in leaf epidermal and stomatal traits of Populus trichocarpa from two transects across the Washington Cascades. Canadian Journal of Botany, 79, 528-536.

Dunphy, B., Murphy, P. \& Lugo, A. (2000) The tendency for trees to be multiplestemmed in tropical and subtropical dry forests: Studies of Guánica Forest, Puerto Rico. Tropical Ecology, 41, 1-7.

Enquist, B.J., Norberg, J., Bonser, S.P., Violle, C., Webb, C.T., Henderson, A., Sloat, L.L. \& Savage, V.M. (2015) Scaling from Traits to Ecosystems: Developing a General Trait Driver Theory via Integrating Trait-Based and Metabolic Scaling Theories. Advances in Ecological Research, 52, 249-318.

Ewe, S.M.L., Sternberg, L. da S.L. \& Busch, D.E. (1999) Water-use patterns of woody species in pineland and hammock communities of South Florida. Forest Ecology and Management, 118, 139-148.

Fargione, J., Brown, C.S. \& Tilman, D. (2003) Community assembly and invasion: an experimental test of neutral versus niche processes. Proceedings of the national academy of sciences, 100, 8916-8920.

Farquhar, G.D., Ball, M.C., von Caemmerer, S. \& Roksandic, Z. (1982) Effect of salinity and humidity on ??13C value of halophytes-Evidence for diffusional isotope fractionation determined by the ratio of intercellular/atmospheric partial pressure of CO2 under different environmental conditions. Oecologia, 52, 121-124.

Feeley, K. (2003) Analysis of avian communities in Lake Guri, Venezuela, using multiple assembly rule models. Oecologia, 137, 104-113.

Fine, P.V.A. \& Kembel, S.W. (2011) Phylogenetic community structure and phylogenetic turnover across space and edaphic gradients in western Amazonian tree communities. Ecography, 34, 552-565.

Fonseca, C.R., Overton, J.M., Collins, B. \& Westoby, M. (2000) Shifts in trait-combinations along rainfall and phosphorus gradients. Journal of Ecology, 88, 964-977.

Franks, P.J., Drake, P.L. \& Beerling, D.J. (2009) Plasticity in maximum stomatal conductance constrained by negative correlation between stomatal size and density: An analysis using Eucalyptus globulus. Plant, Cell and Environment, 32, 17371748. 
Franks, P.J. \& Farquhar, G.D. (2001) The effect of exogenous abscisic acid on stomatal development, stomatal mechanics, and leaf gas exchange in Tradescantia virginiana. Plant physiology, 125, 935-942.

Franks, S.J., Weber, J.J. \& Aitken, S.N. (2014) Evolutionary and plastic responses to climate change in terrestrial plant populations. Evolutionary Applications, 7, 123139.

Galmés, J., Flexas, J., Savé, R. \& Medrano, H. (2007) Water relations and stomatal characteristics of Mediterranean plants with different growth forms and leaf habits: responses to water stress and recovery. Plant and Soil, 290, 139-155.

Garnier, E., Cortez, J., Billès, G., Navas, M.L., Roumet, C., Debussche, M., Laurent, G., Blanchard, A., Aubry, D., Bellmann, A., Neill, C. \& Toussaint, J.P. (2004) Plant functional markers capture ecosystem properties during secondary succession. Ecology, 85, 2630-2637.

Geange, S.W., Pledger, S., Burns, K.C. \& Shima, J.S. (2011) A unified analysis of niche overlap incorporating data of different types. Methods in Ecology and Evolution, 2, $175-184$.

Gillison, A.N. (2016) Vegetation Functional Types and Traits at Multiple Scales. Vegetation Functional Types and Traits at Multiple Scales., pp. 53-97. Springer International Publishing.

Gindel, I. (1969) Stomatal number and size as related to soil moisture in tree xerophytes in Israel. Ecology, 50, 263-267.

Givnish, T.J. (1988) Adaptation to Sun and Shade: A whole-plant Perspective. Australian Journal of Plant Physiology, 15, 63-92.

Gotzenberger, L., de Bello, F., Brathen, K.A., Davison, J., Dubuis, A., Guisan, A., Leps, J., Lindborg, R., Moora, M., Partel, M., Pellissier, L., Pottier, J., Vittoz, P., Zobel, K. \& Zobel, M. (2012) Ecological assembly rules in plant communities-approaches, patterns and prospects. Biological Reviews, 87, 111-127.

Griffiths, M.E. \& Orians, C.M. (2003) Salt spray differentially affects water status, necrosis, and growth in coastal sandplain heathland species. American Journal of Botany, 90, 1188-1196.

Grime, J.P. (2006a) Trait convergence and trait divergence in herbaceous plant communities: Mechanisms and consequences - Grime - 2009 - Journal of Vegetation Science - Wiley Online Library. Journal of Vegetation Science.

Grime, J.P. (2006b) Plant Strategies, Vegetation Processes, and Ecosystem Properties. Wiley. com. 
Gyaneshwar, P., Naresh Kumar, G., Parekh, L.J. \& Poole, P.S. (2002) Role of soil microorganisms in improving P nutrition of plants. Plant and Soil, 245, 83-93.

Hacke, U.G., Sperry, J.S., Pockman, W.T., Davis, S.D. \& McCulloh, K.A. (2001) Trends in wood density and structure are linked to prevention of xylem implosion by negative pressure. Oecologia, 126, 457-461.

Halley, R.B., Vacher, H.L. \& Shinn, E.A. (1997) Geology and hydrogeology of the Florida Keys. Geology and hydrology of carbonate islands, Developments in Sedimentology, pp. 217-248.

Hanan, E.J. \& Ross, M.S. (2010) Across-scale patterning of plant-soil-water interactions surrounding tree islands in Southern Everglades landscapes. Landscape Ecology, 25, 463-476.

Haworth, M., Elliott-Kingston, C. \& McElwain, J.C. (2011) Stomatal control as a driver of plant evolution. Journal of Experimental Botany, 62, : 2419-2423.

Hetherington, A.M. \& Woodward, F.I. (2003) The role of stomata in sensing and driving environmental change. Nature, 424, 901-908.

Hillerislambers, J., Adler, P.B., Harpole, W.S., Levine, J.M. \& Mayfield, M.M. (2012) Rethinking Community Assembly through the Lens of Coexistence Theory. Annu. Rev. Ecol. Evol. Syst, 43, 227-48.

Holdaway, R.J. \& Sparrow, A.D. (2006) Assembly rules operating along a primary riverbed-grassland successional sequence. Journal of Ecology, 94, 1092-1102.

Hubbell, S.P. (2001) The Unified Neutral Theory of Biodiversity and Biogeography. . Princeton University Press, Princeton, NJ.

Hubbell, S.P. (2006) Neutral theory and the evolution of ecological equivalence. Ecology, 87, 1387-1398.

Hulshof, C.M., Violle, C., Spasojevic, M.J., Mcgill, B., Damschen, E., Harrison, S. \& Enquist, B.J. (2013) Intra-specific and inter-specific variation in specific leaf area reveal the importance of abiotic and biotic drivers of species diversity across elevation and latitude. Journal of Vegetation Science, 24, 921-931.

Hultine, K.R. \& Marshall, J.D. (2000) Altitude trends in conifer leaf morphology and stable carbon isotope composition. Oecologia, 123, 32-40.

Ishida, A., Nakano, T., Yazaki, K., Matsuki, S., Koike, N., Lauenstein, D.L., Shimizu, M. \& Yamashita, N. (2008) Coordination between leaf and stem traits related to leaf carbon gain and hydraulics across 32 drought-tolerant angiosperms. Oecologia, 156, 193-202. 
Jung, V., Violle, C., Mondy, C., Hoffmann, L. \& Muller, S. (2010) Intraspecific variability and trait-based community assembly. Journal of Ecology, 98, 1134-1140.

Katabuchi, M., Kurokawa, H., Davies, S.J., Tan, S. \& Nakashizuka, T. (2012) Soil resource availability shapes community trait structure in a species-rich dipterocarp forest. Journal of Ecology, 100, 643-651.

Keddy, P.A. (1992) A Pragmatic Approach to Functional Ecology. Functional Ecology, 6, 621-626.

Keddy, P.A. (2001) Competition, 2nd editio. Kluwer, Dordrecht.

Khurana, E., Sagar, R. \& Singh, J.S. (2006) Seed size: a key trait determining species distribution and diversity of dry tropical forest in northern India. Acta Oecologica, 29, 196-204.

King, D. a. (1996) Allometry and life history of tropical trees. Journal of Tropical Ecology, 12, 25-44.

King, D.A., Davies, S.J., Supardi, M.N.N.U.R. \& Tan, S. (2005) Tree growth is related to light interception and wood density in two mixed dipterocarp forests of Malaysia. Functional Ecology, 19, 445-453.

King, D.A., Davies, S.J., Tan, S. \& Noor, N.S.M. (2006) The role of wood density and stem support costs in the growth and mortality of tropical trees. Journal of Ecology, 94, 670-680.

Van Kleunen, M. \& Fisher, M. (2001) Adaptive evolution of plastic foraging responses in a clonal plant. Ecology, 82, 3309-3319.

Van Kleunen, M., Weber, E. \& Fischer, M. (2010) A meta-analysis of trait differences between invasive and non-invasive plant species. Ecology Letters, 13, 235-245.

Körner, C. (2007) The use of "altitude"in ecological research. Trends in ecology \& evolution, 22, 569-574.

Kraft, N.J.B., Cornwell, W.K., Webb, C.O. \& Ackerly, D.D. (2007) Trait evolution, community assembly, and the phylogenetic structure of ecological communities. The American naturalist, 170, 271-83.

Kraft, N.J.B., Valencia, R. \& Ackerly, D.D. (2008) Functional Traits and Niche-Based Tree Community Assembly in an Amazonian Forest. Science, 322, 580-582.

Kunstler, G., Falster, D., Coomes, D.A., Hui, F., Kooyman, Robert, M., Laughlin, D.C., Poorter, L., Vanderwel, M., Vieilledent, G., Wright, S.J., Aiba, M., Baraloto, C., Caspersen, J., Cornelissen, J.H.C., Gourlet-Fleury, S., Hanewinkel, M., Herault, B., Kattge, J., Kurokawa, H., Onoda, Y., Penuelas, J., Poorter, H., Uriarte, M., 
Richardson, S. \& Ruiz-Benito, P. (2016) Plant functional traits have globally consistent effects on competition. Nature, 529, 1-15.

Laliberté, E. (2017) Below-ground frontiers in trait-based plant ecology. New Phytologist, 213, 1597-1603.

Lamanna, C. a, Blonder, B., Violle, C., Kraft, N.J.B., Sandel, B., Simova, I., Donoghue II, J.C., Svenning, J., Mcgill, B.J., Boyle, B., Buzzard, V., Dolins, S., Jørgensen, P.M., Marcuse-kubitza, A., Morueta-holme, N., Peet, R.K., Piel, W., Regetz, J., Schildhauer, M., Spencer, N., Thiers, B.M., K, W.S. \& Enquist, B.J. (2014) Functional trait space and the latitudinal diversity gradient. Proceedings of the National Academy of Sciences of the United States of America, 111, 13745-13750.

Langevin, C.D., Stewart, M.T. \& Beaudoin, C.M. (1998) Effects of sea water canals on fresh water resources: An example from big Pine Key, Florida. Ground Water, 36, 503-513.

Lapointe, B.E., O’Connell, J.D. \& Garrett, G.S. (1990) Nutrient couplings between onsite sewage disposal systems, groundwaters, and nearshore surface waters of the Florida Keys. Biogeochemistry, 10, 289-307.

Lavorel, S. \& Garnier, E. (2002) Predicting changes in community composition and ecosystem functioning from plant traits: revisiting the Holy Grail. Functional Ecology, 16, 545-556.

Lawson, A.M. \& Weir, J.T. (2014) Latitudinal gradients in climatic-niche evolution accelerate trait evolution at high latitudes. Ecology Letters, 17, 1427-1436.

Lee, D.W., Oberbauer, S.F., Johnson, P., Krishnapilay, B., Mansor, M., Mohamad, H. \& Yap, S.K. (2000) Effects of irradiance and spectral quality on leaf structure and function in seedlings of two Southeast Asian Hopea (dipterocarpaceae) species. American Journal of Botany, 87, 447-455.

Liancourt, P., Tielbörger, K., Bangerter, S. \& Prasse, R. (2009) Components of "competitive ability" in the LHS model: Implication on coexistence for twelve cooccurring Mediterranean grasses. Basic and Applied Ecology, 10, 707-714.

Lin, G.H. \& Sternberg, L. da S.L. (1992) Effect of growth form, salinity, nutrient and sulfide on photosynthesis, carbon isotope discrimination and growth of red mangrove (Rhizophora mangle L.). Functional Plant Biology, 19, 509-517.

MacArthur, R. \& Levins, R. (1967) The limiting similarity, convergence, and divergence of coexisting species. The American Naturalist, 101, 377-385.

Maherali, H., Reid, C.D., Polley, H.W., Johnson, H.B. \& Jackson, R.B. (2002) Stomatal acclimation over a subambient to elevated $\backslash$ mathrm $\{\mathrm{CO}\} \_2$ gradient in a C-3/C-4 grassland. Plant Cell and Environment, 25, 557-566. 
Marques, A.R., Garcia, Q.S., Passos Rezende, J.L. \& Fernandes, G.W. (2000) Variations in leaf characteristics of two species of Miconia in the Brazilian cerrado under different light intensities. Tropical Ecology, 41, 47-56.

Marteinsdóttir, B. \& Eriksson, O. (2014) Trait-based filtering from the regional species pool into local grassland communities. Journal of Plant Ecology, 7, 347-355.

Mayfield, M.M. \& Levine, J.M. (2010) Opposing effects of competitive exclusion on the phylogenetic structure of communities. Ecology Letters, 13, 1085-1093.

McDowell, N., Bond, B., Dickman, L., Ryan, M. \& Whitehead, D. (2011) Relationships Between Tree Height and Carbon Isotope Discrimination. Size- and Age-Related Changes in Tree Structure and Function SE - Tree Physiology, pp. 255-286.

McElrone, A.J., Pockman, W.T., Martínez-Vilalta, J. \& Jackson, R.B. (2004) Variation in xylem structure and function in stems and roots of trees to $20 \mathrm{~m}$ depth. New Phytologist, 163, 507-517.

McGill, B.J. (2008) Exploring predictions of abundance from body mass using hierarchical comparative approaches. The American Naturalist, 172, 88-101.

McGill, B.J., Enquist, B.J., Weiher, E. \& Westoby, M. (2006) Rebuilding community ecology from functional traits. Trends in Ecology \& Evolution, 21, 178-185.

Messier, J., McGill, B.J. \& Lechowicz, M.J. (2010) How do traits vary across ecological scales? A case for trait-based ecology. Ecology Letters, 13, 838-848.

Moses, C.S., Anderson, W.T., Saunders, C. \& Sklar, F. (2013) Regional climate gradients in precipitation and temperature in response to climate teleconnections in the Greater Everglades ecosystem of South Florida. Journal of Paleolimnology, 49, 514.

Mouillot, D., Stubbs, W., Faure, M., Dumay, O., Tomasini, J.A., Wilson, J.B. \& Chi, T. Do. (2005a) Niche overlap estimates based on quantitative functional traits: A new family of non-parametric indices. Oecologia, 145, 345-353.

Mouillot, D., Stubbs, W., Faure, M., Dumay, O., Tomasini, J.A., Wilson, J.B. \& Do Chi, T. (2005b) Niche overlap estimates based on quantitative functional traits: a new family of non-parametric indices. Oecologia, 145, 345-353.

Munoz, F. \& Huneman, P. (2016) From the neutral theory to a comprehensive and multiscale theory of ecological equivalence. The Quarterly Review of Biology, 91, $321-342$.

Navas, M.-L., Roumet, C., Bellmann, A., Laurent, G. \& Garnier, E. (2010) Suites of plant traits in species from different stages of a Mediterranean secondary succession. Plant Biology, 12, 183-196. 
Navas, M.L. \& Violle, C. (2009) Plant traits related to competition: how do they shape the functional diversity of communities? . Community Ecology, 10, 131-137.

Niinemets, Ü. (2015) Is there a species spectrum within the world-wide leaf economics spectrum? Major variations in leaf functional traits in the Mediterranean sclerophyll Quercus ilex. New Phytologist, 205, 79-96.

Ogurcak, D. (2016) The Effect of Disturbance and Freshwater Availability on Lower Florida Keys' Coastal Forest Dynamics. Florida International University.

Orsini, F., Alnayef, M., Bona, S., Maggio, A. \& Gianquinto, G. (2012) Low stomatal density and reduced transpiration facilitate strawberry adaptation to salinity. Environmental and experimental botany, 81, 1-10.

Paine, C.E.T., Baraloto, C., Chave, J. \& Hérault, B. (2011) Functional traits of individual trees reveal ecological constraints on community assembly in tropical rain forests. Oikos, 120, 720-727.

Paz, H., Mazer, S.J. \& Martinez-Ramos, M. (2005) Comparative ecology of seed mass in Psychotria (Rubiaceae): within- and between-species effects of seed mass on early performance. Functional Ecology, 19, 707-718.

Poorter, L. \& Bongers, F. (2006) Leaf traits are good predictiors of plant performance across 53 rain forest species . Ecology, 87, 1733-1743.

Poorter, L., Bongers, L. \& Bongers, F. (2006a) Architecture of 54 moist-forest tree species: Traits, trade-offs, and functional groups. Ecology, 87, 1289-1301.

Poorter, L., Bongers, L. \& Bongers, F. (2006b) Architecture of 54 moist-forest tree species: traits, trade-offs, and functional groups . Ecology, 87, 1289-1301.

Poorter, L., Bongers, F., Sterck, F.J. \& Wöll, H. (2003) Architecture of 53 rain forest tree differing in adult stature and shade tolerance. Ecology, 84, 602-608.

Poorter, L., Wright, S.J., Paz, H., Ackerly, D.D., Condit, R., Ibarra-Manriques, G., Harms, K.E., Licona, J.C., Martinez-Ramos, M., Mazer, S.J., Muller-Landau, H.C., Pena-Claros, M., Webb, C.O. \& Wright, I.J. (2008) Are functional traits good predictors of demographic rates? Evidence from five Neotropical forests. Ecology, 89, 1908-1920.

Preston, K.A., Cornwell, W.K. \& DeNoyer, J.L. (2006) Wood density and vessel traits as distinct correlates of ecological strategy in 51 California coast range angiosperms. New Phytologist, 170, 807-818.

Quétier, F., Lavorel, S., Thuiller, W. \& Davies, I. (2007) Plant-trait-based modeling assessment of ecosystem-service sensitivity to land-use change. Ecological Applications, 17, 2377-2386. 
R Developement Core Team. (2015) R: A Language and Environment for Statistical Computing. R Foundation for Statistical Computing, 1, 409.

Rasband, W. (2012) ImageJ 1997-2012. U. S. National Institutes of Health, Bethesda, Maryland, USA.

Redwine, J. (2007) Leaf Morphology Scales Multi-Annual Trends in Nutrient Cycling and Leaf, Flower, and Fruiting Phenology among Species in the SubTropical Hardwood Forests of the Northern Florida KeysLeaf Morphology Scales Multi-Annual Trends in Nutrient Cycling . Florida International University.

Redwine, J.R., Sawicki, R., Lorenz, J.J. \& Hoffman, W. (2007) Ripe fruit availability in the fragmented hardwood forests of the northern Florida Keys. Natural Areas Journal, 27, 8-15.

Reich, P.B., Ellsworth, D.S., Walters, M.B., Vose, J.M., Gresham, C., Volin, J.C. \& Bowman, W.D. (1999) Generality of leaf trait relationships: A test across six biomes. Ecology, 80, 1955-1969.

Reich, P.B.., Wright, I.J.., Cavender-Bares, J.., Craine, J.M.., Oleksyn, J.., Westoby, M.. \& Walters, M.B.. (2003) The Evolution of Plant Functional Variation: Traits, Spectra, and Strategies. International journal of plant sciences, 164, S143-S164.

Reitalu, T., Prentice, H.C., Sykes, M.T., Lonn, M., Johansson, L.J. \& Hall, K. (2008) Plant species segregation on different spatial scales in semi-natural grasslands. Journal of Vegetation Science, 19, 407-416.

Richardson, A.E., Barea, J.M., McNeill, A.M. \& Prigent-Combaret, C. (2009) Acquisition of phosphorus and nitrogen in the rhizosphere and plant growth promotion by microorganisms. Plant and Soil, 321, 305-339.

Rosenfeld, J.S. (2002) Functional redundancy in ecology and conservation. Oikos, 98, $156-162$.

Ross, M.S., Carrlngton, M., Flynn, L.J. \& Ruiz, P.L. (2001) Forest Succession in Tropical Hardwood Hammocks of the Florida Keys: Effects of Direct Mortality from Hurricane Andrew1. Biotropica, 33, 23-33.

Ross, M.S., Coultas, C.L. \& Hsieh, Y.P. (2003) Soil-productivity relationships and organic matter turnover in dry tropical forests of the Florida Keys. Plant and Soil, 253, 479-492.

Ross, M.S., Mitchell-Bruker, S., Sah, J.P., Stothoff, S., Ruiz, P.L., Reed, D.L., Jayachandran, K. \& Coultas, C.L. (2006) Interaction of hydrology and nutrient limitation in the Ridge and Slough landscape of the southern Everglades. Hydrobiologia, 569, 37-59. 
Ross, M.S., O’Brien, J.J. \& Flynn, L.J. (1992) Ecological site classification of Florida Keys terrestrial habitats. Biotropica, 488-502.

Ross, M.S. \& Sah, J.P. (2011) Forest resource islands in a sub-tropical marsh: Soil-site relationships in Everglades hardwood hammocks. Ecosystems, 14, 632-645.

Ross, M.S., Sah, J.P., Ruiz, P.L., Spitzig, A.A. \& Subedi, S.C. (2016) Inferring implications of climate change in south Florida hardwood hammocks through analysis of metacommunity structure. Diversity and Distributions, 22, 783-796.

Sack, L. \& Frole, K. (2006) Leaf structural diversity is related to hydraulic capacity in tropical rain forest trees. Ecology, 87, 483-491.

Saha, A.K., Saha, S., Sadle, J., Jiang, J., Ross, M.S., Price, R.M., Sternberg, L.S.L.O. \& Wendelberger, K.S. (2011) Sea level rise and South Florida coastal forests. Climatic Change, 107, 81-108.

Sánchez-Gómez, D., Valladares, F. \& Zavala, M.A. (2006) Functional traits and plasticity in response to light in seedlings of four Iberian forest tree species. Tree physiology, 26, 1425-33.

Santiago, L.S., Goldstein, G., Meinzer, F.C., Fisher, J.B., Machado, K., Woodruff, D. \& Jones, T. (2004) Leaf photosynthetic traits scale with hydraulic conductivity and wood density in Panamanian forest canopy trees. Oecologia, 140, 543-550.

Schoch, P.G., Zinsou, C. \& Sibi, M. (1984) Dependence of the Stomatal Index on Environmental-Factors During Stomatal Differentiation in Leaves of Vigna-Sinensis L .2. Effect of different light quality. Journal of Experimental Botany, 35, 14051409.

Schurr, U., Heckenberger, U., Herdel, K., Walter, a \& Feil, R. (2000) Leaf development in Ricinus communis during drought stress: dynamics of growth processes, of cellular structure and of sink-source transition. Journal of experimental botany, 51, 1515-1529.

Shipley, B. (2010) From Plant Traits to Vegetation Structure. Chance and Selection in the Assembly of Ecological Communities.

Shipley, B., Vile, D. \& Garnier, É. (2006) From plant traits to plant communities: a statistical mechanistic approach to biodiversity. Science, 314, 812-814.

Sojka, R.E. (1992) Stomatal Closure in Oxygen-Stressed Plants. Soil Science, 154, 269280.

Spasojevic, M.J. \& Suding, K.N. (2012) Inferring community assembly mechanisms from functional diversity patterns: the importance of multiple assembly processes. Journal of Ecology, 100, 652-661. 
Spasojevic, M.J., Yablon, E.A., Oberle, B. \& Myers, J.A. (2014) Ontogenetic trait variation influences tree community assembly across environmental gradients. Ecosphere, 5, 1-20.

Sperry, J.S. (2003) Evolution of Water Transport and Xylem Structure. International Journal of Plant Sciences, 164, S115-S127.

Sterck, F. \& Bongers, F. (1998) Ontogenetic changes in size, allometry, and mechanical design of tropical rain forest trees. American journal of botany, 85, 266-272.

Sternberg, L. da S.L., Ish-Shalom-Gordon, N., Ross, M. \& O’Brien, J. (1991) Water relations of coastal plant communities near the ocean/freshwater boundary. Oecologia, 88, 305-310.

Sternberg, L. da S.L. \& Manganiello, L.M. (2014) Stomatal pore size and density in mangrove leaves and artificial leaves: effects on leaf water isotopic enrichment during transpiration. Functional Plant Biology, 41, 648-658.

Sternberg, L.D.S.L. \& Swart, P.K. (1987) Utilization of freshwater and ocean water by coastal plants of southern Florida. Ecology, 68, 1898-1905.

Sternberg, L. da S.L., Teh, S.Y., Ewe, S.M.L., Miralles-Wilhelm, F. \& DeAngelis, D.L. (2007) Competition between hardwood hammocks and mangroves. Ecosystems, 10, 648-660.

Suding, K.N., Lavorel, S., Chapin, F.S., Cornelissen, J.H.C., Diaz, S., Garnier, E., Goldberg, D., Hooper, D.U., Jackson, S.T. \& Navas, M. (2008) Scaling environmental change through the community-level: a trait-based response-andeffect framework for plants. Global Change Biology, 14, 1125-1140.

Swenson, N.G. \& Enquist, B.J.E. (2007) and Evolutionary Determinants of a Key Plant Functional Trait : Wood Density and Its Community -. Nature, 94, 451-459.

Swenson, N.G., Enquist, B.J., Pither, J., Kerkhoff, A.J., Boyle, B., Weiser, M.D., Elser, J.J., Fagan, W.F., Forero-Montaña, J., Fyllas, N., Kraft, N.J.B., Lake, J.K., Moles, A.T., Patiño, S., Phillips, O.L., Price, C.A., Reich, P.B., Quesada, C.A., Stegen, J.C., Valencia, R., Wright, I.J., Wright, S.J., Andelman, S., Jørgensen, P.M., Lacher, T.E., Monteagudo, A., Núñez-Vargas, M.P., Vasquez-Martínez, R. \& Nolting, K.M. (2012) The biogeography and filtering of woody plant functional diversity in North and South America. Global Ecology and Biogeography, 21, 798-808.

Swenson, N.G., Enquist, B.J., Pither, J., Thompson, J. \& Zimmerman, J.K. (2006) The problem and promise of scale dependency in community phylogenetics. Ecology, 87, 2418-2424.

Taudiere, A. \& Violle, C. (2016) cati: an R package using functional traits to detect and quantify multi-level community assembly processes. Ecography, 39, 699-708. 
Tomlinson, P.B. (1980) The Biology of Trees Native to Tropical Florida. P. B.

Tomlinson, Allston, Massachusetts, USA.

Uprety, D.C., Dwivedi, N., Jain, V. \& Mohan, R. (2002) Effect of elevated carbon dioxide concentration on the stomatal parameters of rice cultivars. Photosynthetica, 40, 315-319.

Valladares, F., Gianoli, E. \& Gómez, J.M. (2007) Ecological limits to plant phenotypic plasticity. New Phytologist, 176, 749-763.

Valladares, F., Martinez-Ferri, E., Balaguer, L., Perez-Corona, E. \& Manrique, E. (2000a) Low leaf-level response to light and nutrients in Mediterranean evergreen oaks: A conservative resource-use strategy? New Phytologist, 148, 79-91.

Valladares, F., Wright, S.J., Lasso, E., Kitajima, K. \& Pearcy, R.W. (2000b) Plastic phenotypic response to light of 16 congeneric shrubs from a panamanian rainforest. Ecology, 81, 1925-1936.

Vialet-Chabrand, S. \& Brendel, O. (2014) Automatic measurement of stomatal density from microphotographs. Trees, 28, 1859-1865.

Vieira, D.L.M. \& Scariot, A. (2006) Principles of natural regeneration of tropical dry forests for restoration. Restoration Ecology, 14, 11-20.

Violle, C., Enquist, B.J., McGill, B.J., Jiang, L., Albert, C.H., Hulshof, C., Jung, V. \& Messier, J. (2012) The return of the variance: Intraspecific variability in community ecology. Trends in Ecology and Evolution, 27, 244-252.

Violle, C., Navas, M.-L., Vile, D., Kazakou, E., Fortunel, C., Hummel, I. \& Garnier, E. (2007) Let the concept of trait be functional! Oikos, 116, 882-892.

Warren, C.R., Tausz, M. \& Adams, M.A. (2005) Does rainfall explain variation in leaf morphology and physiology among populations of red ironbark (Eucalyptus sideroxylon subsp. tricarpa) grown in a common garden? Tree physiology, 25, 136978.

Webb, C.O., Ackerly, D.D., McPeek, M. a. \& Donoghue, M.J. (2002) Phylogenies and Community Ecology. Annual Review of Ecology and Systematics, 33, 475-505.

Weiher, E., Clarke, G.P. \& Keddy, P.A. (1998) Community assembly rules, morphological dispersion, and the coexistence of plant species. Oikos, 81, 309-322.

Weiher, E. \& Keddy, P.A. (1995) The assembly of experimental wetland plant communities. Oikos, 73, 323-335.

Weiher, E. \& Keddy, P.A. (1999) Ecological Assembly Rules: Perspectives, Advances, Retreats. Cambridge Univ. Press, Cambridge. 
Westoby, M. (1998) A leaf-height-seed (LHS) plant ecology strategy scheme. Plant and Soil, 199, 213-227.

Westoby, M., Falster, D.S., Moles, A.T., Vesk, P.A. \& Wright, I.J. (2002) Plant ecological strategies: Some leading dimensions of variation between species. Annиal Review of Ecology and Systematics, 33, 125-159.

Wetzel, P.R., Van Der Valk, A.G., Newman, S., Coronado, C.A., Troxler-Gann, T.G., Childers, D.L., Orem, W.H. \& Sklar, F.H. (2009) Heterogeneity of phosphorus distribution in a patterned landscape, the Florida Everglades. Plant Ecology, 200, 83-90.

Willis, C.G., Halina, M., Lehman, C., Reich, P.B., Keen, A., McCarthy, S. \& CavenderBares, J. (2010) Phylogenetic community structure in Minnesota oak savanna is influenced by spatial extent and environmental variation. Ecography, 33, 565-577.

Woodward, F.I. \& Kelley, C.K. (1995) The Influence of CO2 Concentration on Stomatal Density. New Phytologist, 131, 311-327.

Wright, I.J., Ackerly, D.D., Bongers, F., Harms, K.E., Ibarra-Manriquez, G., MartinezRamos, M., Mazer, S.J., Muller-Landau, H.C., Paz, H., Pitman, N.C.A., Poorter, L., Silman, M.R., Vriesendorp, C.F., Webb, C.O., Westoby, M. \& Wright, S.J. (2007) Relationships among ecologically important dimensions of plant trait variation in seven neotropical forests. Annals of Botany, 99, 1003-1015.

Wright, I.J., Reich, P.B., Westoby, M., Ackerly, D.D., Baruch, Z., Bongers, F., Cavender-Bares, J., Chapin, T., Cornelissen, J.H.C., Diemer, M., Flexas, J., Garnier, E., Groom, P.K., Gulias, J., Hikosaka, K., Lamont, B.B., Lee, T., Lee, W., Lusk, C., Midgley, J.J., Navas, M.L., Niinemets, U., Oleksyn, J., Osada, N., Poorter, H., Poot, P., Prior, L., Pyankov, V.I., Roumet, C., Thomas, S.C., Tjoelker, M.G., Veneklaas, E.J. \& Villar, R. (2004) The worldwide leaf economics spectrum. Nature, 428, 821827.

Wright, I.J. \& Westoby, M. (2002) Leaves at low versus high rainfall: coordination of structure, lifespan and physiology. New Phytologist, 155, 403-416.

Xu, Z. \& Zhou, G. (2008) Responses of leaf stomatal density to water status and its relationship with photosynthesis in a grass. Journal of experimental botany, $\mathbf{5 9}$, $3317-3325$.

Zhang, H., Zhu, S., John, R., Li, R., Liu, H. \& Ye, Q. (2017) Habitat filtering and exclusion of weak competitors jointly explain fern species assemblage along a light and water gradient. Scientific reports, 7, 298.

Zimmerman, J.K., Everham, E.M., Waide, R.B., Lodge, D.J., Taylor, C.M. \& Brokaw, N.V.L. (1994) Responses of Tree Species to Hurricane Winds in Subtropical Wet 
Forest in Puerto-Rico - Implications for Tropical Tree Life- Histories. Journal of Ecology, 82, 911-922. 


\section{APPENDIX}

\section{Appendix A}

Species code

\begin{tabular}{|c|c|c|c|}
\hline $\mathbf{S N}$ & Code & Species & Family \\
\hline 1 & $\mathrm{AL}$ & Ateramnus lucidus & Euphorbiaceae \\
\hline 2 & AME & Amyris elemifera & Rutaceae \\
\hline 3 & ARE & Ardisia escallonioides & Myrsinaceae \\
\hline 4 & $\mathrm{BO}$ & Bourreria ovata & Boraginaceae \\
\hline 5 & $\mathrm{BS}$ & Bursera simaruba & Burseraceae \\
\hline 6 & $\mathrm{CD}$ & Coccoloba diversifolia & Polygonaceae \\
\hline 7 & $\mathrm{CP}$ & Calyptranthes pallens & Myrtaceae \\
\hline 8 & DD & Drypetes diversifolia & Euphorbiaceae \\
\hline 9 & DL & Drypetes lateriflora & Euphorbiaceae \\
\hline 10 & EA & Eugenia axillaris & Myrtaceae \\
\hline 11 & $\mathrm{EF}$ & Eugenia foetida & Myrtaceae \\
\hline 12 & $\mathrm{FC}$ & Ficus citrifolia & Moraceae \\
\hline 13 & GD & Guapira discolor & Nytaginaceae \\
\hline 14 & GE & Guettarda elliptica & Rubiaceae \\
\hline 15 & GS & Guettarda scabra & Rubiaceae \\
\hline 16 & $\mathrm{KF}$ & Krugiodendron ferreum & Rhamnaceae \\
\hline 17 & LB & Lysiloma bahamense & Fabaceae \\
\hline 18 & MT & Metopium toxiferum & Anacardiaceae \\
\hline 19 & $\mathrm{NC}$ & Nectandra coriacea & Lauraceae \\
\hline 20 & PG & Pithecelobium guadalupense & Fabaceae \\
\hline 21 & $\mathrm{PP}$ & Piscidia piscipula & Fabaceae \\
\hline 22 & SF & Sideroxylon foetidissimum & Sapotaceae \\
\hline 23 & SG & Simarouba glauca & Simaroubaceae \\
\hline 24 & $\mathrm{SM}$ & Swietenia mahagoni & Melliaceae \\
\hline 25 & SS & Sideroxylon salicifolium & Sapotaceae \\
\hline 26 & $\mathrm{ZF}$ & Zanthoxylum fagara & Rutaceae \\
\hline
\end{tabular}




\section{Appendix B}

Citation in the text and references followed the "Functional Ecology" journal.

Citations in the text were given all author names up to three authors. Citations by four or more authors were abbreviated with the use of et al. (e.g. Wright et al. 2004). Work with same first author and date was coded by letters, e.g. Thompson et al. 1991a, b. Citations were listed in chronological order in the test and was separated by a semi-colon.

References was cited as 'in press' only if the paper has been accepted for publication. Work not yet submitted for publication or under review was cited as 'unpublished data' with the author's initials and surname given.

The reference list was in alphabetical order with the journal name unabbreviated. The format of papers, theses, entire books was as follows:

Journal articles:

Lee, D.W., Oberbauer, S.F., Johnson, P., Krishnapilay, B., Mansor, M., Mohamad, H. \& Yap, S.K. (2000) Effects of irradiance and spectral quality on leaf structure and function in seedlings of two Southeast Asian Hopea (dipterocarpaceae) species. American Journal of Botany, 87, 447-455.

Books:

Bazzaz, F.A. (1996) Plants in Changing Environments: Linking Physiological, Population, and Community Ecology. Cambridge University Press.

Theses:

Redwine, J. (2007) Leaf Morphology Scales Multi-Annual Trends in Nutrient Cycling and Leaf, Flower, and Fruiting Phenology among Species in the SubTropical Hardwood Forests of the Northern Florida KeysLeaf Morphology Scales Multi-Annual Trends in Nutrient Cycling . Florida International University. 
VITA

\section{SURESH CHANDRA SUBEDI}

Born Pokhara-24 (Kaskikot), Nepal

- BSc in Biology (2002-2006) Tribhuvan University, Nepal

- MSc Environmental Science (2009-2011) Florida International University, Miami, FL

- PhD candidate, Earth and Environment (2012-2017) Florida International University, Miami, FL

- International Center for Tropical Botany (ICTB) Semester Fellowship, Fall 2016.

- $\quad$ ICTB Graduate Student Research Award, summer 2016.

- Doctoral Evidence Acquisition Award (Spring 2016), College of Arts and Sciences, FIU.

- Kelly Foundation Tropical Botany Scholarship 2014.

- Graduate Scholarly Forum Award 2015, FIU.

- FCE-LTER Student Travel Award 2013.

\section{PUBLICATIONS AND PRESENTATIONS}

don't use bold anywhere in the

vita

- Ross MR, Sah JP, Ruiz PL, Spitzig A, Subedi SC, 2016. Inferring implications of climate change in patchy tropical dry forests through analysis of metacommunity structure. Diversity and Distribution. 22:7, 783-796.

- Subedi SC, Bhattarai KR, Chaudhary RP, 2015. Distribution patterns of Manang's species along the whole Himalayan gradient and their fate against global warming. Journal of Mountain Science 12(6): 1345-1354.

- Bhattarai, KR, Inger Måren, Suresh Subedi 2014. Biodiversity and invasibility: distribution patterns of invasive alien plant species in the Himalayas. Journal of Mountain Science, 11(3):1-9.

- Subedi SC, Michael Ross, Leonard Scinto 2012. Nutrient limitation in two Everglades tree species planted on constructed tree islands. Wetlands. 32(6) 11631173. 
- Subedi SC, Ross MS, Sah JP, Redwine J (2016). Trait-based community assembly pattern along a forest succession gradient in seasonally dry sub-tropical forest, Florida Keys. American Geophysical Union, San Francisco, CA. Dec 12-16, 2016.

- Subedi SC, Ross MS, Sah JP, Vidales R (2016). Variation in stomatal density of Bursera simaruba, a dominant tree species of tropical hardwood hammock forest across a habitat gradient in the Florida Keys. Ecological Society of America, Fort Lauderale, FL. Aug 9-14, 2016.

- Subedi SC, Ross MS, Vidales R, Redwine J (2015). Patterns of plant traitenvironment relationships along a forest succession gradient in Florida Keys. Aug 914, Baltimore, MD, 2015. 